\title{
Mesoscale Storm and Dry Period Parameters from Hourly Precipitation Data: Program Documentation
}

\author{
J. M. Thorp \\ J. L. Durham, EPA Project Manager
}

September 1984

Supported by the U.S. Environmental Protection Agency under a Related Services Agreement with the U.S. Department of Energy

Contract DE-AC06-76RLO 1830

Pacific Northwest Laboratory Operated for the U.S. Department of Energy by Battelle Memorial Institute 
Although the research described in this article has been funded wholly or in part by the United States Environmental Protection Agency (EPA), it has not been subjected to EPA review and therefore does not necessarily reflect the views of EPA and no official endorsement should be inferred.

\title{
DISCLAIMER
}

This report was prepared as an account of work sponsored by an agency of the United States Government. Neither the United States Government nor any agency thereof, nor any of their employees, makes any warranty, express or implied, or assumes any legal liability or responsibility for the accuracy, completeness, or usefulness of any information, appara:us, product, or process disclosed, or represents that its use would not infringe privately owned rights. Reference herein to any specific commercial product, process, or service by trade name, trademark, manufacturer, or otherwise, does not necessarily constitute or imply its endorsement, recommendation, or favoring by the United States Government or any agency thereof. The views and opinions of authors expressed herein do not necessarily state or reflect those of the United States Government or any agency thereof.

\author{
PACIFIC NORTHWEST LABORATORY \\ operated by \\ BATTELLE \\ for the \\ UNITED STATES DEPARTMENT OF ENERGY \\ under Contract DE-AC06-76RLO 1830
}

\begin{tabular}{|c|c|}
\hline \multicolumn{2}{|c|}{ Printed in the United States of America } \\
\hline \multicolumn{2}{|c|}{ Available from } \\
\hline \multirow{2}{*}{\multicolumn{2}{|c|}{$\begin{array}{l}\text { National Technical Information Service } \\
\text { United States Department of Commerce }\end{array}$}} \\
\hline & \\
\hline \multirow{2}{*}{\multicolumn{2}{|c|}{$\begin{array}{l}5285 \text { Port Royal Road } \\
\text { Springfield, Virginia } 22161\end{array}$}} \\
\hline & \\
\hline \multirow{2}{*}{\multicolumn{2}{|c|}{$\begin{array}{l}\text { NTIS Price Codes } \\
\text { Microfiche A01 }\end{array}$}} \\
\hline & \\
\hline \multicolumn{2}{|c|}{ Printed Copy } \\
\hline & Price \\
\hline Pages & Codes \\
\hline 001-025 & A02 \\
\hline 026-050 & $\mathrm{A} 03$ \\
\hline 051-075 & A04 \\
\hline 076-100 & A05 \\
\hline $101-125$ & A06 \\
\hline $126-150$ & $\mathrm{~A} 07$ \\
\hline $151-175$ & $A 08$ \\
\hline $176-200$ & A09 \\
\hline 201-225 & A010 \\
\hline $226-250$ & A011 \\
\hline $251-275$ & A012 \\
\hline $276-300$ & A013 \\
\hline
\end{tabular}


MESOSCALE STORM AND DRY PERIOD

PARAMETERS FROM HOURLY PRECIPITATION

DATA: PROGRAM DOCUMENTATION

J. M. Thorp

J. L. Durham, EPA Project Manager

September 1984

This research has been funded as part of the National Acid Precipitation Assessment Program by the U.S. Environmenta] Protection Agency under a Related Services Agreement with the U.S. Department of Energy Contract DE-AC06-76RLO 1830

Interagency Agreement EPA-DW930059

Pacific Northwest Laboratory

Richland, Washington 99352 
Wet deposition of airborne chemical pollutants occurs primarily from precipitation. Precipitation rate, amount, duration, and location are important meteorological factors to be considered when attempting to understand the relationship of precipitation to pollutant deposition.

The Pacific Northwest Laboratory (PNL) has conducted studies and experiments in numerous locations to collect data that can be incorporated into theories and models that attempt to describe the complex relationship between precipitation occurrence and chemical wet deposition.

Mode1 development of ten requires the use of average rather than random conditions as input. To provide mean values of storm parameters, the task, 'Cl imatological Analysis of Mesoscale Storms', was created as a facet of the Environmental Protection Agency's related-service project, 'Precipitation Scavenging Module Development'. Within this task computer programs have been developed at PNL which incorporate hourly precipitation data from National Weather Service stations to calculate mean values and frequency distributions of precipitation periods and of the interspersed dry periods. These programs have been written with a degree of flexibility that will allow user modification for applications to different, but similar, analyses.

This report describes in detail the rationale and operation of the two computer programs which produce the tables of averages and frequency distributions of storm and dry period parameters from the precipitation data. A listing of the programs and examples of the generated output are included in the appendices. 


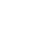

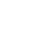

. 


\section{CONTENTS}

SUMMARY

. $i j$

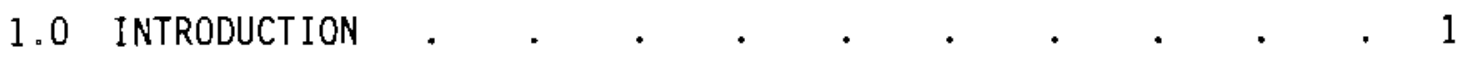

1.1 PURPOSE OF THE SYSTEM $\quad . \quad$.

1.2 SUMMARY OF THE SYSTEM OF COMPUTER PROGRAMS . . . . . 1

1.3 DOCUMENTATION PREFACE $\quad$ - . . . . . . . . . 2

2.0 DATA CONVERSION PROCEDURE BY PROGRAM NCCTAP . . . . . . 5

2.1 INTRODUCTION $. \quad . \quad . \quad . \quad . \quad . \quad . \quad . \quad . \quad 5$

2.2 SUMMARY OF MAJOR FUNCTIONS . . . . . . . . 5

2.2.1 Initialization . . . . . . . . 5

2.2.2 Station and State Processing Control . . . 7

2.2.3 Processing the Hourly Data . . . . 7

2.2.4 End-of-Station and End-of-State Processing. . 7

2.2.5 Normal Termination . . . . . . 8

2.3 SUBROUTINES IN NCCTAP . . . . . . . . 8

2.3.1 Subroutine READ3 . . . . . . . . . 8

2.3.2 Subroutine NEXTAP . . . . . . . . . 10

2.3.3 Subroutine MISS . . . . . . . . 10

2.3.4 Subroutine UNPK4 . . . . . . . 10

2.4 INPUT TO NCCTAP $\quad . \quad . \quad . \quad . \quad . \quad . \quad . \quad$. 11

2.4.1 BCD-Coded Precipitation Data . . . . . 11

2.4.2 Program Control Data . . . . . . . . . 13

2.5 OUTPUT FROM NCCTAP $\quad . \quad$. $\quad . \quad$. . . . 14

2.5.1 Precipitation File Output . . . . . . 14

2.5.2 Printed Output from NCCTAP . . . . . 14 
2.6 DIAGNOSTIC MESSAGES FROM NCCTAP . . . . . 14

2.6.1 "Missing State In Source Data, State No. NN" . 15

2.6.2 "Inconsistent Precip Sum" . . . . . . 15

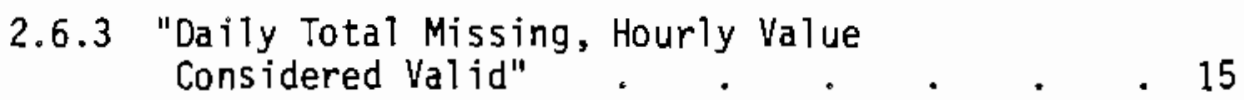

2.6.4 "These Data Wil1 Be Considered Missing" 15

2.6.5 "Read No. $r$, Card No. c, Station ssnnn, Date yymmdd, Data for This Date Considered Missing" . . . . . . . . 15

2.6.6 "NSPS Exceeded 50 Stations for State" . . 15

2.6.7 "Too Many Bad Records, Job Tenminated" . . 15

2.6.8 "Reached EOF On Tape tt" . . . . . . 16

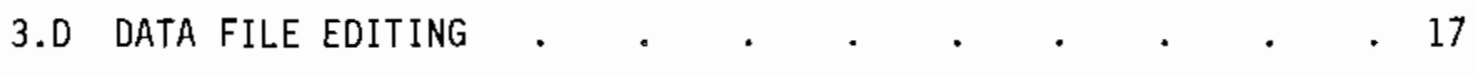

3.1 VISUAL CHECK . . . . . . . . . 17

3.2 CORRECTIONS BY EDITOR . . . . . . . . . 18

4.0 DATA ANALYSES SEQUENCE BY PROGRAM WETDRY . . . . . . 19

4.1 INTRODUCTION

4.2 SUMMARY OF MAJOR FUNCTIONS . . . . . . . 21

4.2.1 Dimensions and DATA Statements . • • . 21

4.2.2 Primary Initialization . . . . . . 21

4.2.3 Reading the Precipitation Data Record . . 21

4.2.4 Secondary Initialization . . . . . . 23

4.2.5 Processing the 24-Hour Record . . . . 25

4.2.6 Treatment of Incomplete Periods . . . . . 28

4.2.7 Recovery of Incomplete Periods . . . . . 32 
4.2.8 Normal Termination . . . . . . 36

4.3 SUBROUTINES USED IN PROGRAM WETDRY . . . . . . . 36

4.3.1 Subroutine MXIMA . . . . . . . . 36

4.3 .2 Subroutine DRYPRD . . . . . . . 36

4.3.3 Subroutine STORM . . . . . . . . . 36

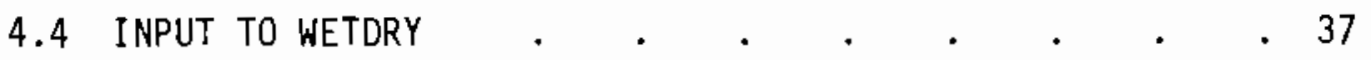

4.4.1 Program Control Data . . . . . . . 37

4.4.2 Hourly Precipitation Data File . . . . 40

4.5 OUTPUT FROM WETDRY . $\quad . \quad$. $\quad . \quad$. . . . . 41

4.5.1 Output Table 1: Average Values and Maxima. . 41

4.5.2 List of Sums and Checks . . . . . 41

4.5.3 Output Table 2: Frequency Distribution of Dry
Periods

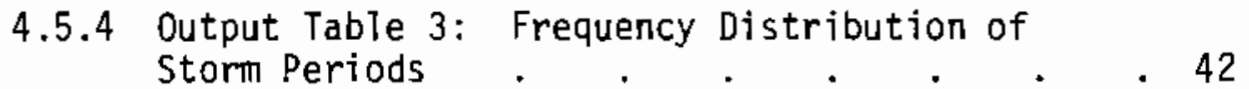

4.6 DIAGNOSTIC MESSAGES FROM WETDRY . . . . . . . 43

4.6.1 Non-Critical Messages . . . . . . 43

4.6.2 Messages Accompanying Abnormat Program
Termination. $. \quad . \quad . \quad . \quad .44$

5.0 REFERENCES . . . . . . . . . . . . . . 46

APPENDIX A - PROGRAM LISTINGS $\quad$. . . . . . . A.1

APPENDIX B - EXAMPLES OF OUTPUT . . . . . . . B.1 


\section{FIGURES}

1 Steps Used in Producing Storm and Dry Period Frequency Distribution Tables from Hourly Precipitation Data Tapes in National Climatic Data Center Format. . . . . . 3

2 Flowchart Showing Major Functions of Program NCCIAP. . . 6

3 Flowchart Showing Major Functions of Program WETDRY. . . 22

\section{TABLES}

1 Decoding Rules for IPRW . . . . . . . . . . 11

2 NCCTAP Control Data (Card) Input . . . . . . . 13

3 Evolution of Program WETDRY . . . . . . . 20

Variables Read in Each Hourly-Daily
Precipitation Record . . . . . . . . 23

5 Rules for Determining Value of Season

6 Descriptions of Output Table $3 \quad . \quad . \quad . \quad . \quad . \quad . \quad 43$ 


\subsection{INTRODUCTION}

\subsection{PURPOSE OF THE SYSTEM}

In the acidic deposition project, climatological analyses of storms are important for a number of different but related reasons: to define "average" storms and variations about the averages; to develop precipitation scavenging "storm signatures;" to obtain Lagrangian statistics, both for the duration of storms and for the time periods between storms; and to enhance the value of data routinely reported by the MAP3S/Precipitation Chemistry Network (PCN) and those data made available from other networks such as in Canada (Scott 1982; The MAP3S/RAINE Research Conmunity 1982).

A storm, as defined in this report, is a period of precipitation composed of one or more precipitation events at a station. An event continues as long as consecutive hours of precipitation are recorded. It frequently happens during a precipitation period that an hour with no precipitation is recorded.

Hourly precipitation data for each observing station in the United States are archived at the National Climatic Data Center (NCDC) in month-long or year-long series. This document describes a system of computer programs developed to produce statistics of storm parameters from the hourly precipitation data. The set of computer programs to be described in this report has been designed to operate on data in the monthly format.

\subsection{SUMMARY OF THE SYSTEM OF COMPUTER PROGRAMS}

The system consists of a two-step sequence of computer programs. This sequence transfers the original hourly precipitation data (HPD) into tables of storm statistics. These storm statistics include tables of frequency distributions of storm duration categories.

The original input data ("original" in terms of entry to this system--an initial conversion of the NCDC data may be needed to make it compatible with the user's hardware and software facilities) are binary coded decimal (BCD) climatological hourly precipitation data in a card image format from the 
National Climatic Data Center (NCDC), Asheville, North Carolina (U.S. Department of Commerce). These data are arranged by station, a year's worth of data for each station. Recent Station File Data can be obtained on monthly tapes from the NCDC.

The first program, NCCTAP, converts the BCD data from the National Climatic Data Center tape (for stations selected by the operator), to a digitized data file on disc. This program is a derivation of a program named PAK developed by T.D. Fox and others at PNL for transforming hourly precipitation data from station-file format (arranged by station) to synoptic-file (arranged by date).

The second program, WETDRY, operates on the file produced by NCCTAP to construct statistics of storms and dry periods from the hourly precipitation data, and arranges these periods in frequency distribution tables with attendant averages and extremes ( $F$ igure 1 ).

\subsection{DOCUMENTATION PREFACE}

In the following chapters, the main programs and their subroutines will be discussed in detail. The text will describe not only how to use the programs, but also how they function. Information required to run the programs is presented. Problems and difficulties inherent in the data base and/or programs will be discussed.

Some users may find the programs useful in their present form. Others may wish to modify the programs to suit particular needs. The structure and logic of each program is described with this need in mind.

Each chapter will discuss, the purpose, structure, subroutines, input and output data types and formats, and diagnostic messages of the programs. It is intended that each chapter be reasonably self contained, so there is therefore considerable redundancy between chapters in the stating of program purposes, description of file structures, and definition of terms. Moreover, cross-referencing information is usually present in descriptions of the interrelationships of system elements, so that characteristics treated more fully in other chapters may be reviewed, if necessary. 


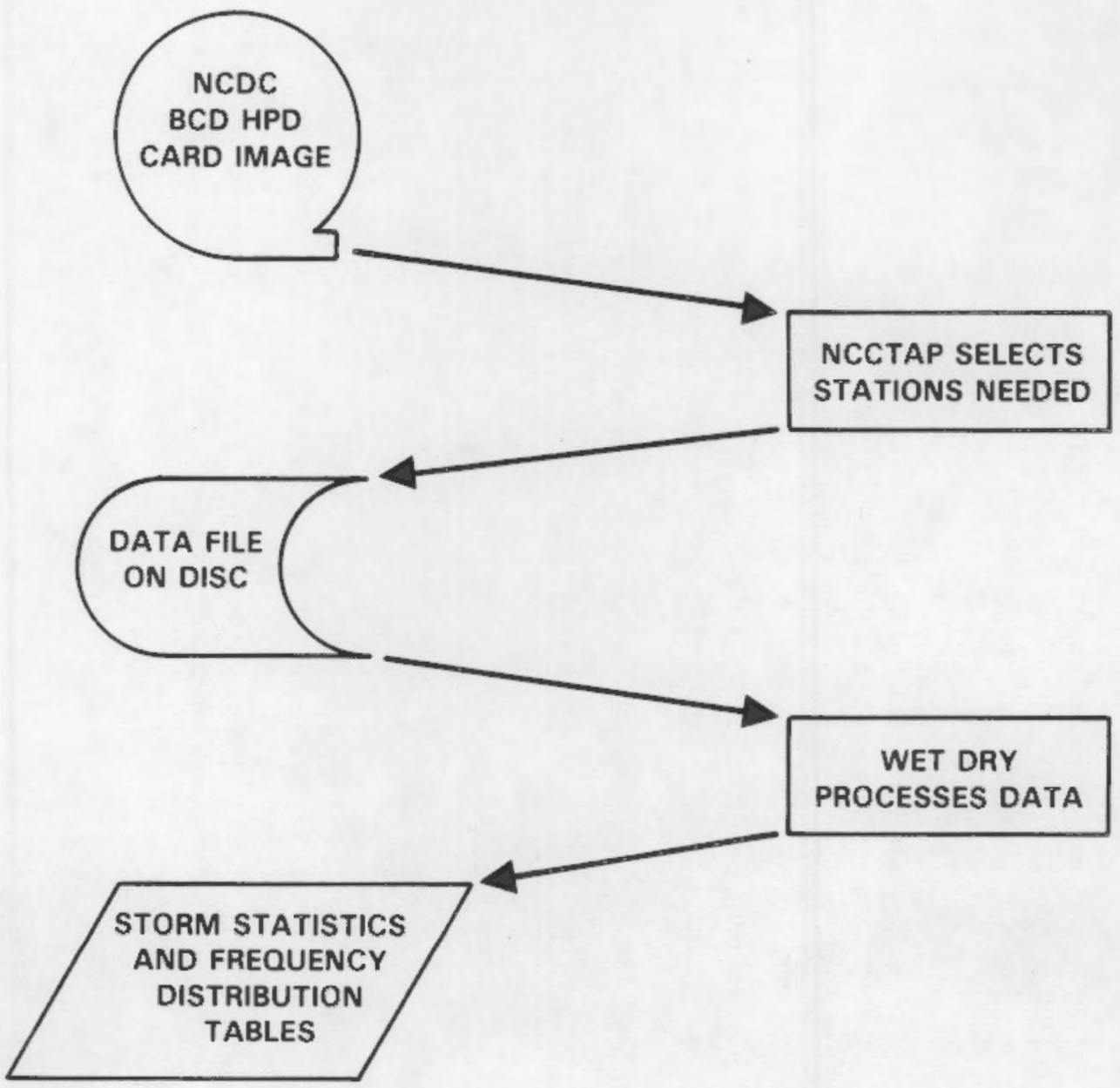

FIGURE 1. Steps Used in Producing Storm and Dry Period Frequency Distribution Tables From Hourly Precipitation Data Tapes in National Climatic Data Center Format 
The generic programs were originally developed for use on the UNIVAC 8800 computer. The later editions described in this documentation are being run on a VAX-11 computer. 


\subsection{DATA CONVERSION PROCEDURE BY PROGRAM NCCTAP}

\subsection{INTRODUCTION}

Program NCCTAP is the first of the two computer programs that are used to generate storm statistics. NCCTAP decodes hourly precipitation data (HPD) written on magnetic tape in binary coded data $(B C D)$, which is a standard code used to represent groups of binary digits as character information (alphanumerics and punctuation). The information is written on the tape in stationfile format (a grouping of the hourly precipitation data by station). After the proper decoding, NCCTAP rewrites the information to disc file.

NCCTAP performs some preliminary error analyses of the data. The types of errors for which NCCTAP checks include:

- illegal characters in the data

- inconsistencies between reported and actual data sums

NCCTAP flags data that are reported missing or that represent precipitation accumulated over more than one hour.

The following discussion of NCCTAP deals with the major functional aspects of its structure, followed by a brief description of each of its subroutines. Input and output formats will then be described. Finally, the meaning of diagnostic messages will be presented.

\subsection{SUMMARY OF MAUOR FUNCTIONS}

A flow chart showing the major functions performed by NCCTAP is shown in Figure 2. Some details of the program functions are discussed below.

\subsubsection{Initialization}

The initialization section of NCCTAP sets counters and flags to initial values. Control information (such as input-file unit numbers, a printcontrol flag, and state-climatic numbers of desired states) is read from cards or a prepared data file. 


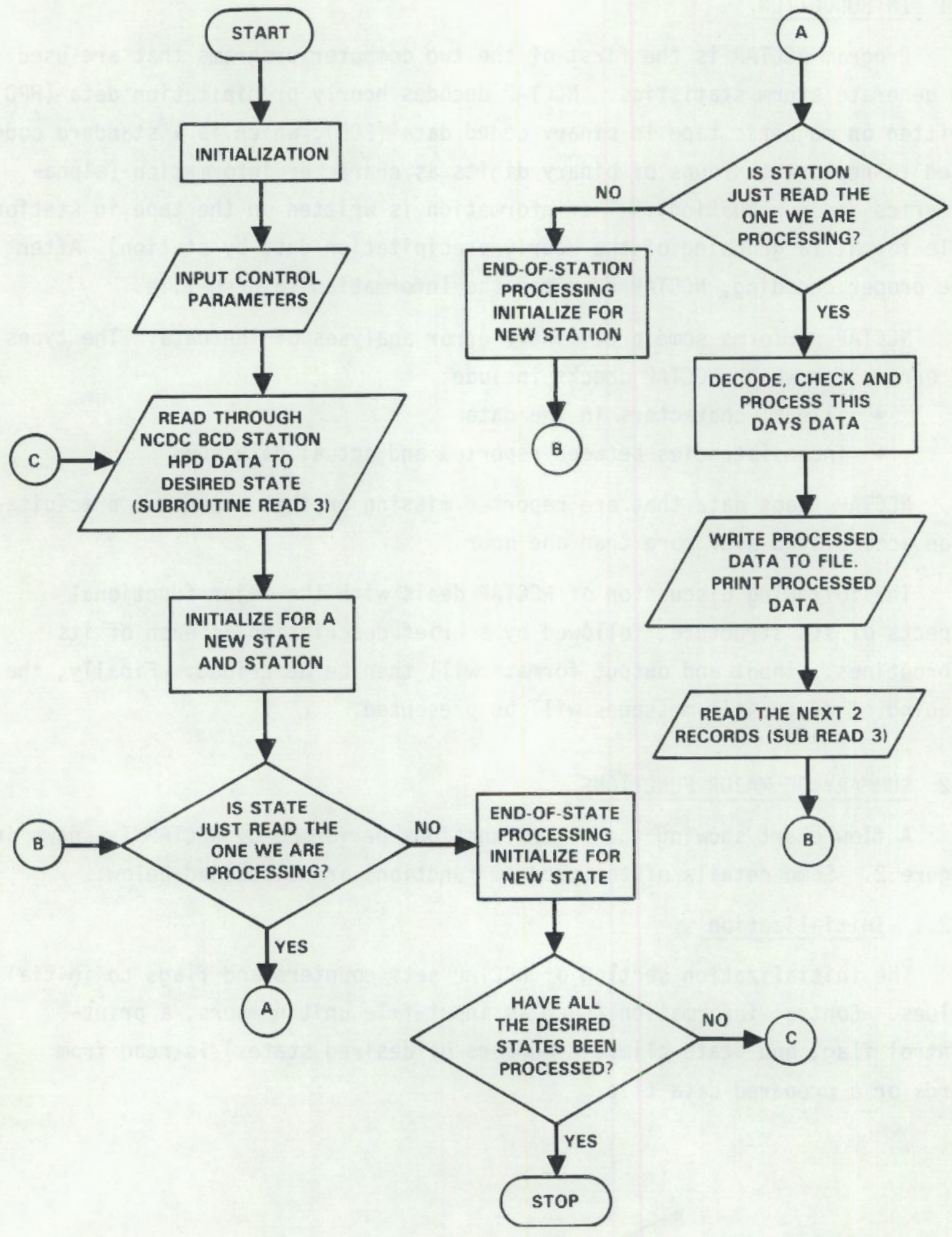

FIGURE 2. Flowchart Showing Major Functions of Program NCCTAP 


\subsubsection{Station and State Processing Control}

NCCTAP's main loop is a DO-loop, which is executed once for each state from which data are to be obtained. Within this loop, the state climatic numbers and 4-digit climatic station numbers are used to control the execution sequence. Initially within the 10op, successive calls to subroutine READ3 (which reads two card-image records, or one day's data, per call) are made until the state climatic number (MSTATE) from tape matches the one specified on card input [NSTT(NS)]. Then, each pair of records is processed until a new 4-digit climatic station-number or state-climatic-number is read. Either of these occurrences causes the appropriate action (end-of-station or end-of-state processing) to take place.

\subsubsection{Processing the Hourly Data}

Tne hourly $B C D$ data are decoded in the main program loop. Each hour's data consist of either three numeric digits, or special characters (bTank or "-") representing specific nonstandard situations. NCCTAP interprets the three characters for each hour and produces appropriate output data. If an hour's entry has a blank in the first column, the data are missing, and the NCCTAP output for that hour is -99. If an hour's entry has a "-" as the first character, the data represent a "trace" and the NCCTAP output for that hour is zero. If a "-" appears as the second character, the NCCTAP output for that hour is -9 , meaning part of an accumulation period. An accumulation period consists of hours during which precipitation occurred, but the hourly amounts are not known. The total sum of the missing hourly amounts is given as the last hourly value for the period. Otherwise, the digits are decoded and used to build a binary integer representation of the precipitation amount in hundredths of inches.

\subsubsection{End-of-Station and End-of-State Processing}

Data from each state are processed one station at a time while data from each station are processed by days. In a single execution of a program loop two 12 hour records ( 80 characters each) for one day's data are read and interpreted. The state and station climatic numbers, read with these daily data, are checked on each execution of the loop. When the climatic number of 
a station or state is read that is different from the one being processed, the loop is exited and end-of-station or end-of-state processing takes place. In both cases, the output record for the station last processed is written. As each valid day's precipitation record is read, it is written to a disc file, which will eventually form the data file to be used by the analysis program WETORY. An optional print variable, KPR, provides a means of generating a printout of what has been written to disc. Following the daily printout for each station, the number of data-days processed for that station is printed.

\subsubsection{Normal Termination}

NCCTAP terminates normally after the final state (specified in the state numbers in array NSTT) has been processed.

\subsection{SUBROUTINES IN NCCTAP}

There are two subroutines called directly by NCCTAP. These are READ3 and UNPK4. READ3 in turn calls two others, NEXTAP and MISS. Each subroutine is discussed below in terms of its structure and functions.

\subsubsection{Subroutine READ3}

Subroutine READ3 (MSTATE, NUMB, IYR, IMO, IDA, IPR, IPRD, NSTN, LU, LLU, IJK, NSTT, NS) reads one day's data (two card image records) from the $B C D$ card-image input file. The parameters are defined as follows:

Name Dimension Definition

MSTATE

State climatic number of the data returned from READ3.

NUMB

4-digit climatic station number of the data returned from READ3.

IYR

2-digit year of the data returned.

IMO

2-digit month number of the data return.

IDA

2-digit day-of-month of the data returned. 

IPR $\quad(24,3)$
IPR $(I, J)$ is the Jth character of the three characters that give the precipitation amount in hour 1 of the data returned. (IPR(1, 1) and $\operatorname{IPR}(1$, 2) are alphanumeric; $\operatorname{IPR}(1,3)$ is an integer).
IPRD
IPRD(J) is the Jth character of the four characters that give the daity precipitation sum returned. (IPRD(1) and IPRD(3) a re alphanumeric; IPRD(2) and IPRD(4) are integers.)
NSTN $\quad(50,50) \quad$ The requested number (up to 50) of stations per state (up to 50 ) to be extracted from the original data tapes.
LU
IJK
The unit number from which the input file is currently being read.
The unit number of the final unit from which the input file will be read.
Flag to indicate that station number just read is not station number wanted.
NSTT
NS
A two-digit state number corresponding to the alphabetical order of states in the original data tape.
The index (or argument) for NSTT.

READ3 checks for an end-of-file (EOF), which indicates the end of data on one tape reel. If an EOF is encountered, subroutine NEXTAP is called to increment the read-unit number LU. If LU becomes greater than LLU (the number of the final unit holding input data), then MSTATE is set to 199 , causing end-of-state processing to occur in NCCTAP, and ultimate termination of the program.

READ3 also checks for two kinds of errors in the input data: card image records that are out of order and nonnumeric character data. In both cases, an appropriate error message is printed, and a call is made to subroutine MISS, which returns a card-image version of missing data for the bad record to be passed back to NCCTAP. If more than 200 bad records of these types are encountered, READ3 prints a message and terminates program execution. 


\subsubsection{Subroutine NEXTAP}

Subroutine NEXTAP (LU, LLU) is called by READ3 whenever an EOF (end-offile) is encountered on reading LU. It increases every other time it is called. During testing with multivolume data sets, it was found that an EOF often (but not always) appeared at the beginning of the next tape, as well as at its end. NEXTAP is designed to ignore the extra EOF. If the extra EOF is not there, the program just hits the EOF at the end of the volume twice before incrementing LU. If the extra EOF is at the beginning of the data, it is encountered without incrementing LU. If $L U$ becomes greater than the final unit number (LLU), a message is printed saying tine EOF on the last unit has been reached, and final processing takes place in READ3 and NCCTAP.

\subsubsection{Subroutine MISS}

The purpose of subroutine MISS (IPR, IPRD, :-T) is to transform a bad record into a correctly formatted one showing only missing hourly values. Parameter definitions are as follows:

Name Dimension Definition

IPR $\quad(24,3) \quad$ IPR $(I, J)$ is the Jth character of the Ith hour's precipitation amount.

IPRD I (4) IPRD (J) is the Jth character of the daily precipitation sum.

LT

The record number ( 1 or 2) of the daily data record pair.

MISS sets $I P R(I, 1)$ to a blank, for $I=1,2, \ldots, 12$, when $L T=1$, or for $I=13,14, \ldots, 24$, when $L T=2$. MISS also sets IPRD (1) to a blank.

\subsubsection{Subroutine UNPK4 (IPRW, LPR, IP)}

Subroutine UNPK4 decodes the four-digit daily sum of precipitation obtained in array IPRW, and returns its integer equivalent in IP. Parameter definitions are:

$\begin{array}{ll}\text { Name Dimension } & \text { Definition } \\ \text { IPRW } & \text { IPRW }(\mathrm{J}) \text { is the } \mathrm{Jth} \text { character read from input in the } \\ \text { daily sum of hourly precipitation. If } \mathrm{J}=2 \text { or } 4 \\ \text { IPRW }(\mathrm{J}) \text { is an integer. If } \mathrm{J}=1 \text { or } 3, \text { IPRW }(\mathrm{J}) \\ \text { is alphanumeric. }\end{array}$


LPR (K) is the Kth of 13 possible characters ('0','1', '2', '3', '4', '5', '6', '7', '8', '9', '-', (blank), ' +') for comparison with the elements of IPRW.

Because the first and third characters may be coded with a special character, they must be checked by UNPK4 individually. UNPK4 does this checking and constructs IP according to the rules in Table 1.

TABLE 1.-Decoding Rules for IPRW

\begin{tabular}{cccc} 
Character & Value & Meaning & IP Is Set To: \\
\hline IPRW (1) & blank & missing & trace \\
IPRW (1) & " " & accumulating & -9
\end{tabular}

\subsection{INPUT TO NCCTAP}

The input to program NCCTAP is of two types: the BCD-coded precipitation data and program control data.

\subsubsection{BCD-Coded Precipitation Data}

The hourly precipitation used as input to NCCTAP is in the format described in the U.S. Weather Service Reference Manual for Deck 488-USWS Hourly Precipitation (U.S. Dept. of Commerce 1960), except that only the first two of the four cards per data day described in that manual are used.

Precipitation data in this format may be obtained from the National Climatic Data Center (NCDC), Asheville, North Carolina. The data are available, one year's worth at a time, for desired stations in station-file format, although it is possible to obtain month-long data files from NCDC for recent months. NCCTAP will also read data from cards punched in this format, by setting the precipitation input unit number (LU) to that for card input (unit 5). 
The sources of data are divided into two groups:

(1) The data for National Weather Service first-order stations are taken from monthly local climatic data (LCD) sheets.

(2) NWS second-order stations and coperative stations mail their rain gage charts to the National weather Records Center (NWRC), where they are evaluated and the data punched on cards. The data eventually are included on the T0-9657 Hourly Precipitation tapes. In the 48 contiguous states, there are aproximately 3100 reporting stations. First-order NWS stations report hourly precipitation to the nearest $1 / 100$ inch. Many of the other stations have used a "Fischer-Porter" precipitation gage since 1963. This type of gage records precipitation amounts to the nearest $1 / 10$ inch.

A few characteristics of the data format, as it is received on tape from NCDC and used by NCCTAP, are discussed below.

The data is written in $\mathrm{BCO} 80$-character (card-image) records, with two records required for one day's data. The data are organized by state cl imatic number (assigned alphabetically) and by four-digit climatic station number within each state. A full year's (or mon'h's) data are grouped together for each station (STA-FILE format). Except on the first day of each station-month (which is always included), data are recorded onty for days on which measurable precipitation was observed, or on the first and last days of periods of missing or accumulating data (see Section 2.2.3). At times, observations for a number of hours are missed and the observation at the end of that period is actually an "accumulation" over that entire period. Such periods are specially coded in the data.

Oata for one year may reside on more than one tape volume. If it does, and if the installation recognizes the end of a tape volume as an end-offile, then each volume should be assigned to a separate tape unit. The first should be assigned to unit 9 , the second to unit 10, and so on. NCCTAP switches from one unit to the next when an end-o*-file is reached (see subroutine NEXTAP). 
The data tapes as received contain hourly precipitation information for approximately 3100 stations. However, most of these stations appear to use the Fischer-Porter type rain gage that records precipitation only in tenths of inches. Monthly or annual precipitation totals may not be significantly affected by such coarse measurements, but precipitation-event rates calculated from such records are fictitious. For our purposes, only those first order NWS stations that report precipitation in hundreths of an inch are used. Such stations make up less than 10 percent of the original data. The time increment for precipitation data is one hour. It is certainly possible that a short-duration precipitation event may occur near the end of one hour and briefly into the next hour. Such an event would be analyzed as a 2-hour event. Such bias on short duration events cannot be avoided because of the data format. We mention this to point out that the shorter duration storm and precipitation-event statistics are less reliable than those for longer storms and events.

\subsubsection{Program Control Data (Card Input)}

The input from cards of program control information for NCCTAP is described in Table 2.2 .

TABLE 2.. NCCTAP Control Data (Card) Input

\begin{tabular}{|c|c|c|c|c|}
\hline Card \# & Cols & Format & Name & Definition \\
\hline 1 & $1-5$ & I5 & NSTA & $\begin{array}{l}\text { Number of states from which } \\
\text { data are to be obtained }\end{array}$ \\
\hline 1 & $6-10$ & I5 & KPR & $\begin{array}{l}\text { Print Control }(1=\text { print } \\
\text { every record, } 0=\text { print } \\
\text { no records) }\end{array}$ \\
\hline 1 & $11-15$ & I5 & LU & $\begin{array}{l}\text { First precipitation input } \\
\text { tape unit number }\end{array}$ \\
\hline 1 & $16-20$ & I5 & LLU & $\begin{array}{l}\text { Last precipitation input } \\
\text { tape unit number }\end{array}$ \\
\hline 2 & $1-80$ & 4012 & $\begin{array}{l}\text { NSTT (I) } \\
I=1, \text { NSTA }\end{array}$ & $\begin{array}{l}\text { Array of state-climatic- } \\
\text { numbers of states whose } \\
\text { data are to be obtained } \\
\text { (numbers should be in } \\
\text { ascending order). } \\
\text { More than one of these } \\
\text { cards may be needed. }\end{array}$ \\
\hline
\end{tabular}




\subsection{OUTPUT FROM NCCTAP}

The output from NCCTAP is of two types: precipitation data files (on tape or disc) and printed output.

\subsubsection{Precipitation File Dutput}

NCCTAP's primary output, the STA-FILE precipitation data, is written to an output file assigned to unit $3^{(a)}$. Each record is produced with the following write statement: WRITE $(3,56)$ MSTATE, NUMB, IMO, IDA, IYR, (IP(I), $I=1,24)$, IPD

Data put on the monthly disc files are arranged by state, station, and day.

\subsubsection{Printed Dutput from NCCTAP}

The standard output from program NCCTAP is a listing of the states and stations from which data have been processed. Setting the optional control parameter, KPR, to one rather than zero results in output of the state number, the station number, date, hourly precipitation amounts, and the daily precipitation sum for each day's record. Because excessive output may result, this option should be taken only when testing with a small amount of data, or when a hard copy is needed to examine data that may need EDIT changes (see 3.1.1).

\subsection{DIAGNOSTIC MESSAGES FROM NCCTAP}

Most of the diagnostic messages printed by NCCTAP refer to errors in the input data set. They are printed to inform the user of these errors and how NCCTAP handles them. NCCTAP usually continues past the point of error, so the messages are often imbedded in the standard output. Each of NCCTAP'S diagnostic messages is discussed briefly below.

(a) Provision is not made for output files that take up more than one tape volume. If the installation does not accommodate multi-volume files, NCCTAP can be run more than once on separate sets of states. 


\subsection{1 "Missing State in Source Data, State No. NN"}

If a state is requested whose data do not appear in the input data set, this message is printed ( $\mathrm{nn}$ is the state climatic number). The program proceeds to the next requested state.

\subsection{2 "Inconsistent Precip Sum"}

If all of the hourly precipitation values are present, but their sum does not equal the reported daily sum, this message is printed, followed by the state and station numbers, date, hourly, and daily precipitation values.

\subsection{3 "Daily Total Missing, Hourly Value Considered Valid"}

When the reported daily sum is actually an accumulation, or is coded as missing, this message is printed.

\subsection{4 "These Data Wi11 Be Considered Missing"}

Print out of the data values are followed by this message, if the value reported for the daily sum is different from the computed sum of hourly values.

2.6.5 "Read No. r, Card No. c, Station ssnnnn, Date yymmdd, Data For This Date Considered Missing"

This message is printed when there is an extra BCD record, or the two daily records are out of order. Here, $r$ is the record number (1 or 2) of the daily pair of records that was expected, $c$ is the number that was read, ssnnnn are the state and station numbers, and yymmdd are the year, month, and day of the record.

\subsection{6 "NSPS Exceeded 50 Stations for State"}

If inadvertently, more than 50 stations for a single state are called for, this message is printed, and control goes to the next state. If a larger limit for stations-per-state is desired, the value of NSPS can be EDITED to suit the needs of the user.

\subsection{7 "Too Many Bad Records, Job Terminated"}

If there are more than 200 occurrences of the card-out-of-order or the illegal-data-in-field errors, the program terminates execution after printing this message. 


\subsection{8 "Reached EOF On Tape $t t^{" \prime}$}

This message is printed if the end-of-file inark on the last designated tape unit is encountered. Here $t t$ is equal to LLU, the last designated tape unit. 


\subsection{DATA FILE EDITING}

\subsection{VISUAL CHECK}

Once the hourly precipitation data have been extracted from the original monthly NCDC Hourly Precipitation Data tapes and written to disc file, that file needs to be edited to remove or correct anomalous data that cannot be digested by the WETDRY program. Our method is to print a hard copy of the selected data, as it is being written to disc file, by using the print control parameter KPR.

There are two types of "errors" common in the NCDC source data. The first is represented by a string of hourly data composed of -9 's in the decoded form. This represents a situation for which hourly distribution is not available, but for which the total accumulation is available. A certain amount of subjectivity must be used to determine whether such data should be estimated or discarded. For example, if 3 hourly amounts are shown as accumulating $(-9)$, but the total accumulation for the period is recorded as 0.03 inch, it may be preferable to estimate an even distribution of 0.01 inch per hour rather than exclude the record in analysis. On the other hand, a 36-hour period of accumulating data with a total accumulation of 2.D0 inches would require considerable knowledge of the precipitation record from nearby stations before an estimate of hourly distribution could be considered. The second type of error shows on the printout from NCCTAP as -99 , signifying unknown or missing data. These data are generally deleted from the disc file. Here too, subjective decisions are needed. Should a 24-hour record be composed entirely of -99 values and should that be the only record for the month, then an abnormaliy long dry period will result if the record is deleted. It may be advisable to delete the entire station month. Another possibility is to change the -99 's to zero amounts (except for assigning a few hours of 0.01 on those days which have missing data). Such small amounts for short periods have little effect on the frequency statistics, but do preserve the occurrence of a precipitation day. All such changes should be fully documented. 


\subsection{CORRECTIONS BY EOITOR}

Once the changes have been made on the printout and documented, the data file is accessed and the changes and deletions made to the file. The conposite seasonal file is likely to be quite large (about 7000 blocks for 1 month for the approximately 200 National Weather Service stations in the 48 states).

Our procedure is to Tet NCCTAP create a file for each month's data. This way, each month is edited separately. Once editing is complete, the months are appended to create a seasonal file for input to program WETDRY. 


\subsection{DATA ANALYSES SEQUENCE BY PROGRAM WETORY}

\subsection{INTRODUCTION}

The original version of program WETDRY was developed in 1980 to provide estimates of average storm parameters for input into in-cloud conversion models (Scott 1982).

Program WETDRY uses the hourly precipitation data file for selected stations that has been created by program NCCTAP from TD-9657 data tapes. The file should be checked for errors or anomalous data, and the proper corrections made before submitting it to WETDRY for the analys is run.

Program WETDRY reads hourly precipitation data from the input $f i$ le and interprets the periods of continous or near-continous precipitation as storms, and the hours between 'storms' as dry periods. Storm and dry period durations are measured in whole hours. The user has the option of allowing a few dry hours to occur within a single storm. In this case, the storm is made up of one or more precipitation events, which represent periods of uninterrupted precipitation. For each storm identified by the program, the precipitation amount, number of wet hours, number of events, sum of event rates, and the number of 'dry' hours occurring within the storm are determined.

Once the data have all been read and each hour has been assigned to a storm, dry period, or to some category for unusable data, the program calculates a series of averages and frequency distributions, identifies maxima in the data, performs internal audits and checks, and produces a printout of lists and tables.

There have been severa] versions of this program as a result of a continuing effort to eliminate bias in the output and to maximize the use of the rather limited data base at $\mathrm{PNL}$. The operating versions and main feature associated with each one are listed in Table 3.

Version 2 of WETDRY processed a11 the data fed to it as either a storm or dry period. Because of the arrangement of the data (i.e., by month 


\title{
TABLE 3. Evolution of Program WETDRY
}

\author{
Version Feature \\ WETDRY2 Treated all periods, including month-end, as full \\ storms and dry periods. \\ WETDRY3 Dropped all month-end and inonth-beginning periods \\ from analyses. \\ WETDRY4 Dropped all month-end and month-beginning wet-periods; \\ paired continuing dry periods. \\ WETDRY7 Recovers all usable month-end continuing storms \\ and dry periods.
}

rather than by station), month-end and month- beginning periods are not complete as read from the file. When such periods are treated as complete in the analyses, they produce a bias toward greater frequency of shorter duration periods.

In response to this situation, Version 3 of WETDRY was written. It excluded all month-end and -beginning periods, but excluding data also causes some bias in the analyses, especially when the data base is limited. As a rule, there are more dry hours than wet at stations in the United States, so there is greater probability of bias in dry period analyses than wet.

Since the data base at Pacific Northwest Laboratory is limited to Iess than 3 full years, it is desirable to make maximum use of that which is available. WETDRY4 is the program version that recovers month-end and -beginning dry periods that span months within a season. The first period of the first month and the last period of the third month in a season are excluded for each station because the duration of these dry periods is unknown.

Recovery of month-end and -beginning wet periods is considerabiy more complicated because of the storm parameters (precipitation amount, number of events, event rates, number of wet hours, etc.) that must be handled in such a way that they can each be recovered after all the data are read. WETDRY7 is the version which recovers both wet and dry periods that span sequential seasonal months. As in Version 4 , the first period of the first month and 
the last period of the third month are not recoverable. The flow chart of major WETDRY functions is shown in figure 3 .

\subsection{SUMMARY OF THE MAJOR WETDRY FUNCTIONS}

\subsubsection{Dimensions and Data Statements}

Our analyses are based on the following array sizes:

Storm Frequency Table

Dry Period Frequency Table

Max Number of Events in a Storm

First and Last Monthly Period

Arrays

\author{
$300 \mathrm{Classes}$ (1 hour each) \\ 42 classes (20 hours each) \\ 20 Events \\ 90 Stations, 4 Years, \\ 12 Months
}

There are three DATA statements. The first, which indicates the number of days in a calendar month plus 1 , is used to flag the end of a stationmonth when the last precipitation day occurs before month end. The second DATA statement sets the class limits (in hours) for the dry period frequency analys's. The third DATA statement 1 ists the four-digit station numbers in the same order as they will appear in the data file produced by NCCTAP. The user must be sure that there is no duplication of station number (for example it is possible for stations in different states to have the same station number). In the event such duplication occurs, the elements of the DATA statement could be rewritten using a six-digit composite number made up of state number and station number.

\subsubsection{Primary Initialization}

A 1 the variables that serve as counters for the input data as it is read are initialized at the beginning of the program. At statement no. 5, certain variables are initialjzed as each new station-month is encountered. Input control data are described in Section 4.4.1.

\subsubsection{Reading the Precipitation Data Record}

The READ statement reads one record at a time. The record consists of state number, station number, month number, year, day, 24 values of hourly 


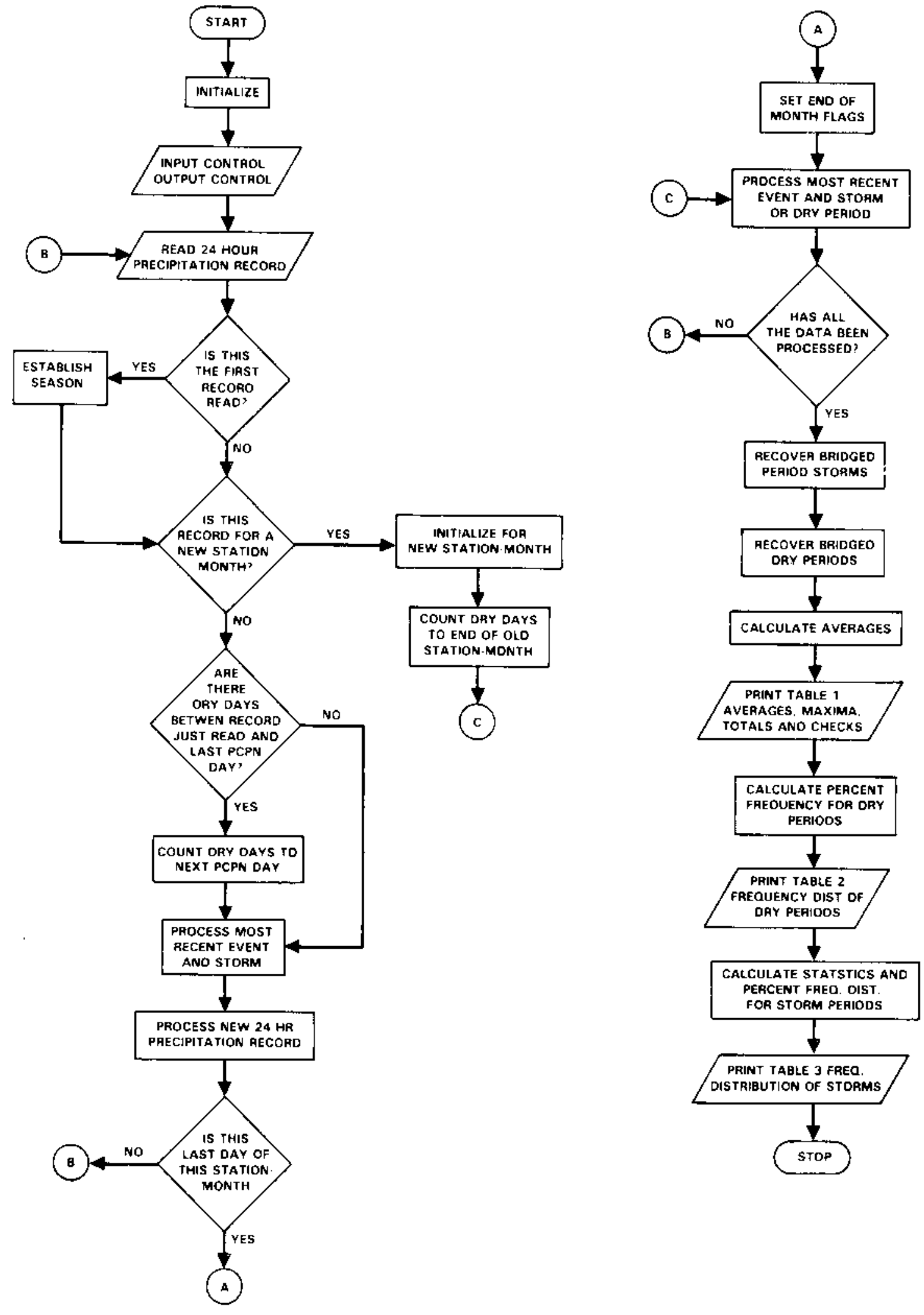

FIGURE 3. Flowchart Showing Major Functions of Program WETDRY 
precipitation (integer form), and the daily total precipitation (integer) (see Table 4). Amounts are reported in 1/100ths inches of water without decimals. Immediately following the READ statement is a WRITE statement that is generally used only on small data files, as a verification that the data are being properly read. The WRITE statement is normally commented out when the program is run with data files of more than a few stations and months. Two commands are built into the READ: 1) if unrecognizable data are encountered, control goes to statement 350 , and the program is stopped with a message indicating where the trouble occurred; 2) when an end of file is encountered control goes to statement no. 12 for setting flags and last month and year indicators. A check is made to compare the sum of hourly precipitation values with the daily total precipitation. A message announces the location of any inconsistencies.

TABLE 4. Variables Read in Each Hourly-Daily Precipitation Record

\begin{tabular}{lcl} 
Name & Dimension & \multicolumn{1}{c}{ Definition } \\
\cline { 2 - 3 } MSTATE & I2 & Two digit climatic State number \\
NUM & I4 & Four digit climatic Station number \\
MO & I2 & Two digit Month number \\
DA & I2 & Two digit Day number \\
YR & I2 & Two digit Year number \\
IP & (24) I3 & Three digit hourly Precipitation amount \\
IPD & I4 & Four digit daily sum of 24-hour Precipitation
\end{tabular}

\subsubsection{Secondary Initializations}

After the first record in the data file is read, certain run parameters are se:. Among these are determination of the season. Values are assigned to M1, M2 and M3, which represent the months of the season for which the data occur. The first year and month in the data set are also noted at this time (FYR and FMO). When the EOF is reached at the end of the data file, the last month and last year ( $L M O$ and $L Y R$ ) are set. A number of other values are assigned in this section of the program that are used later in table headings, etc. Checks are made to detect instances of unknown accumulations 
(-9) and missing data (-99) that may have been overlooked in the hand-editing process.

A maximum number of read cycles is established: MAXM. A guide to the value of this number is the number of stations times the number of months times 15. This assumes that on the average precipitation will occur on no more than half the days in each month. If greater frequency is likeiy, the above calculation should be appropriately increased. MAXM provides an emergency stop to the program should there be an inadvertent endless loop in the READ cycle. The value of MAXM is set or changed via EDITOR.

Except for day 1 , only days with precipitation are included in the data file. Thus dry days must be inferred. There are three situations when dry periods longer than one day in duration may occur. The first is 'withinmonth', that is, when precipitation days are separated by one or more dry days. The procedures at statement no. 315 handle this situation. The other situations happen when the last period of precipitation ends more than one day before the end of the station-month, or if there should happen to be no precipitation during the month at a station. In these cases, the statements at no. 325 cause a count of dry days unti 1 JDAY exceeds NDMO, and contro 1 goes to month-end processing. There may be an event or storm to process before proceeding to treat the next record. The accumulation register for total hours in data, ITHRS, is incremented 24 hours at a time in the above routines.

To establish the number of dry days to be included within end-of-month periods following the last precipitation record, the elements, MM, in DATA statement MDAYS correspond to the number of days in each month plus one, (the last MM element, number 13, is for February of leap year). The variable JDAY is incremented each time a daily record is read or each time a dry day is added. At the end of each day's tally, NDMO is compared with JDAY. As long as JDAY is less, the program continues to process data one day at a time; when JDAY exceeds NDMO, control is passed to rousines to perform end of station-month operations before proceeding to the next record processing. 
As each daily precipitation record is read, the daily total precipitation is accumulated in GSIPD, the grand sum of regional precipitation. At the end of data processing, the sum of individual hourly amounts used, plus those not used, will be compared against this grand sum to guarantee that all the hourly precipitation data have been treated.

When a new year is encountered from the READ, variables MON(NN), IYR(NN), and $Y$ are incremented or set. The arrays are used later in table headings, and $Y$ provides the value for 'year' when assigning month-end periods to arrays.

\subsubsection{Processing the 24-Hour Record}

Each 24-hour record is processed, 1 hour at a time, in 100p, DO $13 \mathrm{D}$. Each hour is checked for missing data (-99), in case manual editing of the file created by NCCTAP failed to identify all such hours. The program is not stopped by the -99 indicator, but an error message is written identifying the location of such data. Each hour in the record is added to the total hour accumulation sum, ITHRS. If the tests of $K$ (hour) and DA (day) indicate that the hour just encountered is the first hour of the first day of a stationmonth the following flags are set or incremented:

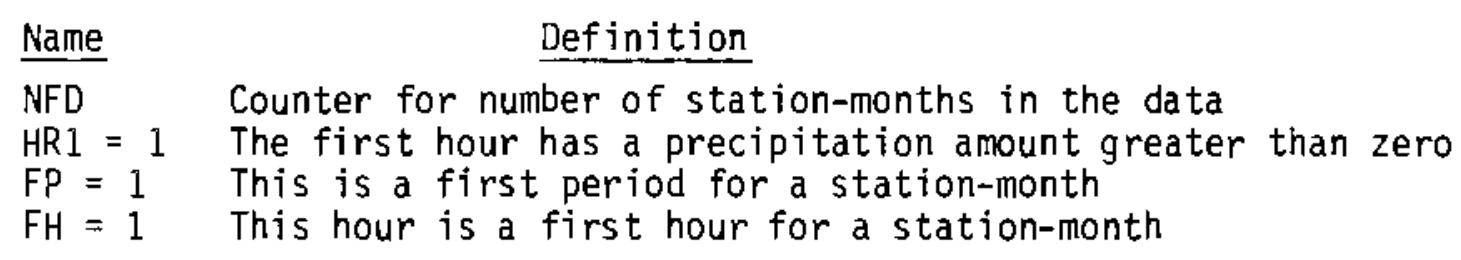

Next, the value of IP(K) is determined to be either negative (error), zero (a dry hour), or positive (an hourly precipitation amount equal to the value of $I P(K) / 100)$. The handling of each of these possibilities is described below: IP $(K)<0$ :

- An accumulation period exists that was not detected in data file EDITING. A message is printed showing the data file location of the negative value. 
IP $(K)=0$ :

- Start a dry period duration, IDURD, count.

- If there is no unprocessed wet period, go tc the next hour.

- If there is an unprocessed wet event, process it, but postpone event rate calculation.

- When event is processed, test to see if dry hour accumulation exceeds NDHR.

- If NDHR is exceeded and the unprocessed storm was a 'first period' storm, Section 4.2.6 describes the procedure for treating this situation. Otherwise the last storm is tested for maxima.

- Calculate the event rates.

- Cal1 Subroutine STORM to process the storm.

- Proceed to the next hour; continue to add to IDURD until the dry period ends.

IP $(K)>0$ :

- Increment wet hour accumulation counter, ITRHRS.

- Test for maximum hourly amount, MXIP.

- Set IFLAG indicating beginning or continuation of event.

- Start, or add to wet period duration count, IDURR.

- Start, or add to wet hour count for this event, IWETHR.

- Set event number within this storm, IV.

- If last dry period has not been processed, and if its duration is less than NDHR, the dry hours are added to IDURR as pseudo-wet hours. Accumulate the sum, IDH, of pseudo-wet hours in the storm, and in all the data, IDRY.

- If this should be a first wet period for a riew station-month with first hour dry, assign the number of beginning dry hours to KD for later placement into a recoverable array.

- Add the hourly amount to the grand sum precipitation register, JPTOT.

- Add the hourly amount to the current storm cmount accumulation register, ISTAM.

- Add the hourly amount to the current event amount accumulation register, IPEV.

- Reset the first hour flag, FH to zero. 
- If there are no remaining untreated dry hours, go to the next hour. If there are remaining dry hours, process the dry period which has just ended.

- If the unprocessed dry period is a 'first period', the method of processing is described in Section 4.2.6. Otherwise test for maximum dry period duration, then process normaliy with Subroutine DRYPRD.

- Go to next hour.

After each 24-hour record has been processed, the following day end variables are set:

Name Definition

LDA The day (DA) of the record just finished.

LNUM The station number (NUM) of the record just finished.

LASTATE The state number (MSTATE) of the record just finished.

LM The month (MO) of the record just finished.

LAYR The year (YR) of the record just finished. In addition, the 24-hour record just processed is tested to see if it is the last day of the current station-month. If so, and if the last hour was wet, flag P24 is set to 1 , and last-period-wet flag LP, is set to 2 . If the last hour was dry, but the last period was wet, the flag LP, is set to 1 .

If the last precipitation day was not the last day of the month, the next record ia read to determine if there are more precipitation days for this station-month or if there are only dry days to the end of the month. This will be determined by whether DA as read is 1 , indicating a new stationmonth, or if DA is some number greater than the day just processed, LDA. If the lat.ter, the program adds dry hours ( 24 per dry day) until the next record 
day is reached. Then control passes to loop DO 130 again for hourly processing. If the newly read DA equals 1 (signifying a new station-month), and if there are dry days at the end of the old station-month, the program adds dry hours at 24 per day unti] the end of the current month is reached (see Section 4.2.4). Before proceeding with a new station-month, any unprocessed periods in the old month must be treated. Whether wet or dry, if they are from the month-end period, they are processed with the routines described in Section 4.2.6. Otherwise, they are processed nomally using Subroutine STORM or DRYPRD.

After all end period processing for a station-month has taken place, control goes to statement no. 5 ahead of the READ to initialize certain variables in preparation for a new station-month. Recall that the new record for Day 1 has already been read. When DA equals 1 , the program skips over the READ and proceeds to process the first 24 hours of this first day of the new station-month before reading another record.

After all the data have been read and processed, an end-of-file is encountered on READ, and control passes to statement no. 12 where the state number is set to 99 to indicate that the EOF has been reached. The last month, last year and last state number are also identified at this point. Any last dry hours (or days) remaining in the last station-month are added in to the last period, or if the last period was a storm that has been processed, then control is passed to the program section which recovers monthbeginning and -end periods (see 4.2.8).

\subsubsection{Treatment of Incomplete Periods}

The first period and last period of each station-month are incomplete periods. Recall that the data file is arranged by year, seasonal month, state, and station. Thus, each storm or dry period is processed as it is encountered, and treated as a regional event independent of time or precise location. The original version of WETDRY made no distinction between storm and dry periods that occurred within a month from those that began or ended a month. End periods so treated have a high probability of being incomplete periods. In the statistical analyses, inclusion of these incomplete periods 
introduces a bias toward greater frequency of shorter duration storms and dry periods. To combat this problem, the next version of WETDRY dropped all end periods from the analyses. This, of course, biased the analyses to some extent since not all the data were being used. Another difficulty in using this approach at PNL stems from our rather limited data base of only about 30 months. In order to make maximum use of the PNL data base and to reduce bias in the analyses caused by the above reasons, Version 7 of Program WETDRY was developed.

This version identifies monthly beginning and ending periods, and if they continue from the proceeding month or continue into the following month they are assigned to arrays for recovery and pairing later. In a season for which 3 months of data are present, four of the six month-end periods for each station can normally be paired and recovered later. However, the first period of the first seasonal month, and the last period of the last seasonal month are never available for analysis, but hours from such periods are accounted for in the total hour audit. If a season is incomplete, but two consecutive months are present, then only two of the six end-periods can be included for anatyses. A season with only one month or with the central month missing will have all its end-period data consigned to the unused data registers. The routines for treating 'first' periods are quite similar to those treating 'last' periods. Detailed description of the procedure will be limited then to 'first' periods, with appropriate comments describing any differences used in treating the 'last periods'.

Before any precipitation data are read or analyzed, user input informs the prcgram of the completeness of the seasons making up the data file. The code ard rationale are described in Section 4.4.1. Briefly, there are code numbers, MMF (one for each year that is represented in the seasonal data file), which are used to inform the program of the completeness of the seasonal data for each year. The coded values of MMF have the following meanincs:

$M M F(K Y F)=0 \quad$ All three months of the season are present in the yearly data. 
$\operatorname{MMF}(K Y R)=1 \quad$ Month 1 of the season is missing for KYR.

$\operatorname{MMF}(K Y R)=2 \quad$ Month 3 of the season is missing for KYR.

$\operatorname{MMF}(K Y R)=3 \quad$ Month 2 is missing, or there are data for only one month of the season for this KYR.

$\operatorname{MMF}(K Y R)=9 \quad$ There are no seasonal data for this KYR.

A more detailed description of this coding procedure is found in Section 4.4.1.

After the first 24-hour record is read for each station-month, enough information is available for the program to determine whether the first period is wet or dry. Consider the situation of the first period for a station-month being 'wet', i.e. a storm. In this case, the procedures in loop DO 130 will have set flag FP $=1$, indicating that a first period is in progress. If the first hour of this period has a measurable amount of precipitation, flag HRI will be greater than zero. These flags will be sufficient to lead control to the 'First Period Wet' routine, which does the following:

- Determines the station sequence number, I, and assigns that number to the first dimension in the 'First Period Wet' array.

- Tests for seasonal month. If it is the first seasonal month, control skips to the unusable data section as the first period of the first month cannot be paired.

- Tests for WINTER season. If it is WINTER, and Month-l is December, set year number, $Y$, to $Y Y$ (for previous year). This will accomodate the year break that is present in WINTER.

- Test for completeness of season as coded by MMF (of $Y$ or YY).

- If the period in question can be paired later, its duration is assigned to variable $\mathrm{FPW}(\mathrm{NW}, \mathrm{Y}, \mathrm{MO})$ where $\mathrm{NW}=$ station sequence no., $Y=$ year, $M 0=$ month .

- If the first hour of the period was wet, then calculation of the first event rate is postponed untill recovery (since the last hours of the other leg of the period may also be wet). 
- If the first hours of the period were dry (but fewer than NDHR), these hours are placed in array KFD because, at this stage, it is unknown whether they will form part of a dry or a wet period.

- Event rates are calculated for all events except in the case of the first event described above.

- The sum of the event rates is assigned to XRATF (NW, Y, MO)

- The storm amount is assigned to ISTAMF (NW, Y, MO).

- The sum of pseudo-wet hours (dry hours less than NDHR) is pu: in IDHF (NW, Y, MO).

- If the period cannot be paired for any reason, then the above vaiues for number of wet hours, dry hours that would have been al lowed to count as wet, and the amount of precipitation in the period are assigned to:

MWH Missing Wet Hours

$\mathrm{MDH} \quad$ Missing Pseudo-wet Hours

MP Missing Storm Precipitation Amount,

and the following Grand Sums are reduced by the appropriate amounts:

ITRHRS-NUMWET Grand Sum of Wet Hours by wet hours in this storm.

IDRY-IDH Grand Sum of Pseudo-wet hours by pseudo-wet hours in this storm.

JPTOT-ISTAM Grand Sum of precipitation by this storm amount.

Treating a 'Last Period Wet' is very similar. However, in that case it is the last period in Month 3 of a complete season that cannot be paired.

The routine for treating first and last dry periods is considerabiy shorter since duration is the only parameter used. For a 'First Period Dry', the procedure is:

- The station sequence number, I, is found and assigned to array index ND.

- Test for seasonal month. If month equals M1, control skips to the unusable data section. 
- Test for WINTER season. If season is WINTER, the single code for MMF (KYR) cannot represent KYR for both December and the following January. Thus, for WINTER seasons, if December is missing, set $Y Y=Y-1$. Otherwise, using the year, $Y$, as read for January or February will, in such cases, result in choosing the wrong MMF(KYR) code.

- Depending on season completeness code, $\operatorname{MMF}(Y$ or $Y Y$ ), either assign the duration of the dry period, IDURD, to array FPD (ND, Y, MO) for recovery, or if it cannot be recovered, the dry hours are added to MDH, (Missing Dry Hours).

The routine for 'Last Period Dry' is essentially identical except as noted in a previous paragraph: it is the last period in Month 3 that is not recoverable, rather than the first period of Month 1 .

\subsubsection{Recovery of Incomplete Periods}

In the previous section, we have described how storms and dry periods that occur at the beginning and end of each station-month may be periods that can be paired with their respective previous or continuing portion. All the pertinent parameters have been retained in arrays identifiable by station sequence number, year number, and month. For convenience, the following abbreviations will be used to identify the respective periods:

FPW First period wet

FPD First period dry

LPW Last period wet

LPD Last period dry

Should the program be run with only a single month's data, array index NN will be less than 2. Such a value will cause the program to skip the endperiod recovery section. This will reduce run time. Normally the flag, NOWET is set to 1 , signifying that recovery of both wet and dry end periods is desired. If NOWET $=0$ (changed in EDITOR), the program recovers dry periods only. Data may consist of reports from a very dry region, and the very rare wet end period may not justify the extra run time required to examine each station-year for possible beginning and ending wet periods. The procedures dealing with storm parameters are considerably more time consuming 
and complex than those dealing with dry periods. The recovery of wet periods will be discussed first.

Wet periods that span months fall into five cases or types. These types cannot always be identified at the assignment stage, so are identified and treated in the recovery process. Recall that NDHR is the number of dry hours allowed within a storm. The five cases and a brief description of each follows:

CASE 1: The number of dry hours separating LPW and FPW is greater than NDHR. Process as two separate storms and assign the intervening dry period to an array for later recovery.

CASE 2: The number of dry hours separating LPW and FPW is less than NDHR. Either the last hour of the LPW is wet or the first hour of the $\mathrm{FPW}$ is wet, but not both. Because the last (or first) hour is wet, there is one event rate yet to be calculated in this case because when it was assigned to the array it was not yet known whether the situation would be a CASE 2 or CASE 4 .

CASE 3: Either the LPW or the FPW is actually followed or preceded by a FPD or LPD. Dry hours less than or equal to NDHR that formed the end or beginning of the LPW or FPW are assigned to an array for addition later to the proper FPD or LPD.

CASE 4: Both LPW and FPW are continuous wet periods. The number of events in the combined periods will be 1 less than that shown by the assigned arrays. A new event rate must be calculated for the event formed by the coupling of LPW and FPW.

CASE 5: Quite similar to CASE 2 in that the period following the L.PW or the period preceding the FPW was dry. However, the last hour of the LPW or the first hour of the FPW is always wet. Earlier in the program this situation caused the calculation of the event rate to be postponed. The event rate calculation is made at this point in the program.

The end-period recovery routine is contained in loop D0 600, which examires each station for each year of data for any LPW or FPW periods. If 
$\operatorname{MMF}(\mathrm{KYR})$ indicates there were no months having recoverable data for the year in question, control skips to the next year or station. But if the value of $\operatorname{MMF}(K Y R)$ is less than 3 , there is a possibility of recoverable wet periods. An inner loop, D0 680 performs the necessary steps to identify periods that can be paired, combines the matching parameters after the proper case has been determined, and puts the arrayed data into non-array arguments. Subroutine STORM is then called to process the period. Storms formed by pairing are also tested for maxima of duration and amount.

The first test within 100p DO 680 determines whether the season for the current year is complete or not by examining MMF (KYR). KYR in this loop is denoted by II. If the season-year under examination is complete, there will be two passes through the loop. If there is only one set of consecutive months for the season being examined, the flag J0 is set to 2 and only 1 pass through the loop will occur. In the arrays, station-sequence number is $\mathrm{N}$; year number is either Indices IX or IY; month is either MX or MY. If the season is WINTER and if it is complete, or if Oecember and January are present, the first pair of coupled periods involve two different years. IX and IY must be adjusted for this situation, and a series of decisions at the beginning of loop 680 sets the values for $I X$ and $I Y$ and transfers control to the appropriate set of consecutive months; i.e., MX and MY equal $M 1$ and $M 2$ for pairing of the first months of a season, but equal M2 and M3 for the pairing of periods from the last months of a season.

Once the proper values for IX, IY, MX, MY are assigned, program steps follow that determine the Case type from the arrays to be paired. The first test sums the appropriate LPW and FPW. If the sum is zero, then there were no wet beginning and ending periods; i.e., those particular last and first periods were dry and the pairing of LPD and FPD will take place in the Dry Period Recovery routine. If the sum is greater than zero, at least one of the periods was wet. The program then proceeds to determine which leg was the wet one (or whether they were both wet) by testing the difference between $L F$ and FF. If both were wet, a sum, KDO, of the dry hours at the end of the LPW and at the beginning of the FPW is formed. The value of KOD determines the following cases: 


\begin{tabular}{ll}
\multicolumn{1}{l}{$\begin{array}{l}\text { KDD } \\
<\text { NOHR }\end{array}$} & $\frac{\text { Meaning }}{\text { Two storms separated by a dry period. CASE } 1 .}$ \\
$<$ NOHR but >0 & A continuing wet period with dry hours at the \\
& month break. CASE 2 or 5. \\
$=0$ & Precipitation continues through the month \\
& break. CASE 4.
\end{tabular}

If only one leg is wet as determined by the difference, LF-FF being not equal to zero, control skips over the KDD detemination and, using flag KL or KF, determines whether the last or first hour was wet. If either is wet, treatment is assigned to CASE 2 or 5 routine. If neither is wet, a CASE 3 situation is indicated, and control skips to that part of the recovery routine.

The pairing of wet periods and the processing of the storms thus formed is quite similar in all cases. Differences are due to the number and position of any dry hours that occur in the paired periods. If the sum of consecutive dry hours is less than, or equal to NDHR, then those hours are included within the storm. If the sum of such hours is greater than NDHR, the hours are assigned to arrays which will be used in the Dry Period Recovery section. When the stom segments have been combined from the appropriate arrays, the values are put into nondimensioned arguments for Subroutine STORM, which is then called for processing the stom.

The recovery of paired dry periods LPD and FPD takes place in DO LooP 183. Since duration is the only dry period parameter considered, the process is considerably shorter than for the storm periods. The basic procedure is similar, however, and the following steps are taken:

1. Test MMF(KYR) for season completeness. The MMF code determines which, if any, end periods can be processed.

2. Test for WINTER season. If WINTER, make the appropriate adjustment for year break in values of IX and IY.

3. Depending on value of $M M F(K Y R)$, process both periods if MMF $=0$, or only one period if MMF is greater than zero.

4. Assign the arrays containing LPD and FPD to nondimensioned arguments for Subroutine DRYPRD, test for maximum duration, then call the subroutine to process the dry period. 
Descriptions of Subroutine MXIMA, DRYPRD and STORM are found in Section 4.3.

\subsubsection{Normal Termination}

Once the recovery and processing of the month spanning wet and dry periods is complete, program WETDRY proceeds to the analys is section. This section produces lists of sums, averages, and extremes, followed by the frequency distribution tables of dry period duration and storm characteristics. This output is described in Section 4.5.

\subsection{SUBROUTINES USED IN PROGRAM WETDRY}

\subsubsection{Subroutine MXIMA}

As each hourly precipitation amount is processed, it is compared to the previous maximum encountered. Each new value of storm duration, IDURR; calculated event rate, IRATEV; storm precipitation amount, ISTAM; and duration of dry period, IDURD; is also compared with previous high values, and is established as new maxima if old values are exceeded. The final maximum values are printed out in Dutput Table 1.

\subsubsection{Subroutine DRYPRD}

Each time a dry period terminates as the hourly data from the input file are being processed, or each time a dry period is recovered from end periods being paired in the recovery routine, the dry period is processed by a call to Subroutine DRYPRD. Subroutine DRYPRD also keeps accumulating sums of the number of dry periods in the assigned class interval, ISUMD(d), and of the number of dry hours in that class, $\operatorname{IDHR}(\mathrm{J})$. In addition, the grand sums of the number of dry periods, NMDP, and of dry hours in the data, ITDHRS, are incremented by the appropriate amount. The dry period duration counter, IDURD, is then cleared in preparation for the next dry period.

\subsubsection{Subroutine STORM}

Each time a stom period ends, Subroutine STORM is called to process the period. This subroutine performs the following actions on the stom data:

- Accumulates a total sum of all the precipitation events in the data, NEVENT . 
- Accumulates a total sum of all the event rates calculated, TOTRAT.

- Accumulates a total sum of all the storms processed, SSUM.

- Accumulates a total sum of all storm precipitation amounts, JGRSUM.

- Assigns the storm to its proper frequency class L.

- Accunulates a sum of all storms assigned to class $L$, NSTM(L).

- Accunulates a sum of all the precipitation occurring in class L storms, $\operatorname{TSTAM}(L)$.

- Accunulates a sum of all the events occurring in storms of class $L$, NEV $(L)$.

- Accunulates a sum of all the wet hours in storms of class $L, I T W H R(L)$.

- Accunulates a sum of all the hours in storms of class $L$, ITOUR(L).

- Accumulates a sum of all the pseudo-wet hours in storms of class L, $\operatorname{ISSDH}(\mathrm{L})$.

- Clears the storm and event counters in preparation for the next wet hour when events or storms have ended.

\subsection{INPUT TO WETDRY}

\subsection{1 . Program Control Input}

There are four lines of user input, near the beginning of the program, that provide file names and variable values which control program operation. The program request for input, and a description of the responses follow:

1. 'NAME OF INPUT DATA FILE' Response: The program is asking for the name of the hourly precipitation data file that has been created by program NCCTAP. This file must have been checked and edited by the user to el iminate by change, correction, or substitution, all values of -9 or -99 that may have appeared in the file when it was initially created from the NCDC data.

2. 'NAME OF OUTPUT DATA FILE' Response: The user inputs the name of the file to which the output data is to be written. After the program has run, the user makes the appropriate keyboard command to have the output file printed. 
3. 'ENTER VALUES FOR NO. OF DRYHOURS AND NO. OF STATIONS' Response: NDHR is the variable name for the continuous number of dry hours the user will allow to occur within a continuing stom. In storm analyses it is usually desirable that each precipitation event not be considered a total storm. Frequently, precipitation periods may be separated by dry periods of only 1 or 2 hours duration. If these dry hours are to be considered part of a single storm, the user must limit their length to be in harmony with the data, and the desired analyses. For the northeast United States in SUMMER and AUTUMN, one dry hour may be an acceptable in-storm dry period. It may be acceptable to allow 2 to 6 dry hours within WINTER and SPRING storms.

NX is the number of stations that will occur in the input file. This number must equal the number of elements, LL, in the data statement, $\operatorname{DATA}(\mathrm{NS}(\mathrm{LL}))$.

4. 'ENTER FIRST AND LAST DATA YEARS AND KYR CODES FOR EACH YEAR' Response: The number of the first year in tine data, NFYR, is always 1. The number of the last year in the data, NLYZ, is determined chronologically from the first year, even if there is a break in the continuity of years for which there are data. For examole, if the input data file has data for $1977,1978,1980$, and 1981, NFYR $=1$, representing 1977, and NLYR $=5$, representing 1981. The KYR code, which is explained below, makes it possible to inform program WETDRY that there will be no data for 1979, but it must be included as year 4, nevertheless.

Within the program, nomalized year numbers are calculated by subtracting a 'base year' from the value of year (YR), as read from the input file. This base year is built into our current version of the program, and is the last calendar year (last two digits only) preceding the first data year. For example, the PNL data base is made up of months from 1977(77), 1978(78), 1979(79), and 1980(80). The base year then, is defined as $1976(76)$. Subtracting the base year from the above data years, will thus assign year numbers $1,2,3$ and 4 to the PNL data. If the program is to be used in situations wnere data years are quite 
An example of complete responses to Entry $\# 4$ are shown below. Consider an AUTUMN data file composed of the following monthly data:

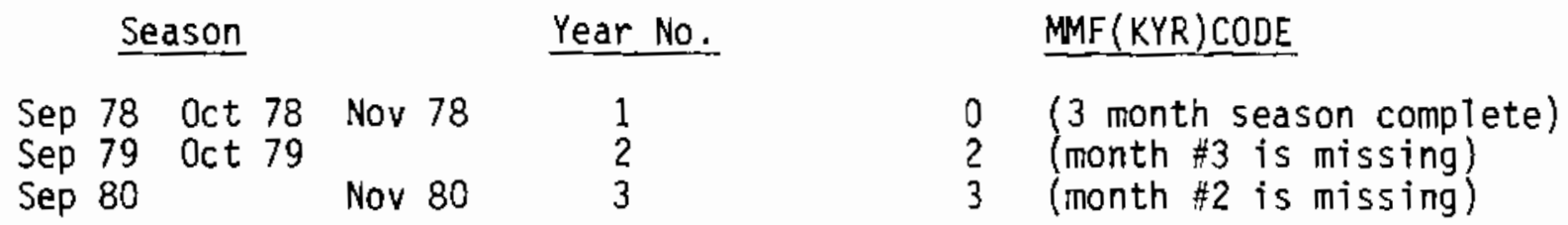

The user repiy to the input request would be: 13023 , where 1 and 3 are values for NFYR and NLYR, and values for $\operatorname{MMF}(K Y R), K Y R=1,3$, are 023 .

As another example, a WINTER file might contain the following months:

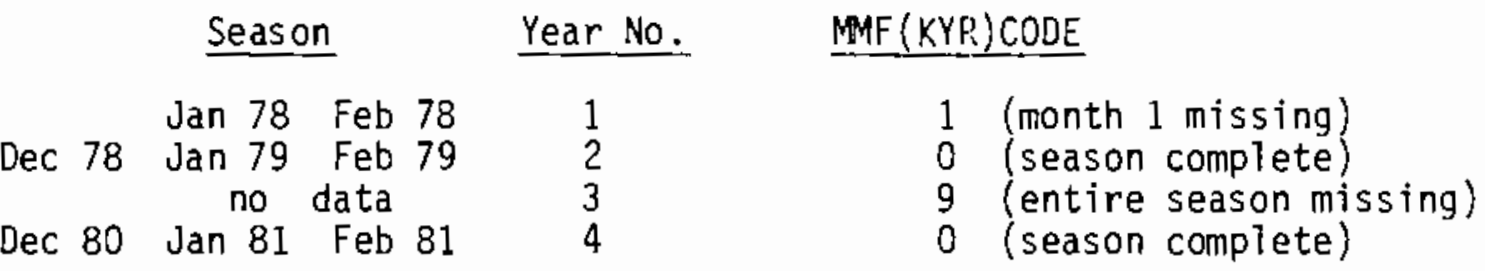

The input entry for the above situation would be: 141090 .

The code numbers for MMF (KYR) refer to the year corresponding to the first month in a season, regardless whether that inonth has input data or not. Confusion may arise with season WINTER. There, December will be of one year, while January and/or February will be for the subsequent year. To restate the rule for coding MMF(KYR) for WINTER: MMF(KYR) is coded to correspond to the year representing December, regardless of whether there is data for December. For the other three seasons, MMF (KYR) represents the year in which March, June or September occur. Since there is no 'year break' in these seasons, coding is self-explanatory.

\subsubsection{Hourly Precipitation Data File}

The hourly precipitation data file has been frepared by program NCCTAP and then checked for anomalous data by visual inspection. Proper changes have been made manually via EDITOR, and the individual monthly files have been combined to form a seasonal file for the region of interest. The name of this data file is entered from the keyboard, or through a command file, when the program asks for NAME OF INPUT DATA FILE. Since this data file may 
be a large one, it may be desirable to copy it to tape if there will be lengthy intervals between runs of WETDRY.

\subsection{OUTPUT FROM WETDRY}

4.5.1 Output Table 1: Average Values and Maxima

Output Table 1 (see Appendix B) is a 'one liner', that contains the following information:

- Last State, Station, Year, and Month encountered in the data file.

- Average storm precipitation rate (inches per hour).

- Average storm duration, and average dry period duration.

- Total number of storms, and total number of dry periods processed.

- Grand total of regional precipitation from processed storms (inches).

- Grand sums of wet hours, of dry hours, and of pseudo-wet hours.

- Grand sum of all event rates in the processed storms (inches/hour).

- Grand sum of all events in processed storms.

- The average event rate for all events from processed storms (inches/hour).

\subsubsection{List of Sums and Checks}

Irmediately following the Table 1 output, is a list of maximum values of the following storm and dry period characteristics:

- Maximum hourly precipitation amount.

- Maximum storm duration.

- Maximum event rate.

- Maximum storm amount.

- Maximum dry period duration.

Next, a list containing sums and counts of various parameters that consti-ute an internal audit of program operation, is printed. These counts provide Quality Assurance checks of the reliability of the program operation, and also are a valuable aid in diagnosing problems resulting from program changes that may temporarily produce unexpected output. These checks include 1) sums of the total regional precipitation, determined by three different 
procedures within the program, and 2) the grand sum of hours in the data, compared with a sum composed of the hours assigned to various categories. Disagreements in these comparisons indicate flaws in the program operation, in the data, or both, and must be reconciled before analysis runs are accepted as valid.

The last list on the page containing Table 1 is a summary of actions occurring within the routines that recover the month-end and -beginning dry and wet periods. They include:

1. The number of dry hours, MDH, in first and last periods that are excluded from the anaiyses.

2. The number of dry hours, NRDH, recovered from paired first and last periods.

3. The distribution, by Case type, of the number of recovered storms.

4. The number of recovered dry periods.

\subsubsection{Output Table 2: Frequency Distribution of Dry Periods}

Output Table 2 displays the frequency distribution of dry periods by class intervals of 20 hours. This class interval is arbitrary. It may be made smaller or larger by EDIT changes of the appropriate DATA statement elements of IDPX $(K K)$, and the corresponding dimensions for IDPX.

Column 1 of the output table lists the sequential number of the frequency class. The second column defines the class interval by hours, column 3 is the frequency for each class, and column 4 is the percent frequency of each class. Column 5 represents a 3-point running average percent frequency for each class.

\subsubsection{Output Table 3: Frequency Distribution of Storm Periods}

This table provides the frequency of storms by a class interval of 1 hour. Other storm and event statistics are shown for each of the class intervals as well. Table 6 lists the information printed in Output Table 3 , and a brief description of the variables.

The six column totals in Output Table 3 are used as checks of data utilization, and possible program idiosyncracies. Following Table 3, is a 
short list of sums and calculated values. These too, provide checks on certain of the sums and averages calculated by different procedures. A final line shows the number of dry hours allowed to occur within a storm.

TABLE 6 . Description of Output Table 3

\begin{tabular}{l} 
Column Heading \\
\hline STORM LENGTH \\
$\operatorname{CUMPCT}(\mathrm{J})$ \\
$\operatorname{NSTM}(\mathrm{J})$ \\
$\operatorname{TSTAM}(\mathrm{J})$ \\
$\operatorname{AVPPS}(\mathrm{J})$ \\
$\operatorname{FRTOT}(\mathrm{J})$ \\
$\operatorname{AV} 3 \operatorname{PPT}(\mathrm{J})$ \\
$\operatorname{NEV}(\mathrm{J})$ \\
$\operatorname{AVEVS}(\mathrm{J})$ \\
$\operatorname{CUMFR}(\mathrm{J})$ \\
$\operatorname{ITWHR}(\mathrm{J})$ \\
$\operatorname{GAVHR}(\mathrm{J})$ \\
$\operatorname{AVPPE}(\mathrm{J})$ \\
$\operatorname{AVSTRT}(\mathrm{J})$
\end{tabular}

\section{Description}

The frequency class. Also, the storm duration in hours.

The cumulative percent of the number of storms in each class.

The number of storms in each class.

The total precipitation from all storms in each class.

Average precipitation amount in each storm of class $\mathrm{J}$.

The fraction of the total regional precipitation from storms in class $\mathrm{J}$.

A 3-point smoothed average of FRTOT.

The total number of events in each storm class. The average number of events in storms of class $\mathrm{J}$. The cumulative fraction of total regional precipitation from each storm class. Expressed as a percentage. The total number of wet hours in all storms of class $\mathrm{J}$.

The average number of hours in all events from storms of class $\mathrm{J}$.

The average hourly precipitation rate for each event occurring in storms of class $\mathrm{J}$. The average hourly precipitation rate for storms of class $\mathrm{J}$.

\subsection{D.AGNOSTIC MESSAGES FROM WETDRY}

\subsubsection{Non-Critical Messages}

To check the accuracy of changes made manually in the hourly precipitation data file, the sum of the 24 hourly precipitation values, IP(K), for each day of record, is compared with the daily sum of precipitation, IPD. If there $s$ disagreement, the following message is printed out: INCONSISTENT PRECIP SUM AT (state \#, station \#, month, day, year) 
Should an hourly precipitation value of -99 (missing data) slip through the manual editing process, WETDRY will indicate the occurrence with: -99 ENCOUNTERED AT (state \#, station \#) ON (month, day, year) HR

The above statements do not signal termination of the program, but do identify data records which need to be corrected.

\subsubsection{Messages Accompanying Abnormal Program Termination}

Errors, or certain anomaties in the data, and excessive counts or cycles of some operations in a program run, will cause termination of the run, and a diagnostic statement indicating the nature of the problem. The diagnostic statements and their meaning are listed below:

1. 'NEG VALUE OF (DA-1) AT'.

If the variable read for day, DA, is zero, the program stops, and the location of the erroneous value is given (state, station, month, day, year). The data file must be corrected before trying the run again.

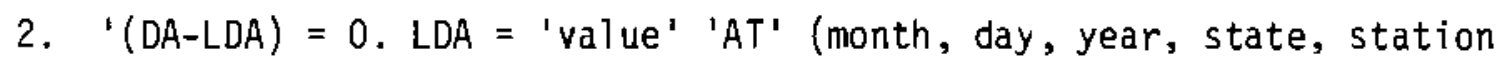
number).

If the day number should be duplicated for a station-month, the program will stop with the location of the occurrence given. The data file must be corrected.

3. 'ABNORMAL VALUE OF IDURR. IDURR =' (value).

The program is set to stop if a storm exceeds "nnn" hours. Any desired limit, nnn, can be set through EDITOR.

4. 'AFTER ( ) PASSES NUM (OR LNUM) FAILED TO FIND A MATCH AT DD 212, 241 , 222, OR 231. STOP'

The four loops indicated are the ones which locate the station sequence number when assigning LPW, FPW, LPD or FPD to arrays. If a station number other than that shown in the DATA list is encountered, the program terminates, and the questionable station numbers are printed out. Check the data file for duplicated or spurious station numbers. Correct if necessary.

5. 'ERROR ENCOUNTERED IN READ, OR M COUNT EXCEedEd AT ( $) . M='$ ' 
If unrecognizable data are encountered as a record is being read, control is passed to this statement, and the location is printed out. M is a counter for controlling the number of passes through the READ statement. The 1 imiting vaiues for $M$ and MAXM are assigned through EDITOR (see 4.2.4).

6. 'TOO MANY DAYS WITH MISSING DAILY TOTALS. STOP'.

A daily sum of precipitation IPD, is read with each record. If the nunber of missing daily sums exceeds 100, (the user can change the limit through EDIT) the program terminates. 


\subsection{REFERENCES}

The MAP3S/RAINE Research Community. 1982. "The MAP3S/RAINE Precipitation Chemistry Network: Statistical Overview for the Period 1976-1980." Atmos. Environ. 16:1603-1631.

Scott, B. C. 1982. "Predictions of In-Cloud Conversion Rates of $\mathrm{SO}_{2}$ to $\mathrm{SO}_{4} "$. Atmos. Environ. 16:1735-1752.

U.S. Department of Commerce, National Oceanic and Atmospheric Administration, Environmental Data Service. National Climatic Oata Center (NCDC). 1960. TD-9657 Hourly Precipitation. Available from the National Climatic Data Center, Asheville, North Carolina. 
APPENOIX A

PROGRAM LISTINGS 


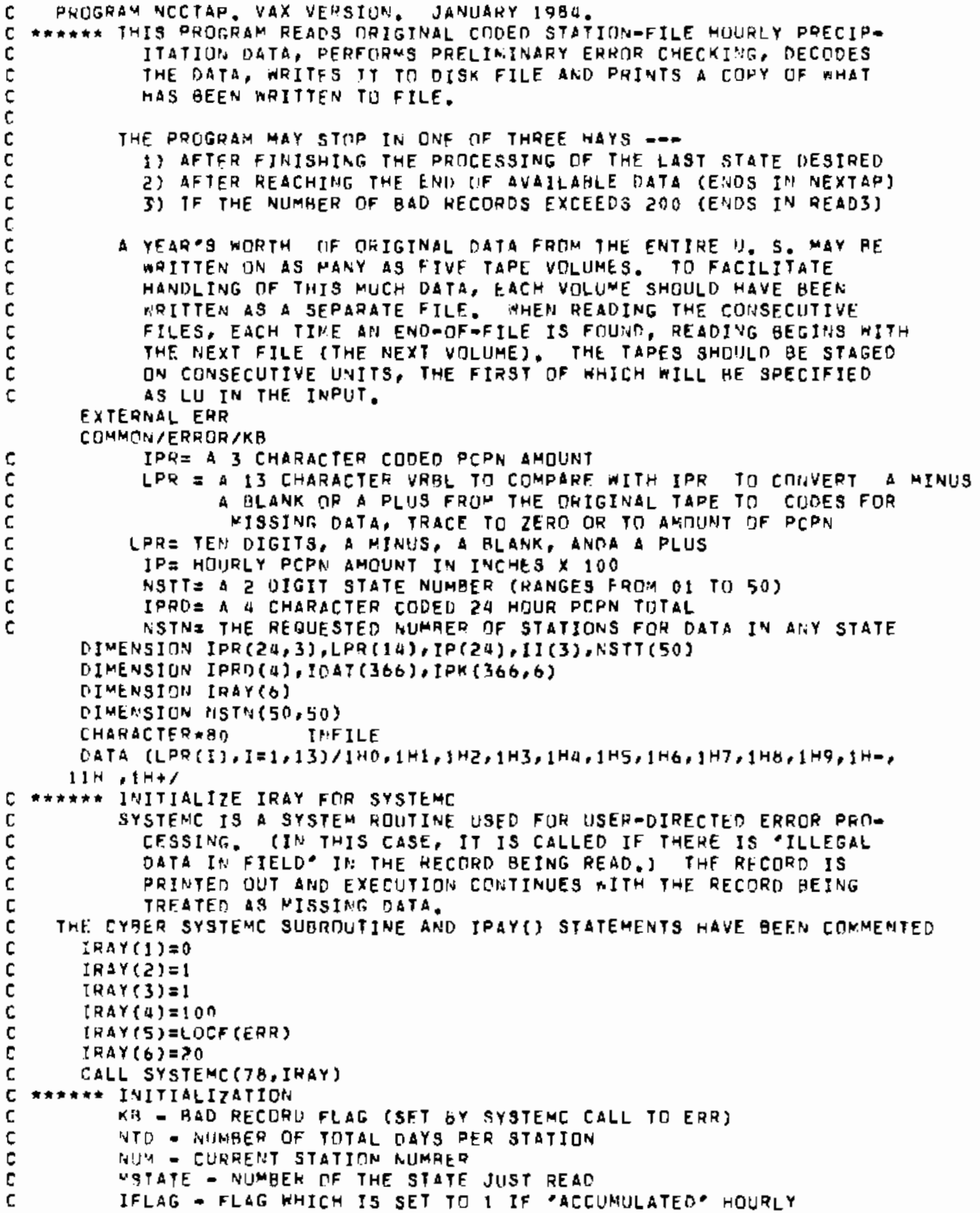




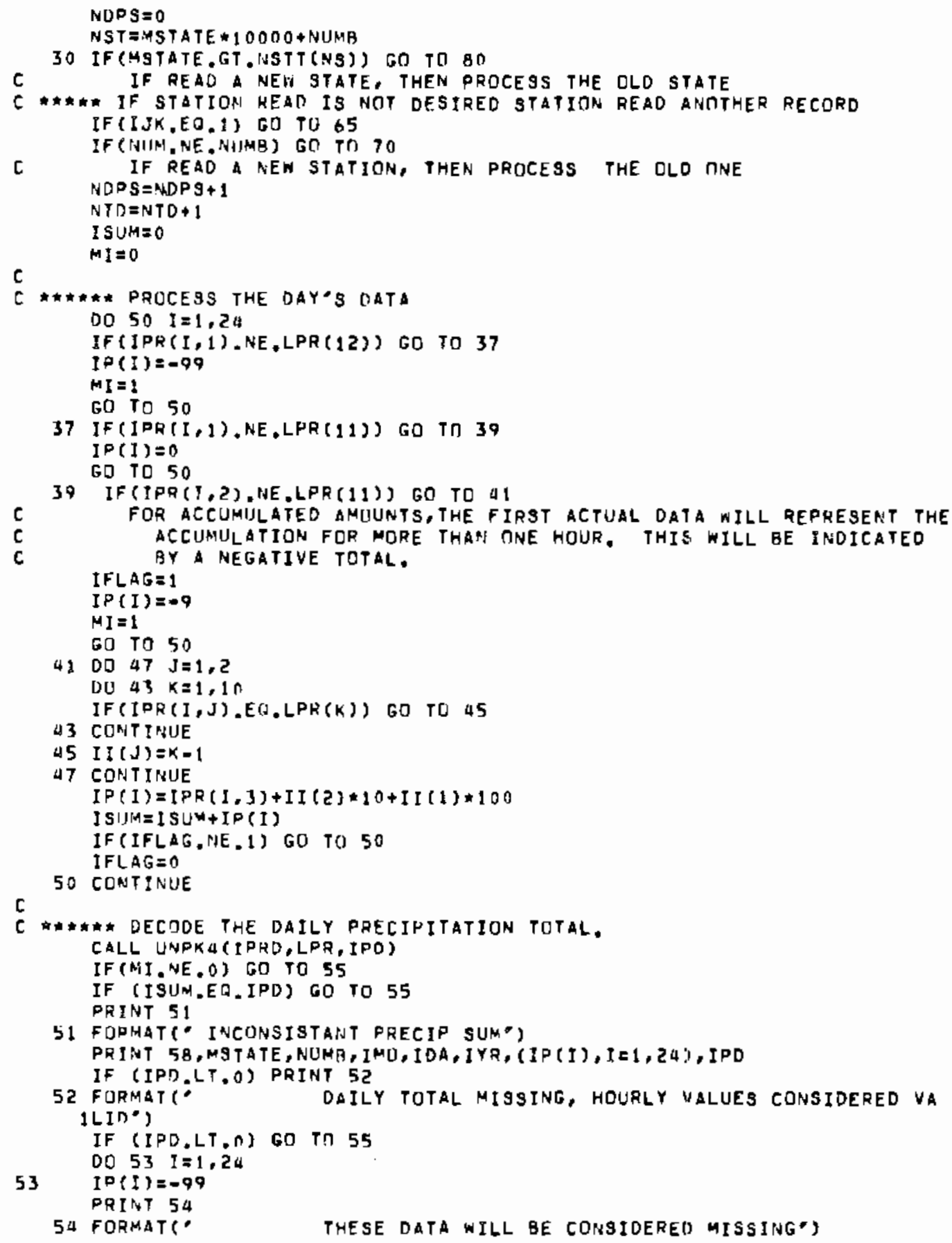




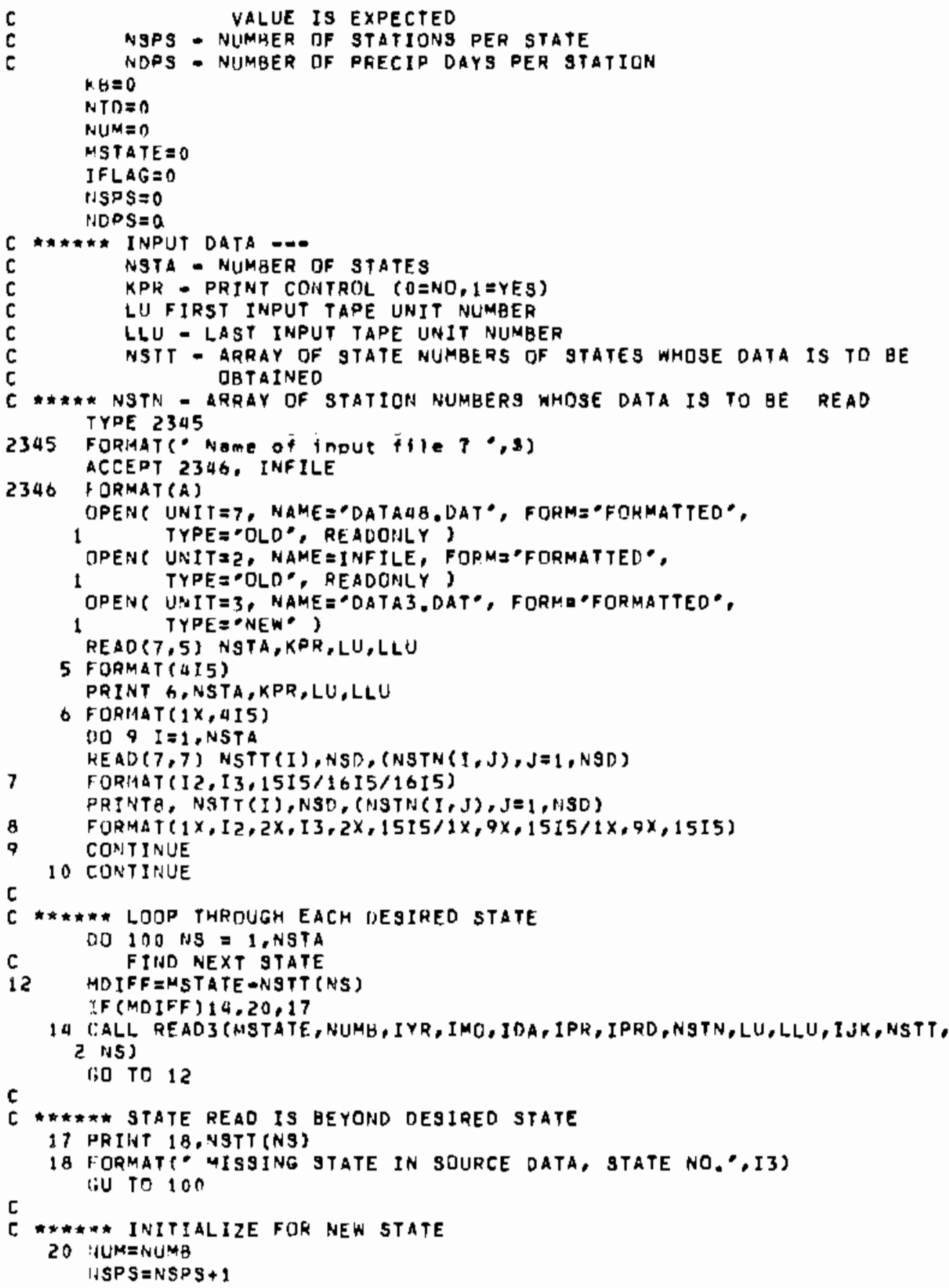


55 IF (KPR,EO,O) GO TO 60

WRITE (3,56) MSTATE, NUMA, IMN, IDA, IYR, (IP (I), I=1,24), IPD

56 FORMAT (I 2, I 4, 3I 2, 24I I, I4 ]

PRINT 5B,MSTATE, NUMB,IMD, IDA, IYR, (IP(I),I I1,24), IPD

FORMAT $(1 X, 12,3 x, 14,3 x, 12,3 x, 12,2 x, 12,3 x, 2514)$

60 IOATE $=I Y R * 10000+1 M 0 * 100+I D A$ IDAT (NOPS) =IDATE

C ****** READ THE NEXT DAY'S DATA (TWO RECORDS)

65 CALL READ3(MSTATE, NUM(I, IYR, IMD, IDA, IPR, IPRD, NSTH, LU,LLU, IJK, NSTT, 5 (4S)

$60 \mathrm{TI} 30$

C

C $\# \star * * *$ ENO-OF-STATION PROCESGING FOLLOWS

70 PRIN 75, NUH, NDPS, NUMB

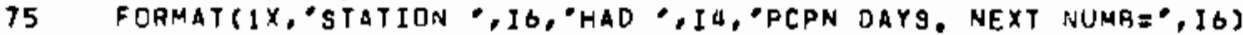
NUM $=$ NUMB

NSPS $=N S P S+1$

IF (NSPS.6T.5O) GO TO 78 NOPS $=0$

NGT $=$ MSTA TE $* 10000+$ NUMA

GO TO 30

c

$c$

C \#\#\#END-OF-STATE PROCESSING FOLLOWS

78 PRINT ES, MSTATE

65 FORMATLIX, NNSPS EXCEEDEO 50 STATIONS FOR STATE *IU)

80 PKINT 75, NUM, NOPS, NUMP NSPS $=0$ $N T D=0$

100 CONTINLIE

ST TPP

END 


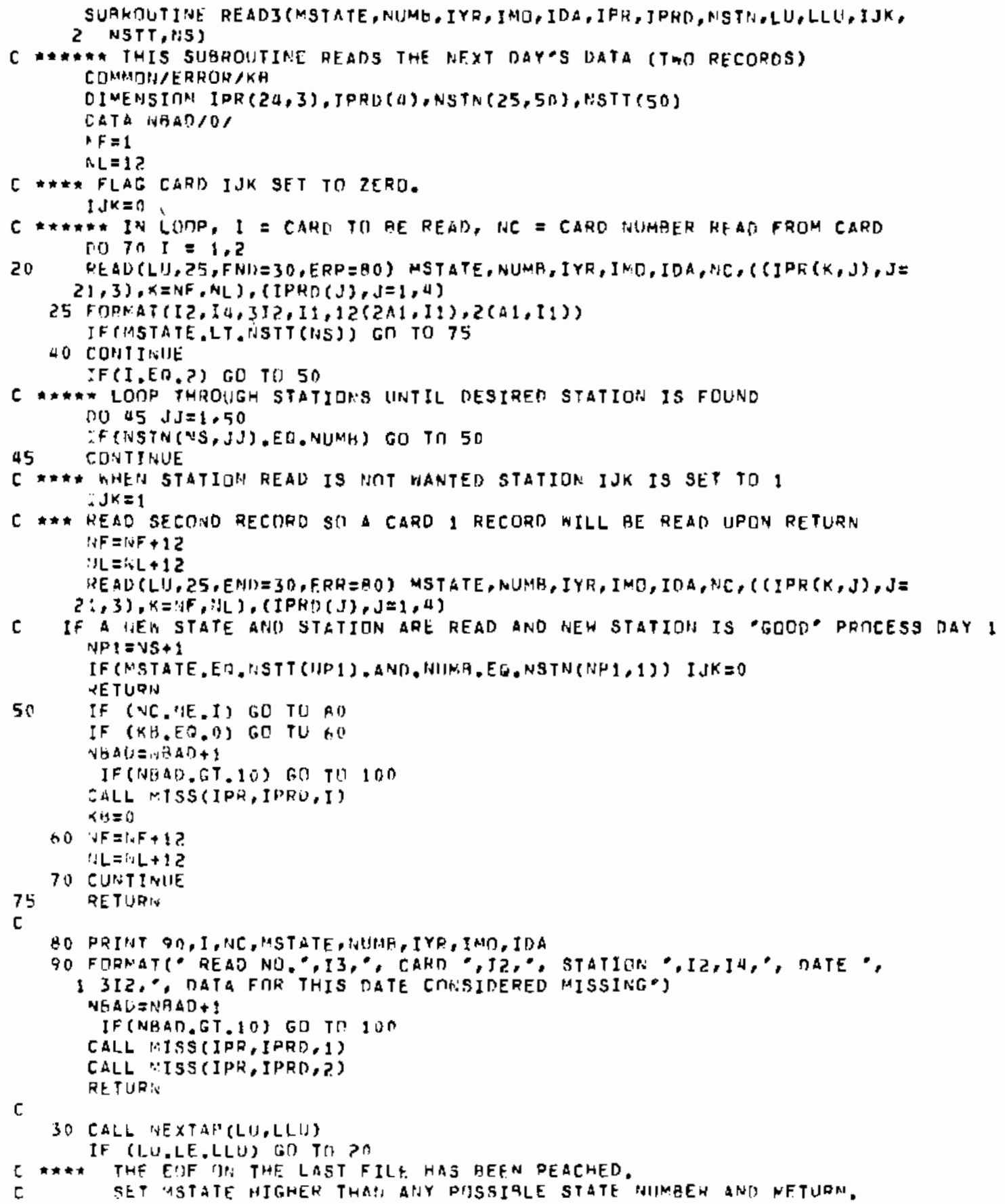


SUBROUTINE NEXTAP(LU,LLU)

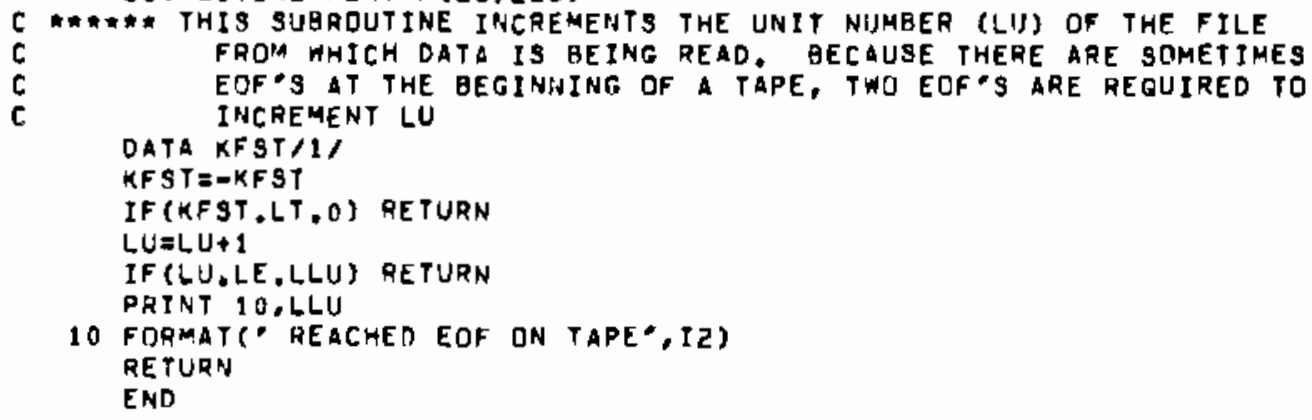




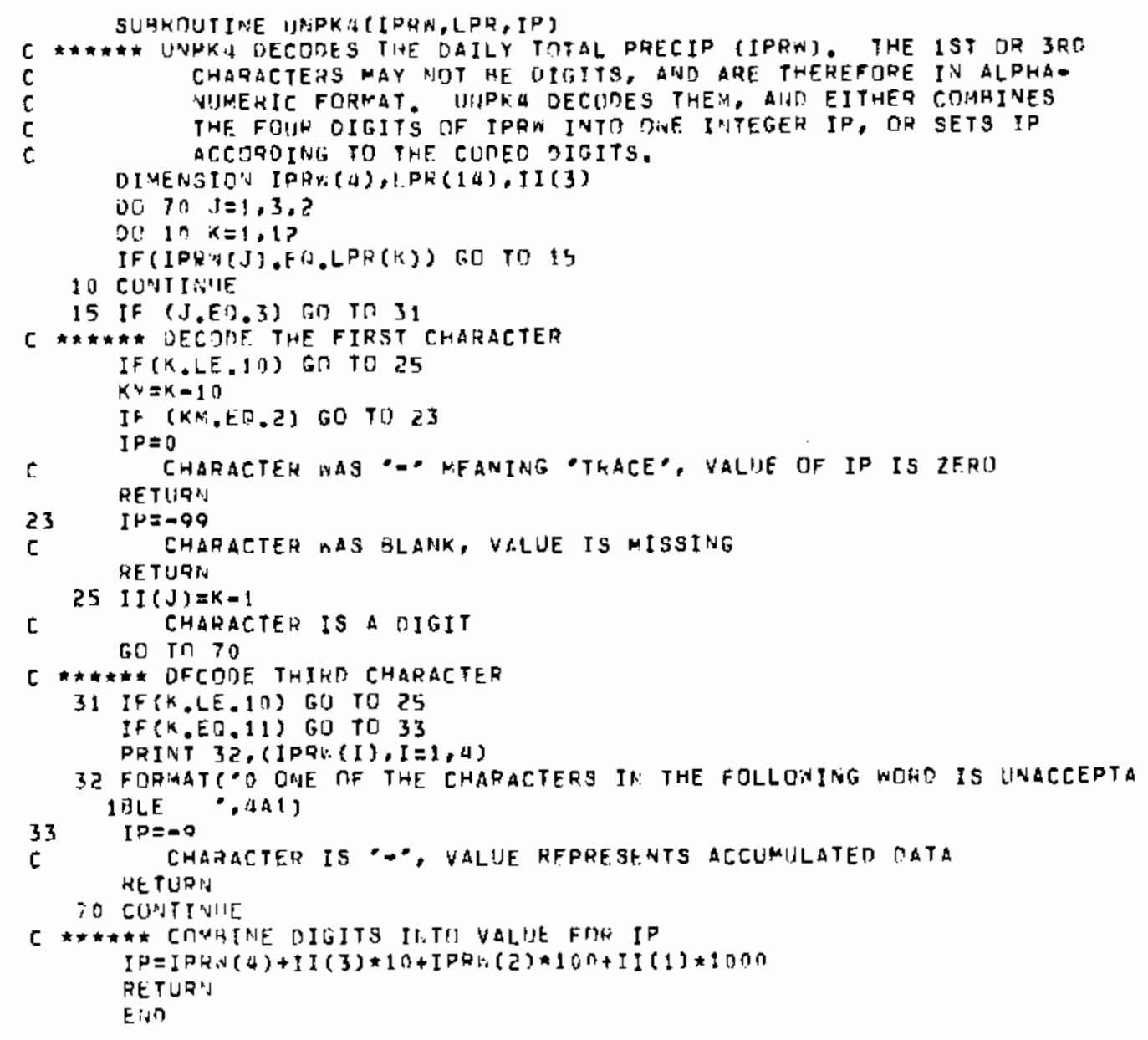


SURROUTINE ERH

C ***** THIS SUBROUTINE IS CALLED BY THE SYSTEM ERHOR ROUTINE SYSTEMC.

c IT SETS FLAG KB TO 1.

COMHDW/ERROR/KB

$K B=1$

RETURN

END 
SURROUTINE MISS (IPR, IPRO,LT)

C ***** IF BAD DATA IS ENCOUNTEREO, IT IS TRANSFORMEO BY MISS TO BE

C TREATED AS MISSING

DIMENSION IPR $(24,3)$, IPRD (4)

DATA LPR/" "

IF (LT.EO.Z) GO TO 40

$200030 \quad I=1,12$

$30 \quad \operatorname{TPR}(1,1)=L P R$

60 TO 60

40 OU $50, I=13,24$

50 IPR $(1 ; 1)=L P R$

60 IPRO $\{1\}=L P R$

RETURN

END 


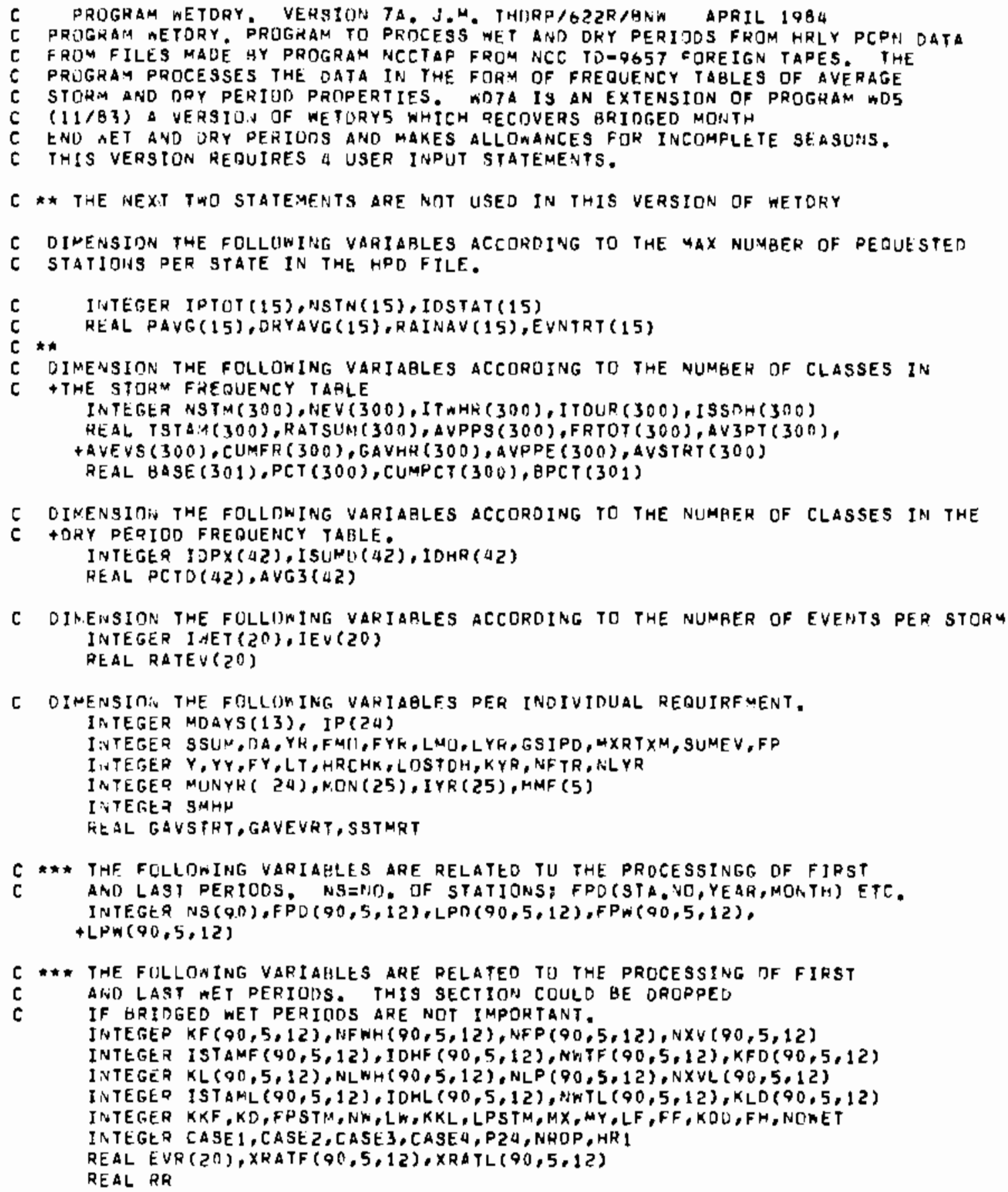


CHAFACPERAR FILE,FILE]

DATA (MDAYS (MF), MM=1,13)/32,29,32,31,32,31,32,32,3:,32,31,32,30/

DATA (IDPX(KK),KK=:1,42) $10,20,40,60,80,100,120,140,160,180,200$, $+220,240,260,280,300,320,340,360,380,400,420,440,460,480,500,520$.

$+540,560,580,600,620,640,660,680,700,720,740,700,760,800,25001$

C * *isata statement fuf selecting actual station number

UATA (NS (LL), LL $=1,89) / 800,3456,9595,0237$,

$+1166,1549,1577,5751,6711,7382,8179,2738,3037,4259,8187,1760,2367$, $+1855,4746,4954,1175,6905,0465,0470,0736,0770,9923,0164,2103,2846$, $+3333,3936,4641,5178,5712,7366,2248,5435,7455,1683,5639,0311,6026$, $+8683,0042,0687,1012,5801,5803,5811,7167,8383,3630,0058,1561,1657$, $+1786,2075,4865,8357,9406,0106,2682,3699,6889,6916,6993,6997,9705$, $+9726,0496,6698,1094,6402,1061,5120,6139,7201,7285,8849,6906,0582$. $+1570,2718,4393,6859,3269,4961,54791$

C SET THE CONOITIONS FDR MAX CYCLES (HAXY) ALLOHED BEFORE TERMINATING THE

C RUN ABNORMALLY. AS A GUIDE SET MAXHE NO.STATIDNSENO,MUNTHS\#IS MAXM $=15000$

C**\#**USER INPUT-NAHE OF DATA INPUT FILE ANO OATA DUTPUT FILE***\#\# WRTTE $(6,3000)$

3000 FORMAT, NAME OF INPUT DATA FILE ? ? READ 5,3001\} FILE

3001 FURMAT \{RRO) GPEIV $\left(U N I T=0, N A M E=F I L E, T Y P E={ }^{\circ}\right.$ QLD", READONLY) WRI TE $(6,3002)$

3002 FORNAT(" NAME OF OUTPUT DATA FILE? ") PEAD (5.3003) FILE?

3003 FORNAT $(A B O\}$

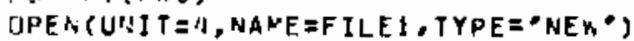

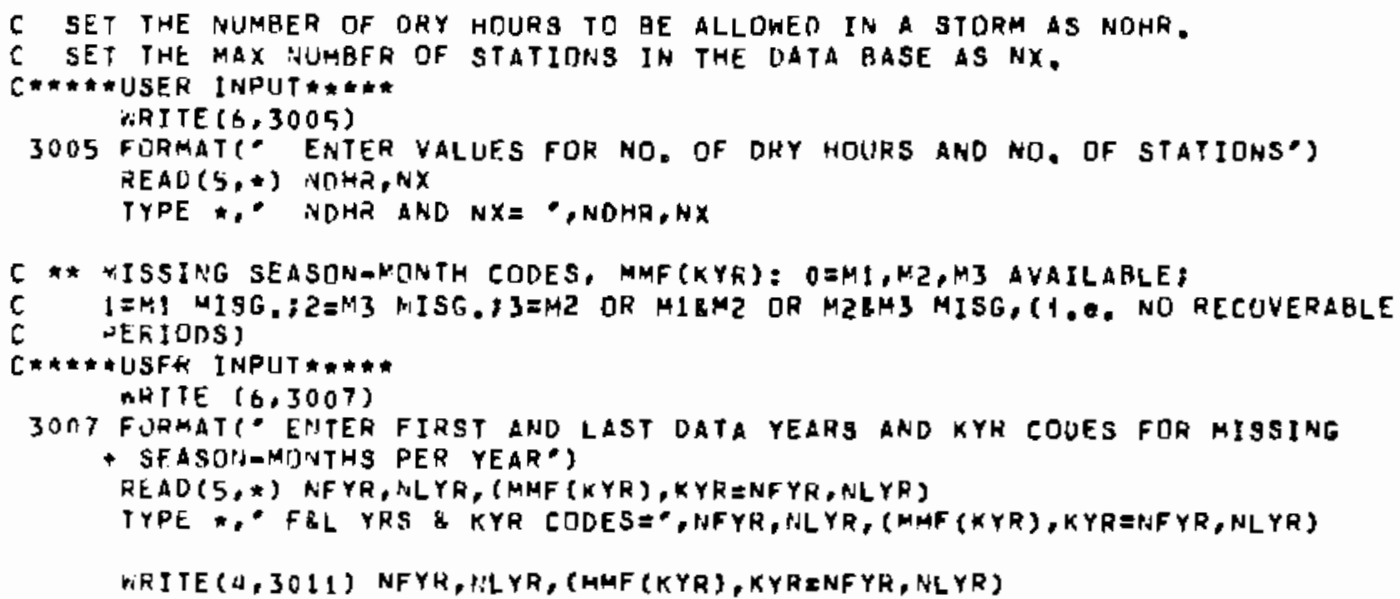




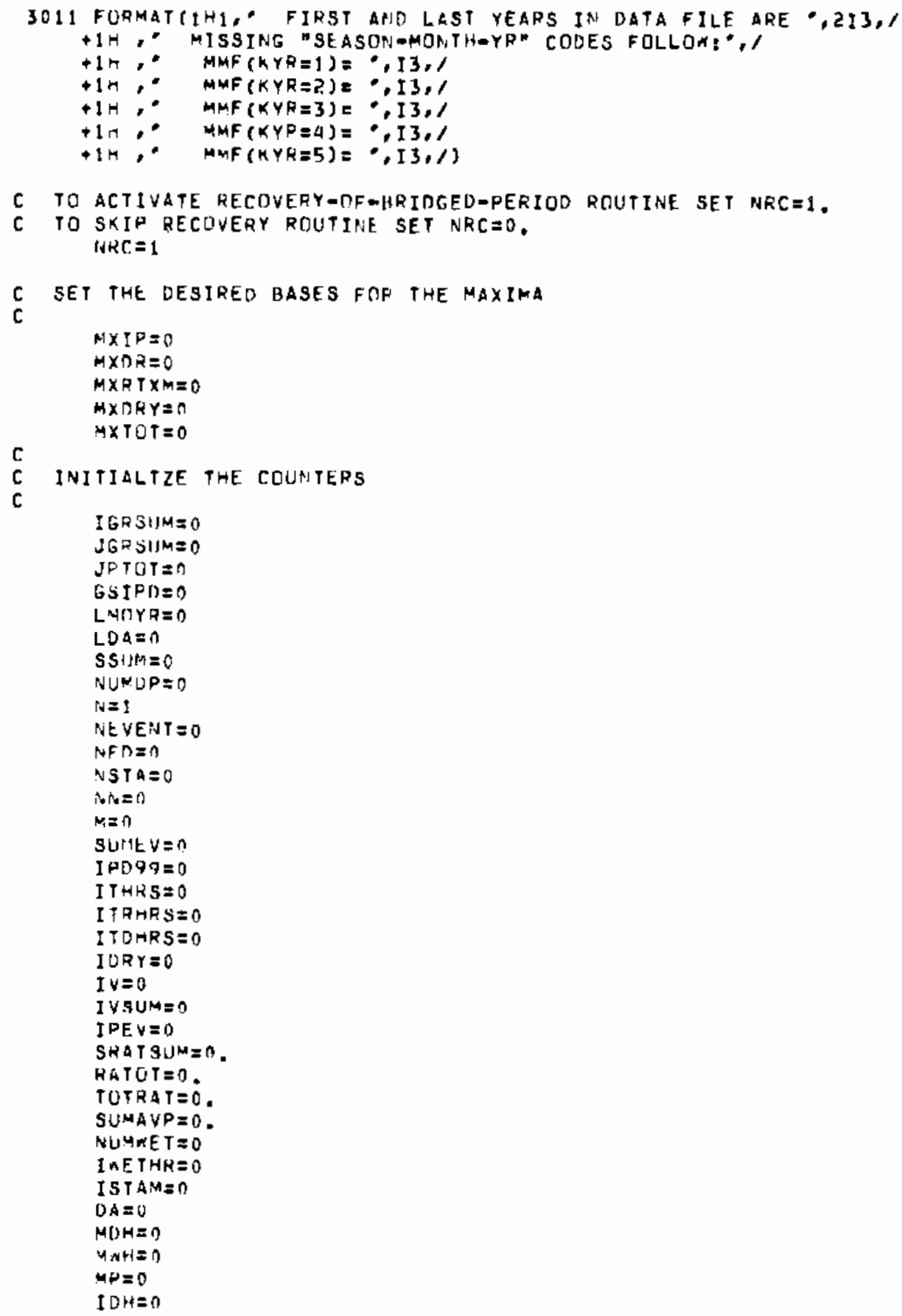




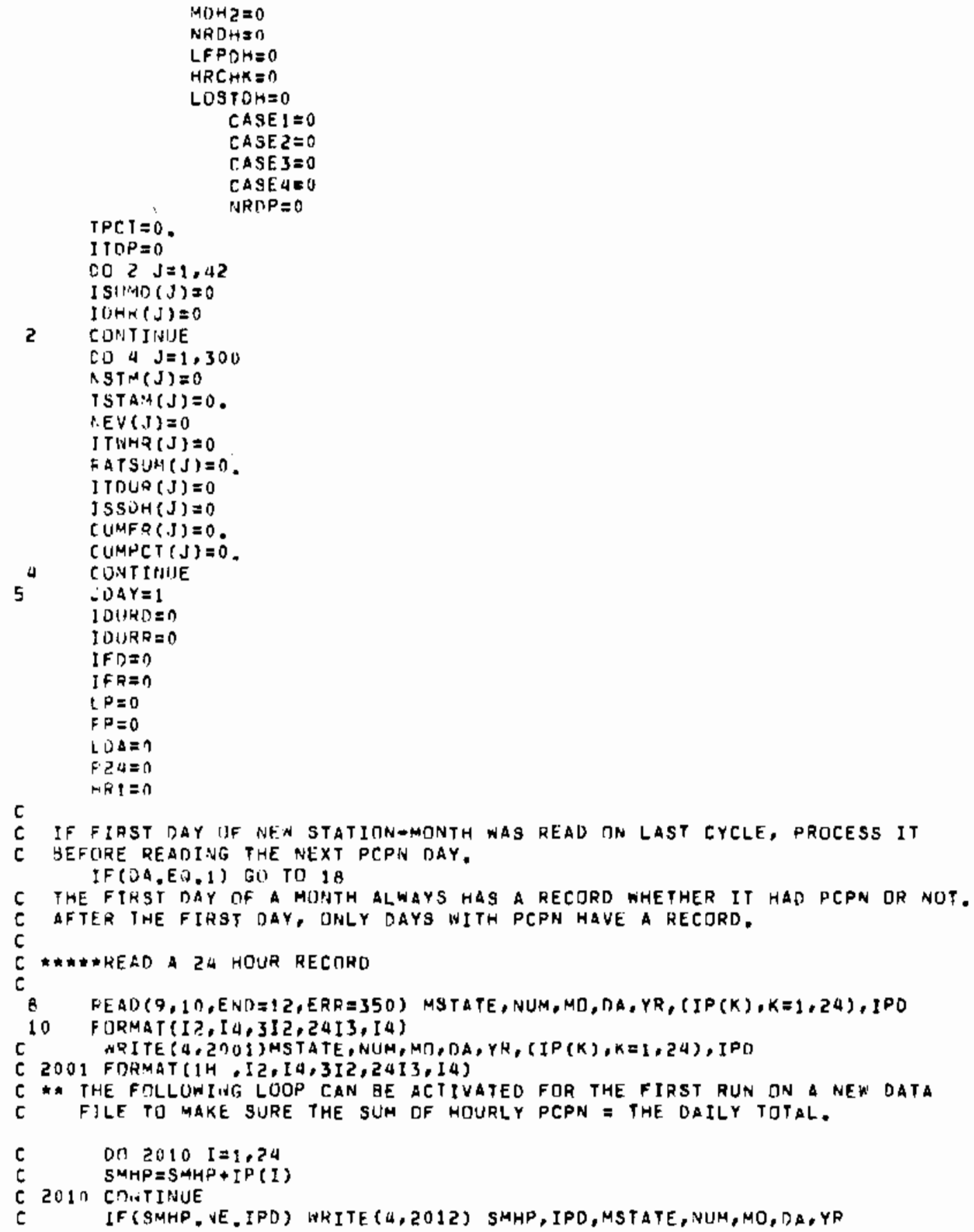




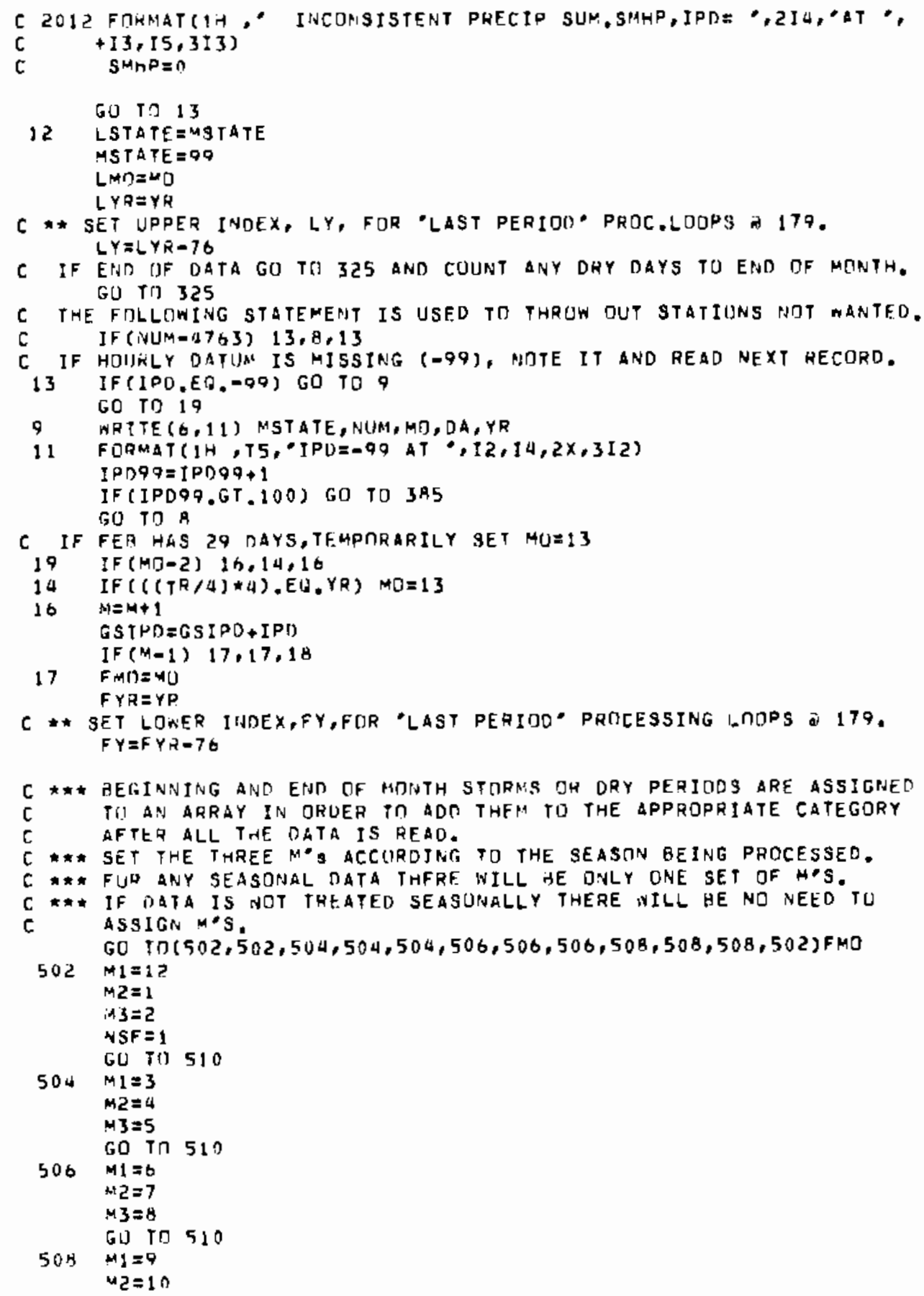




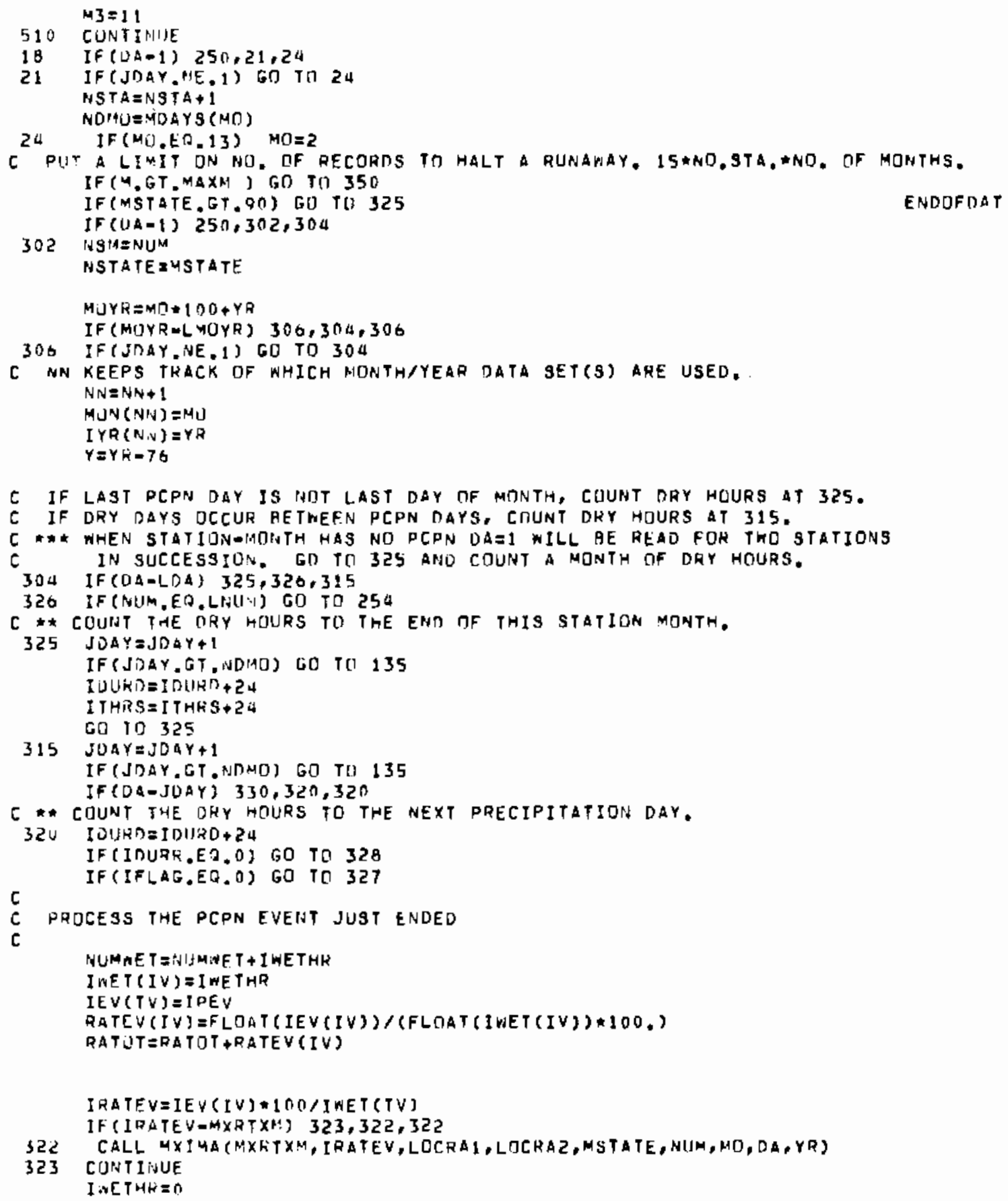




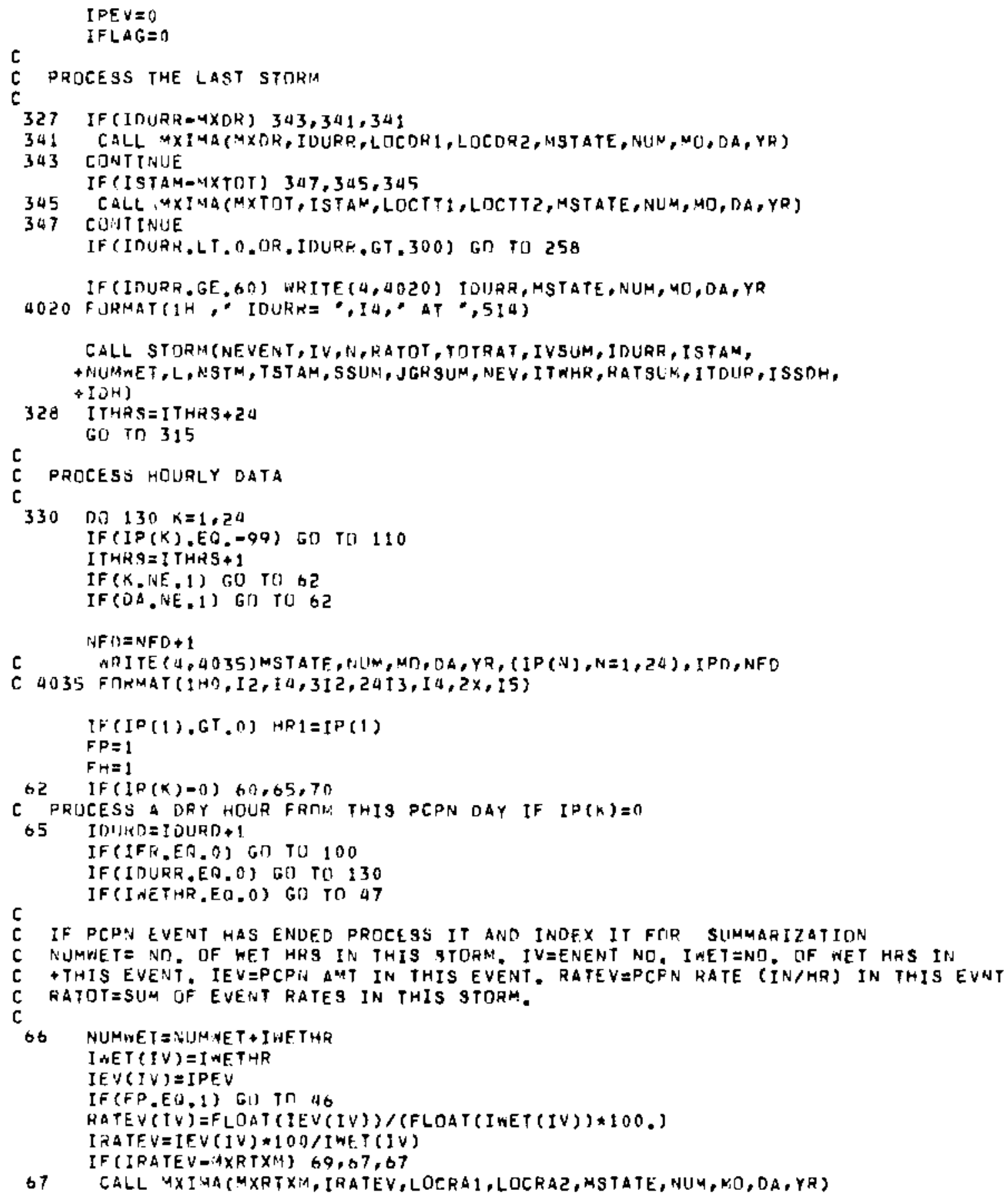




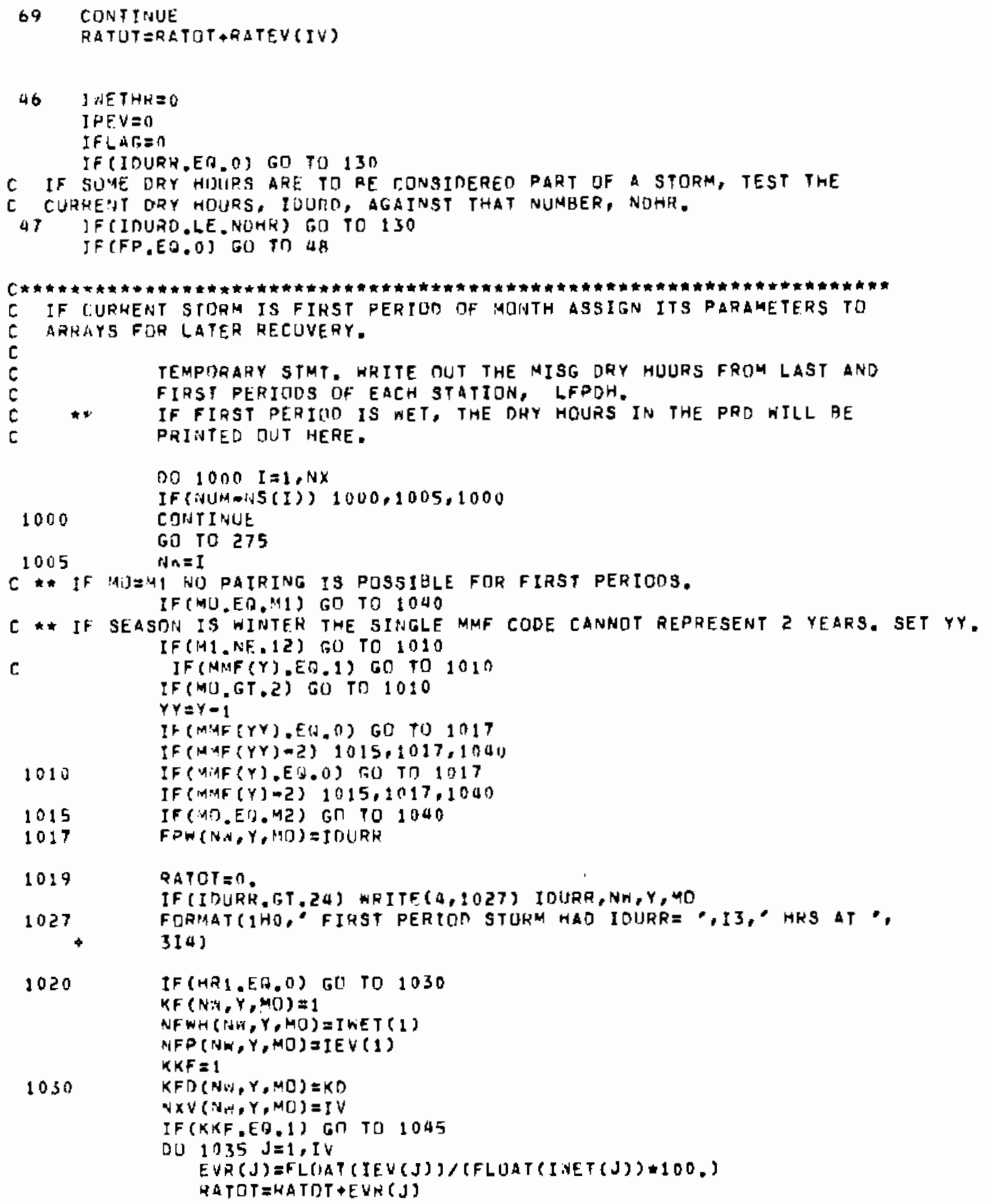




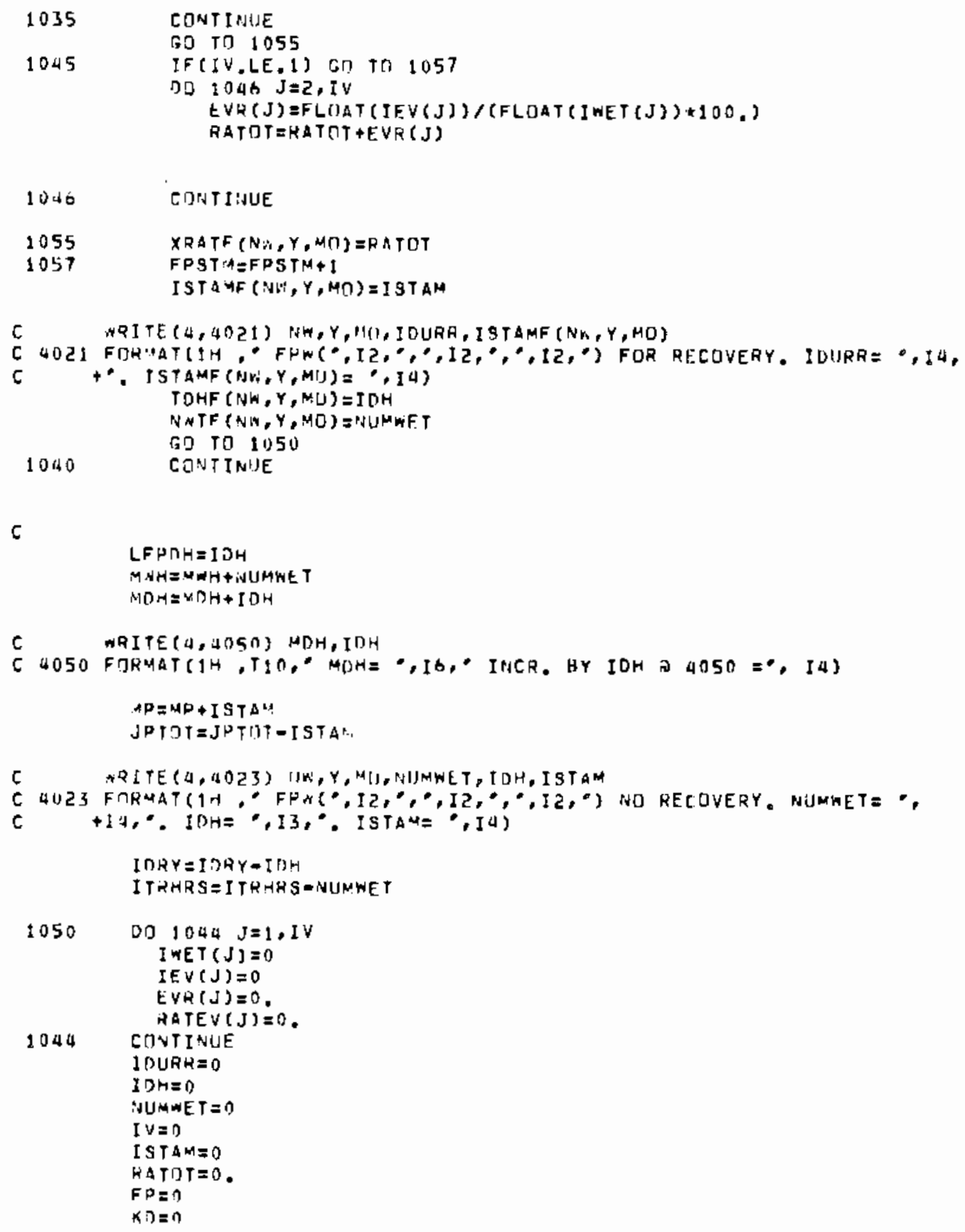




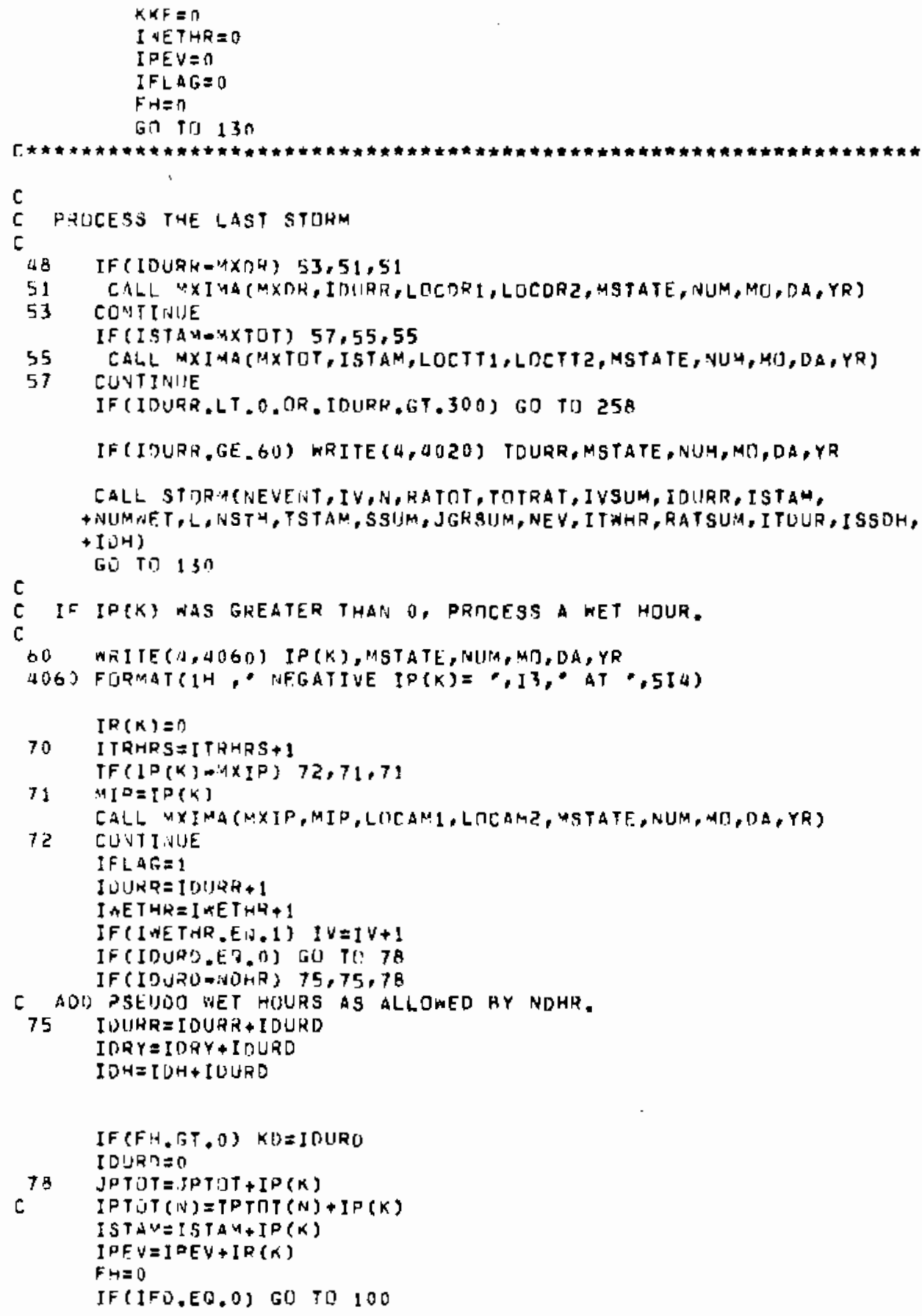




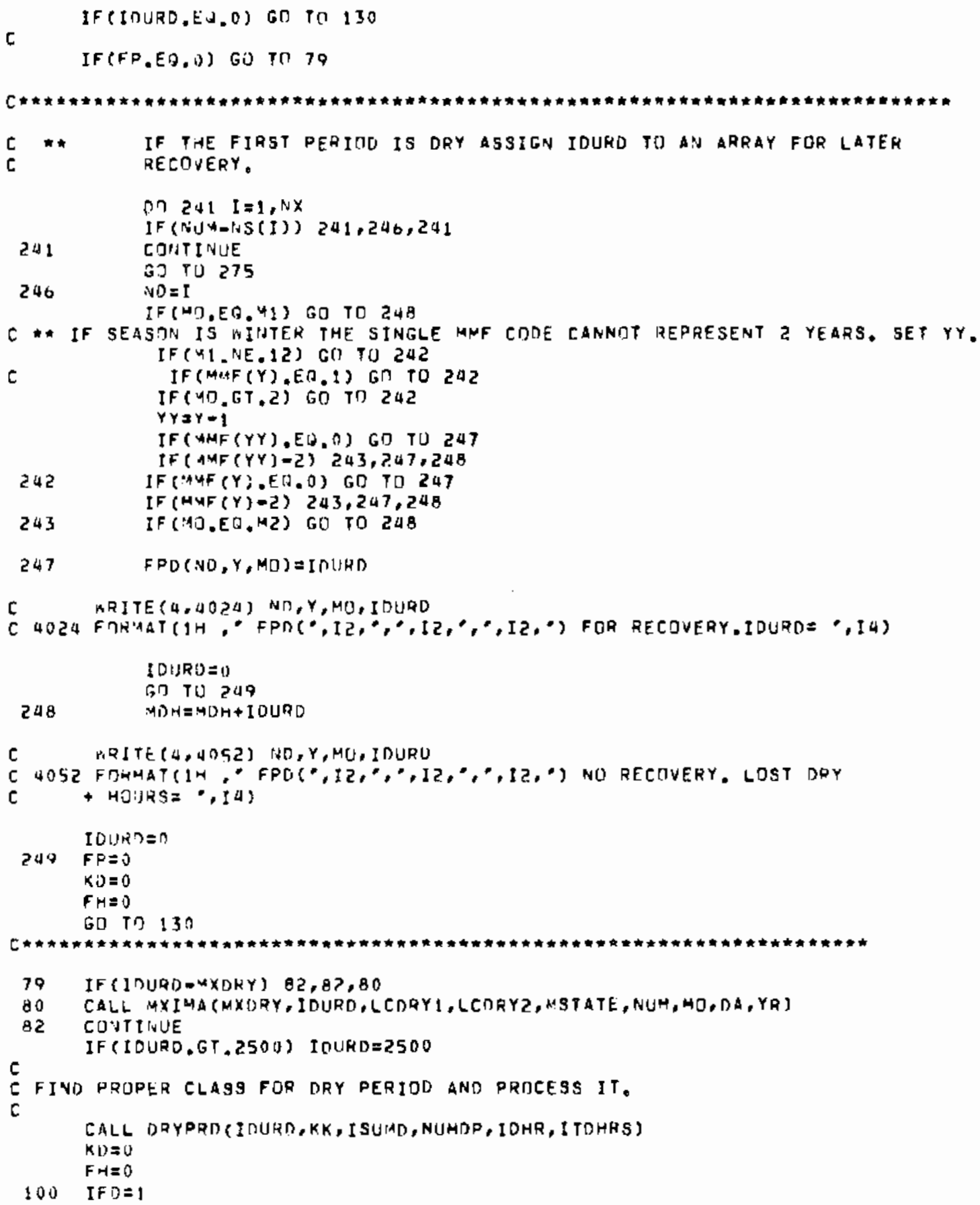




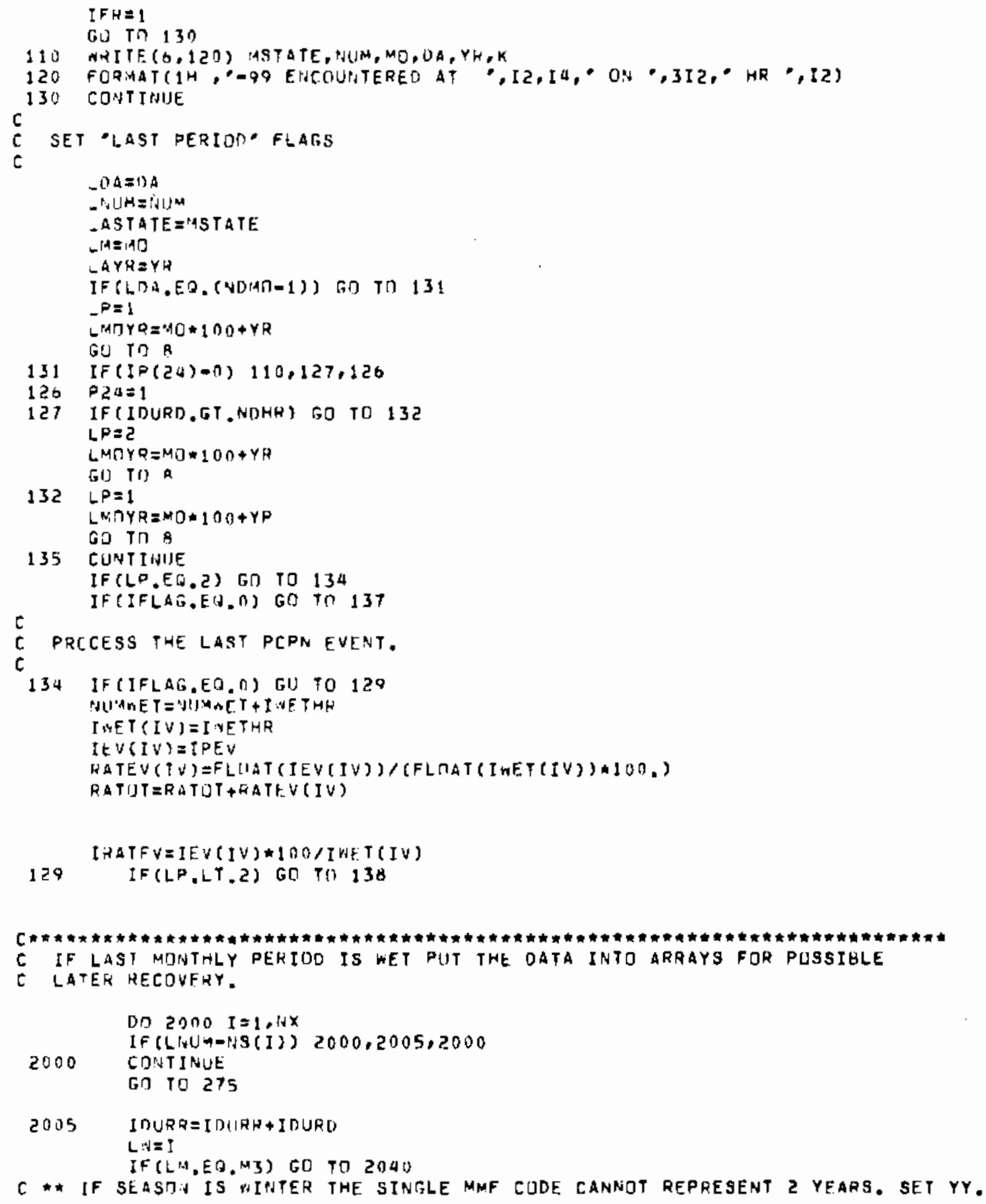




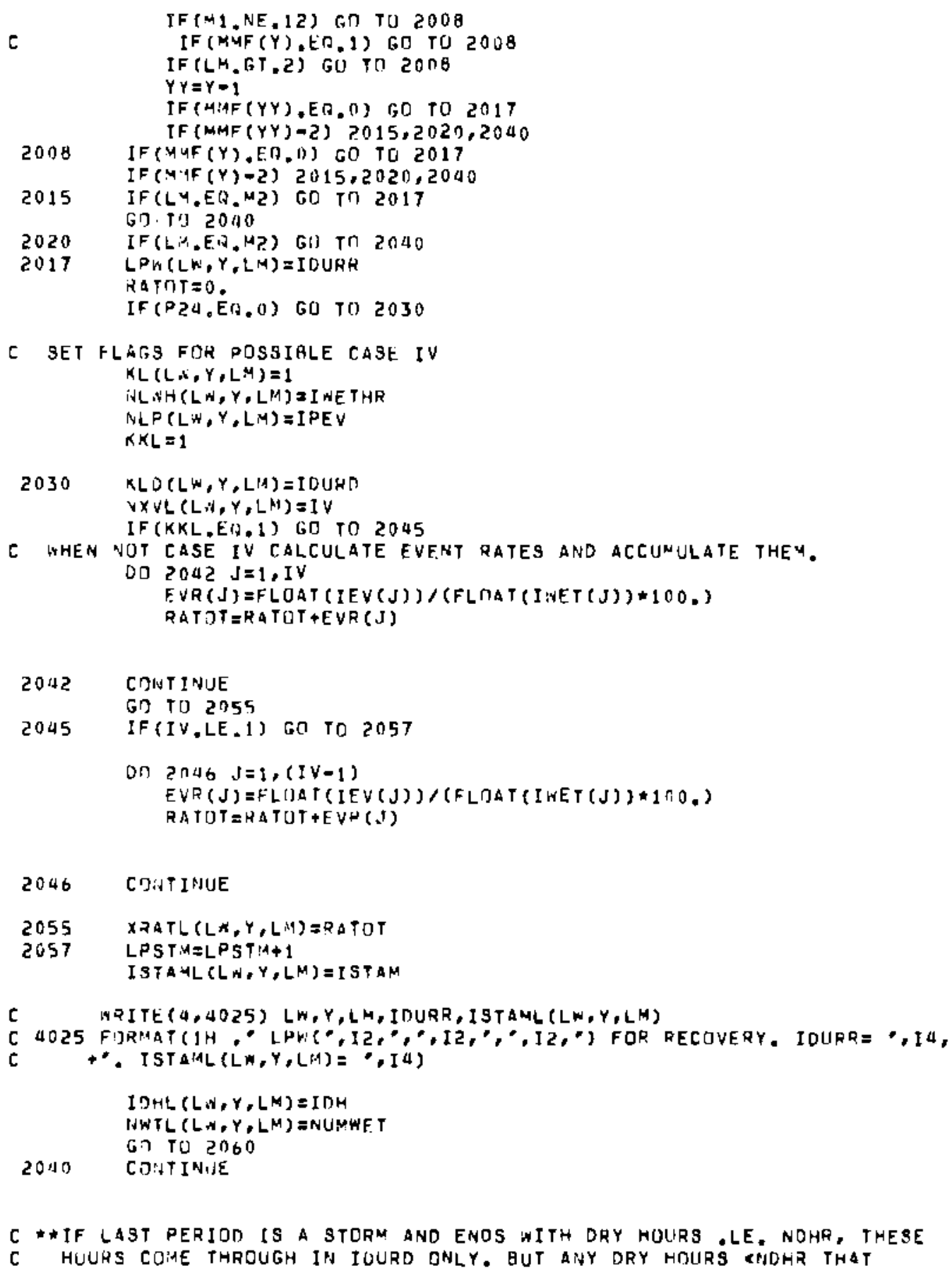




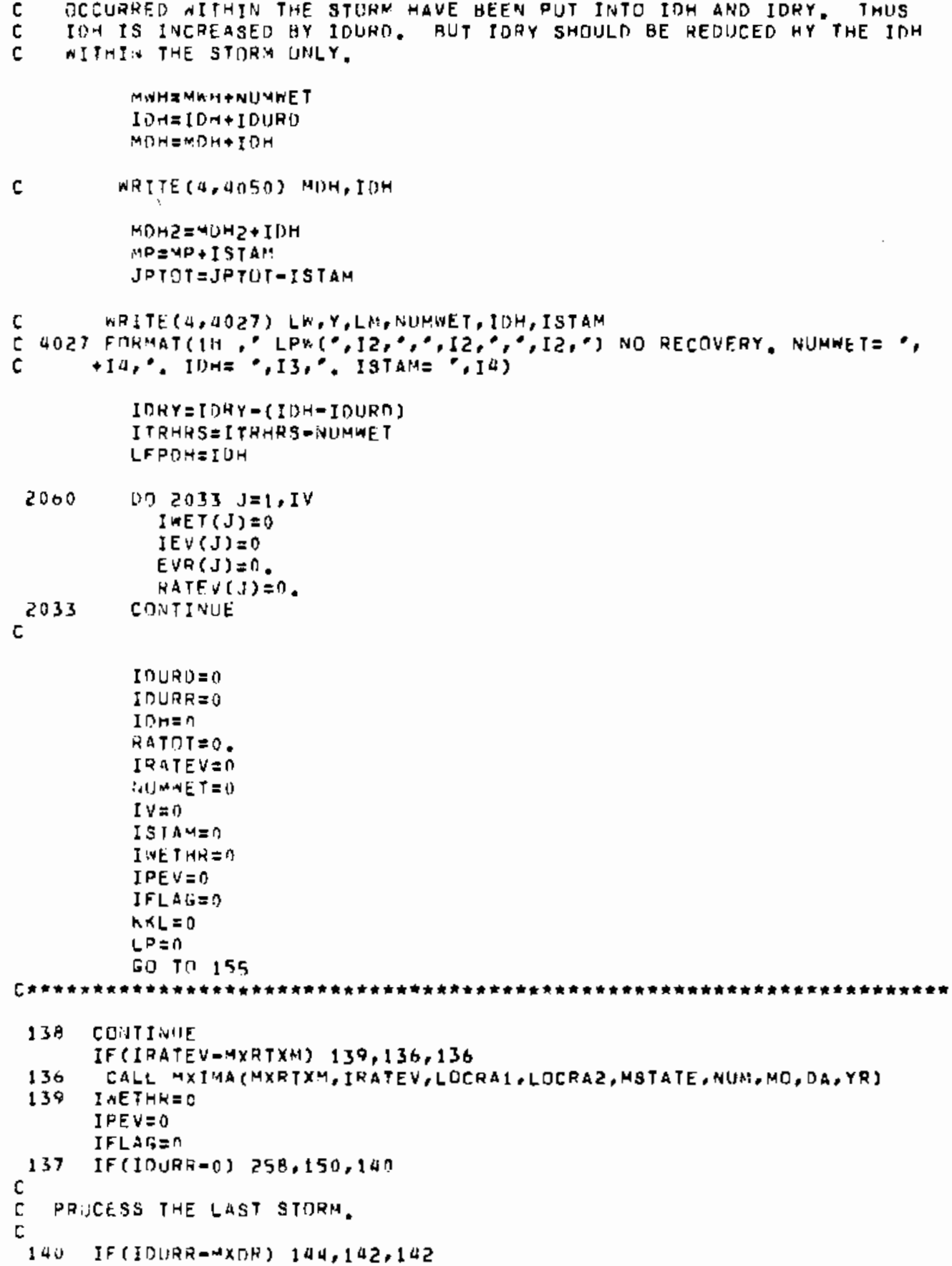




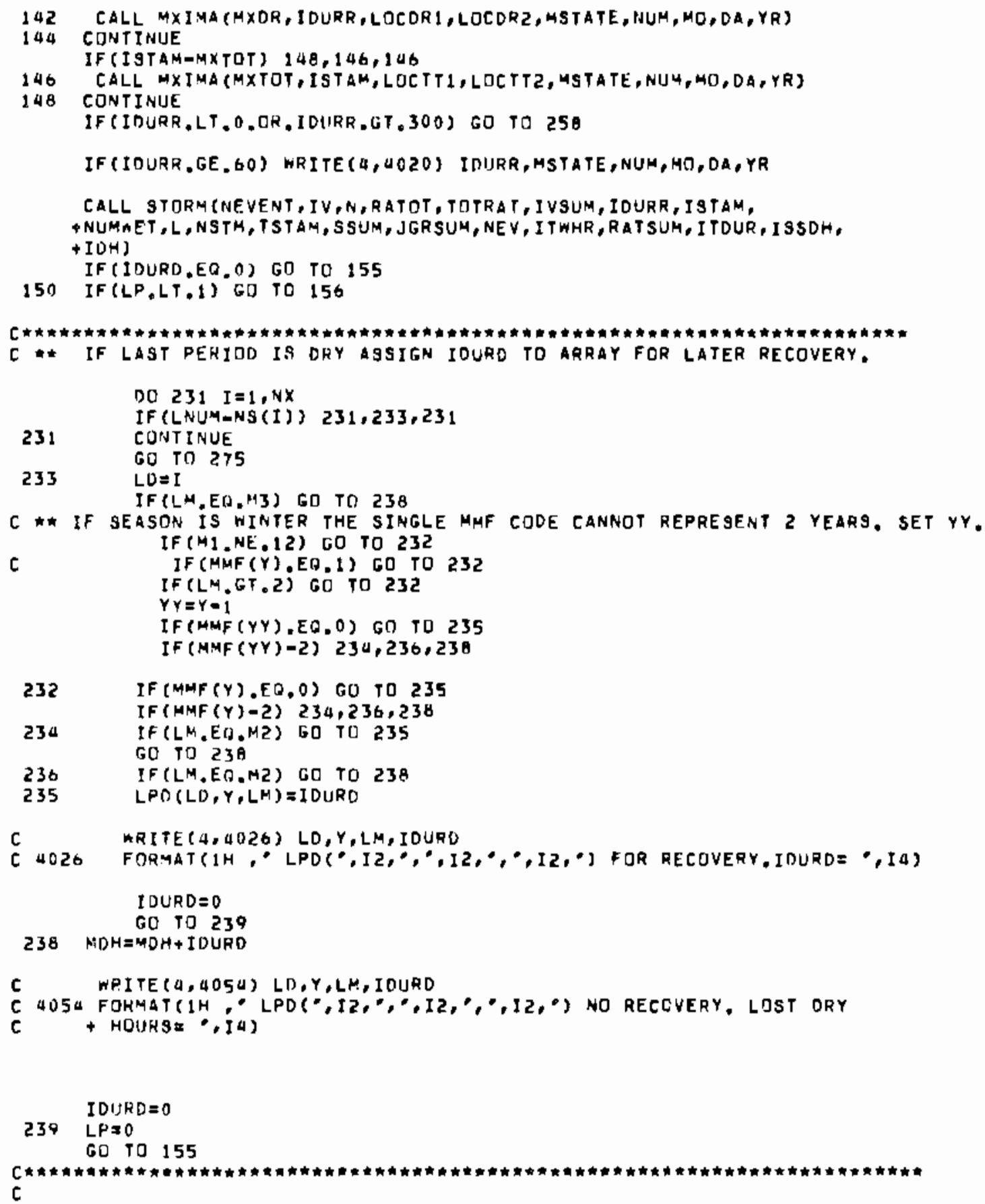




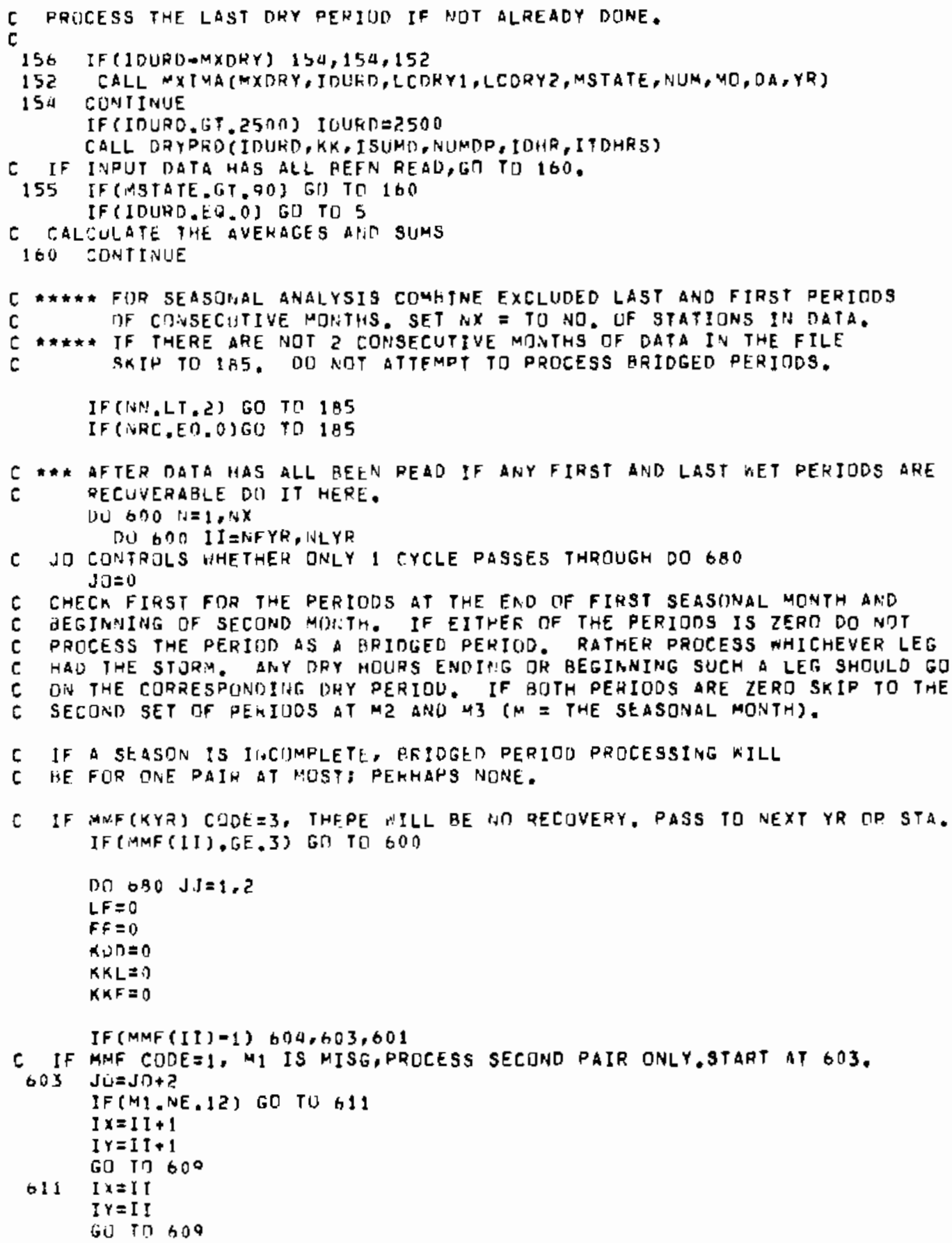




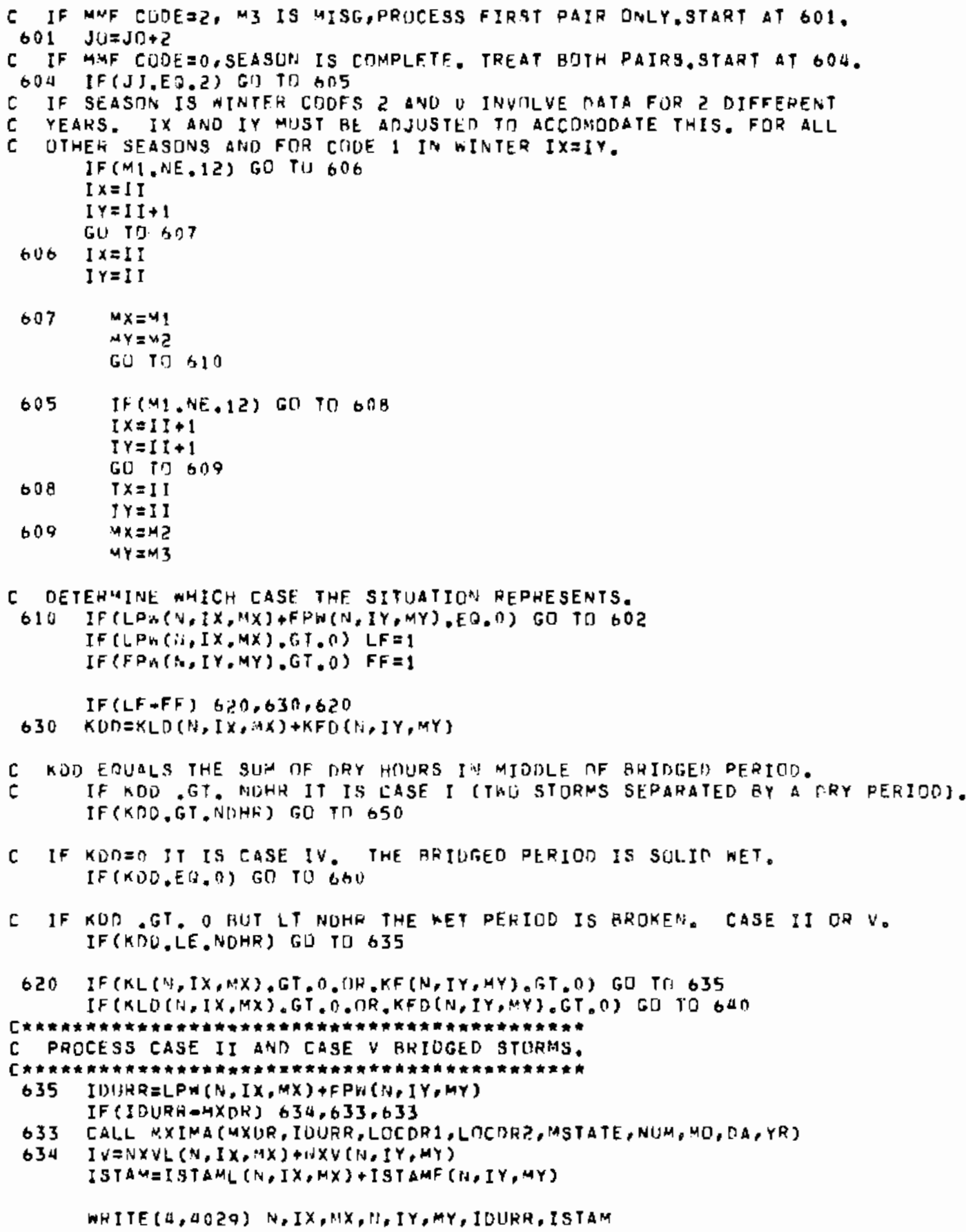




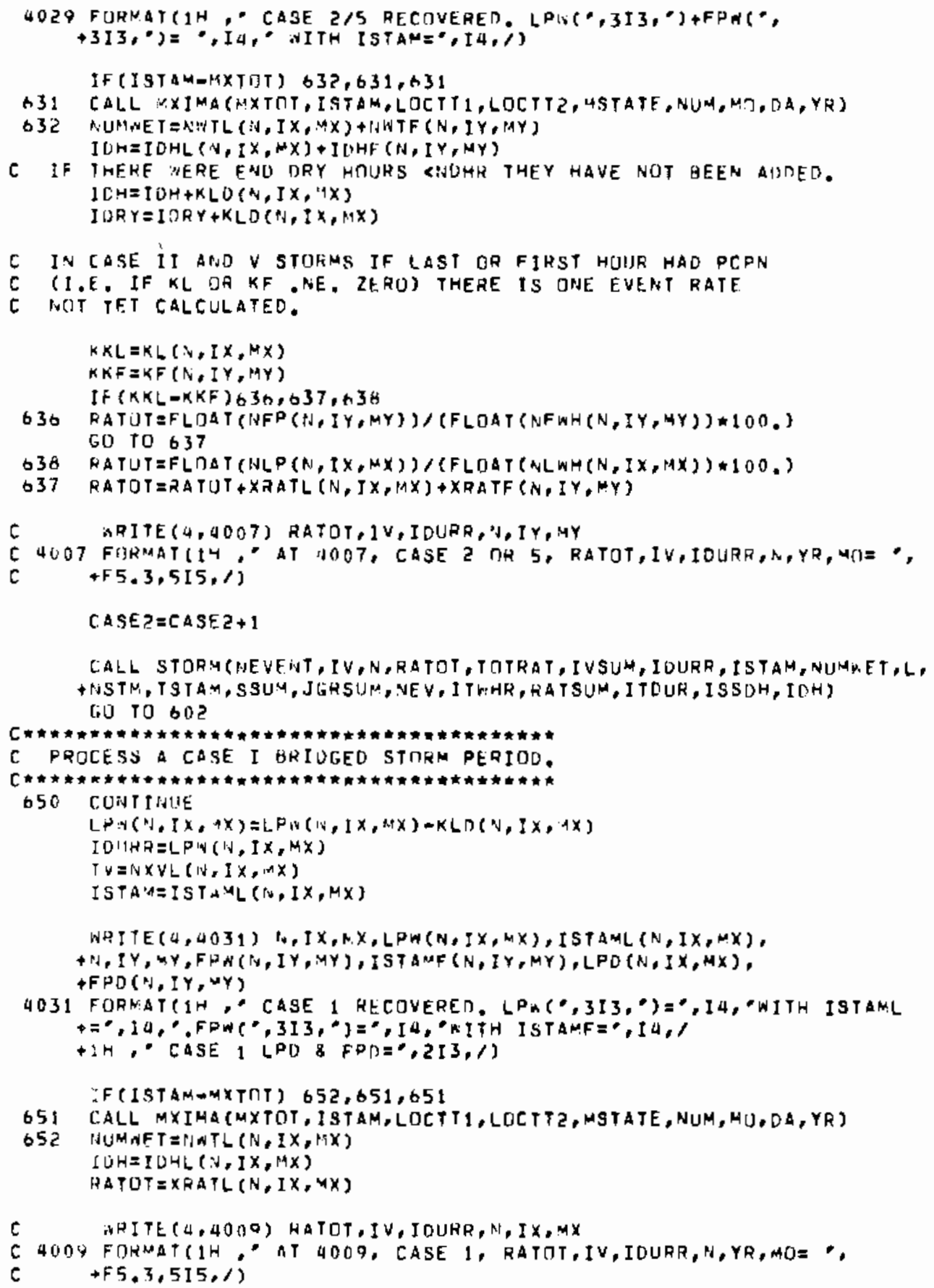




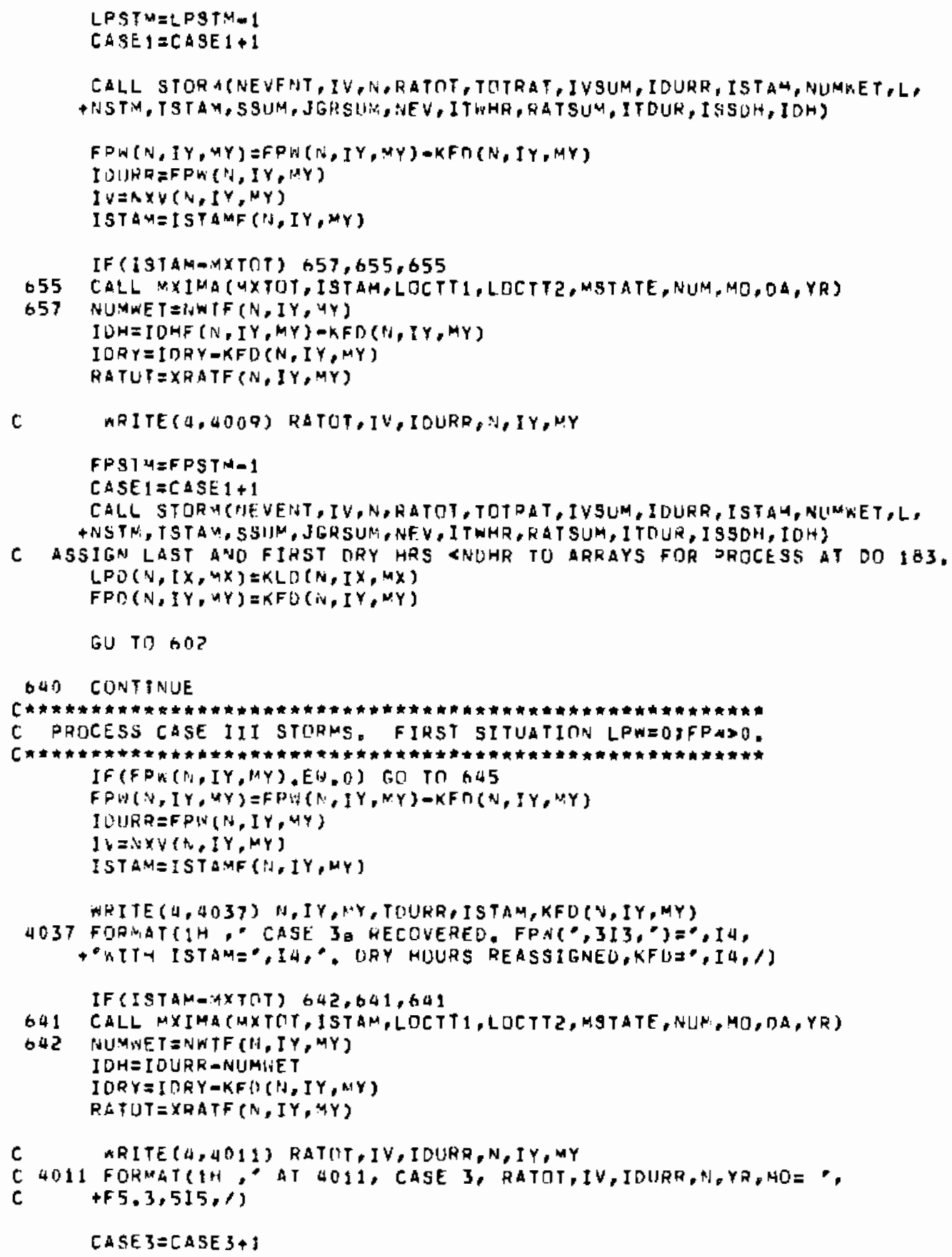


CALL STORM(NEVERT, IV, NI, RATOT, TOTRAT, IVSUM, IOURR, ISTAM, NUMWET,L, \NSTM, ISTAM, SSUM, JGRSUM, INEV, ITWHF, KATSUM, ITDUR, ISSDH, IDH)

$F P D(Y, I Y, M Y)=K F[D(N, I Y, M Y)$

GO TO

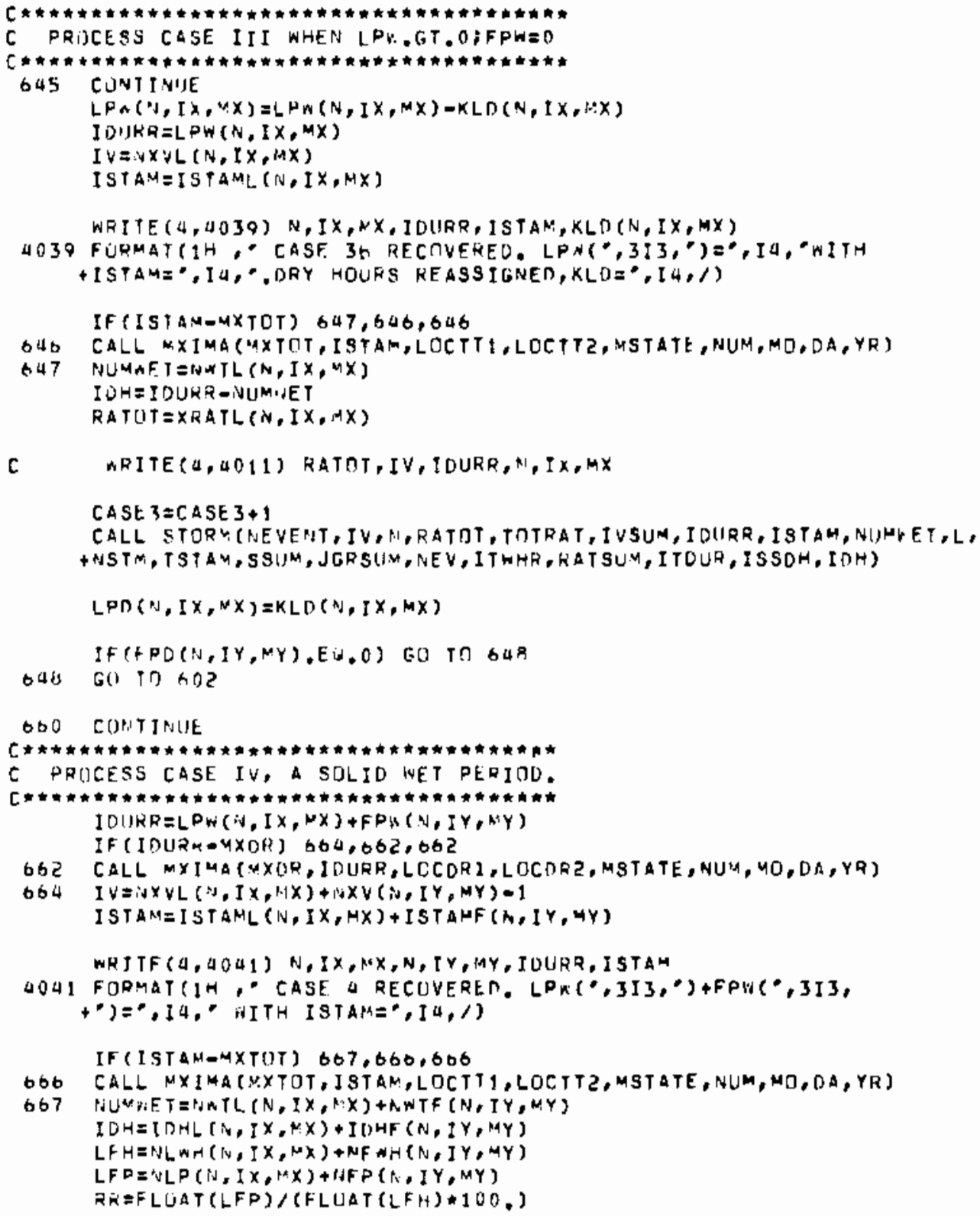




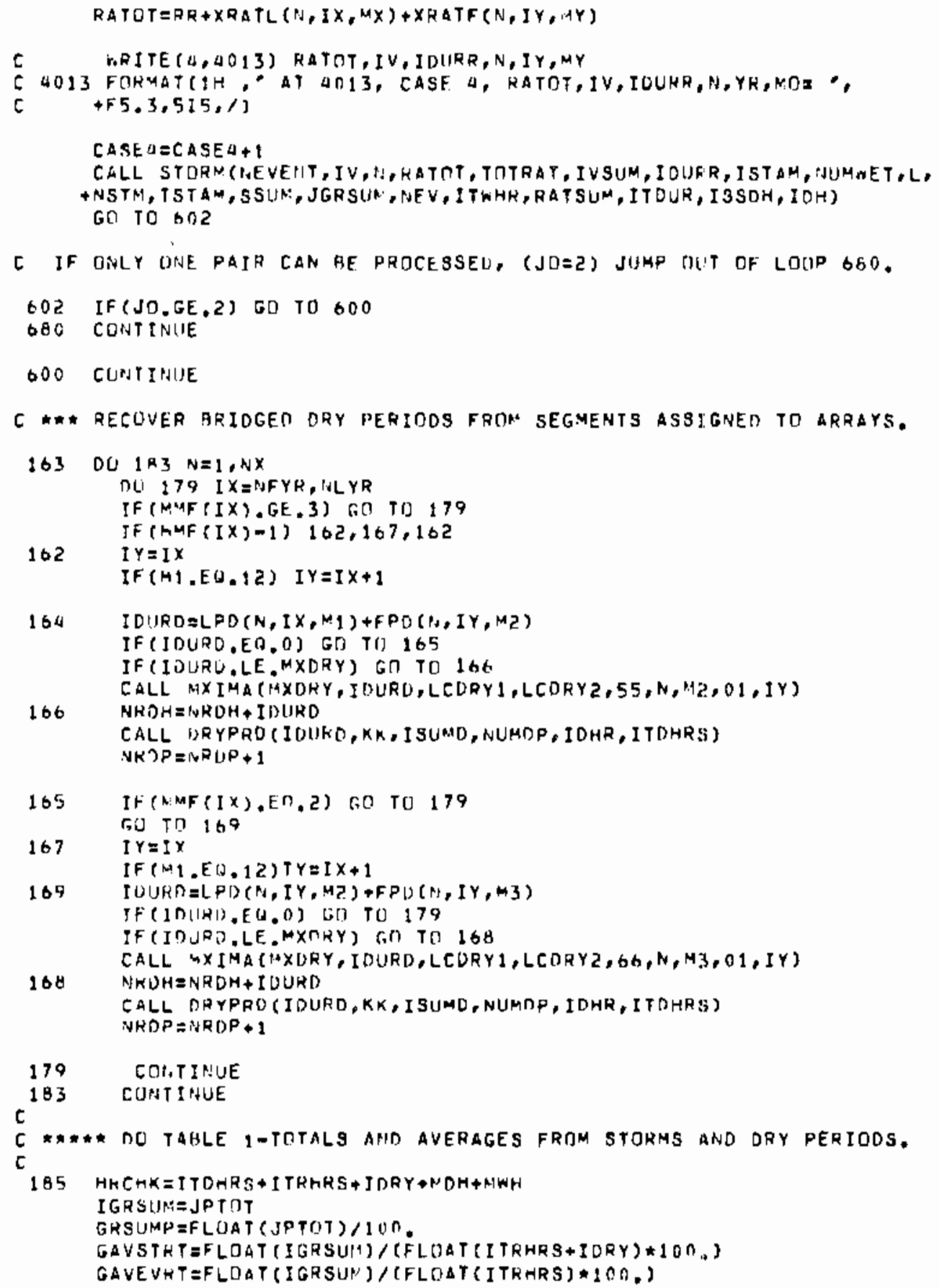




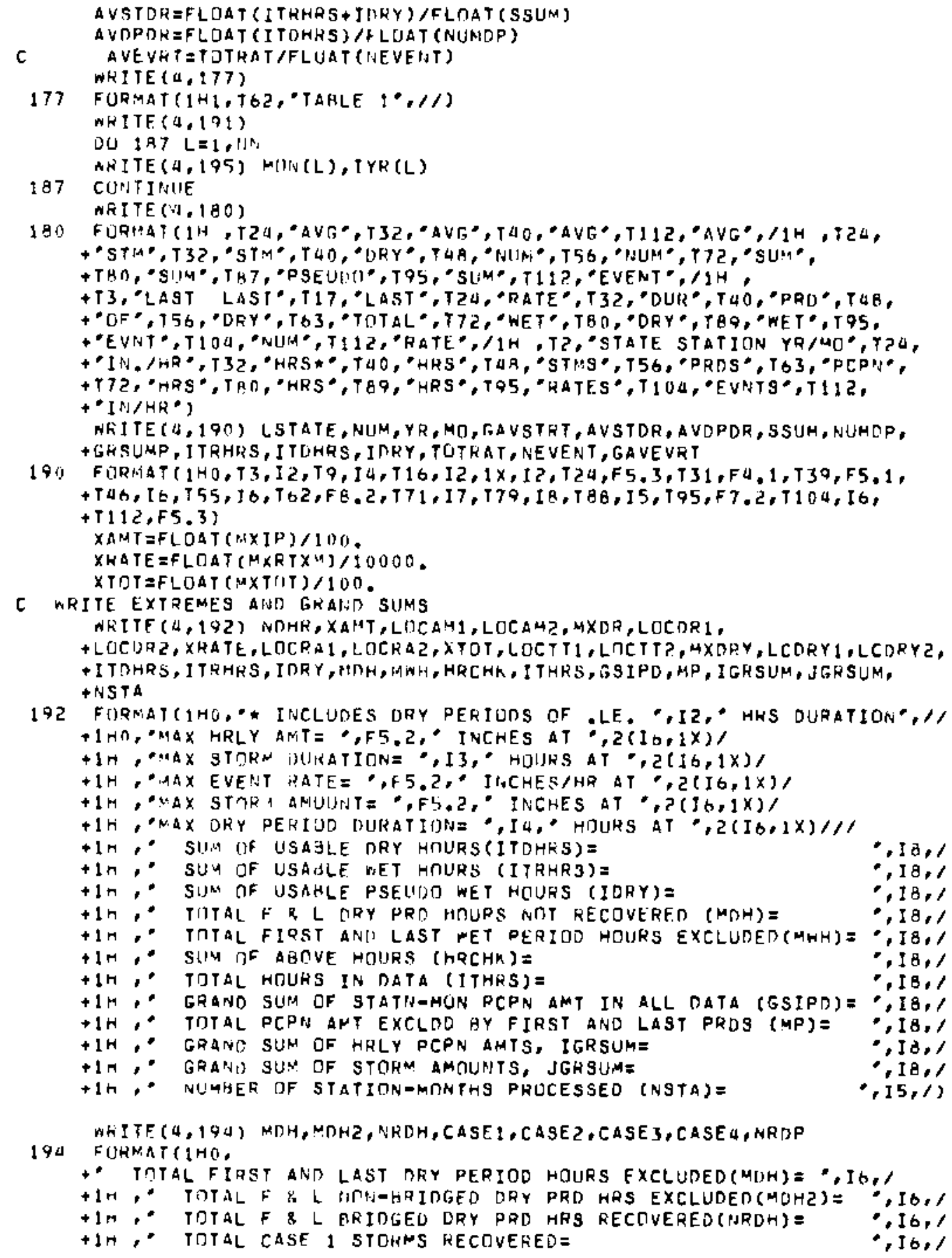




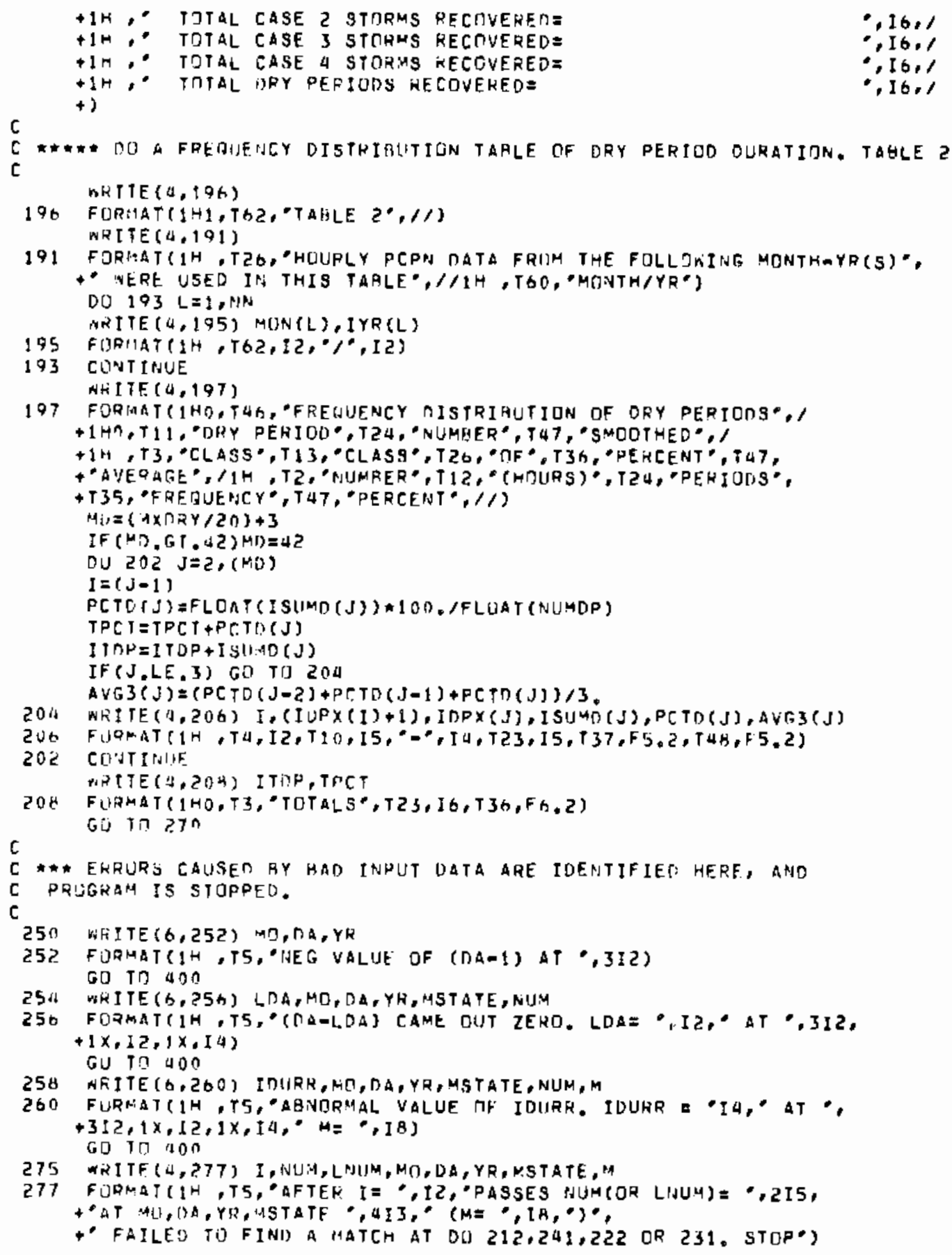




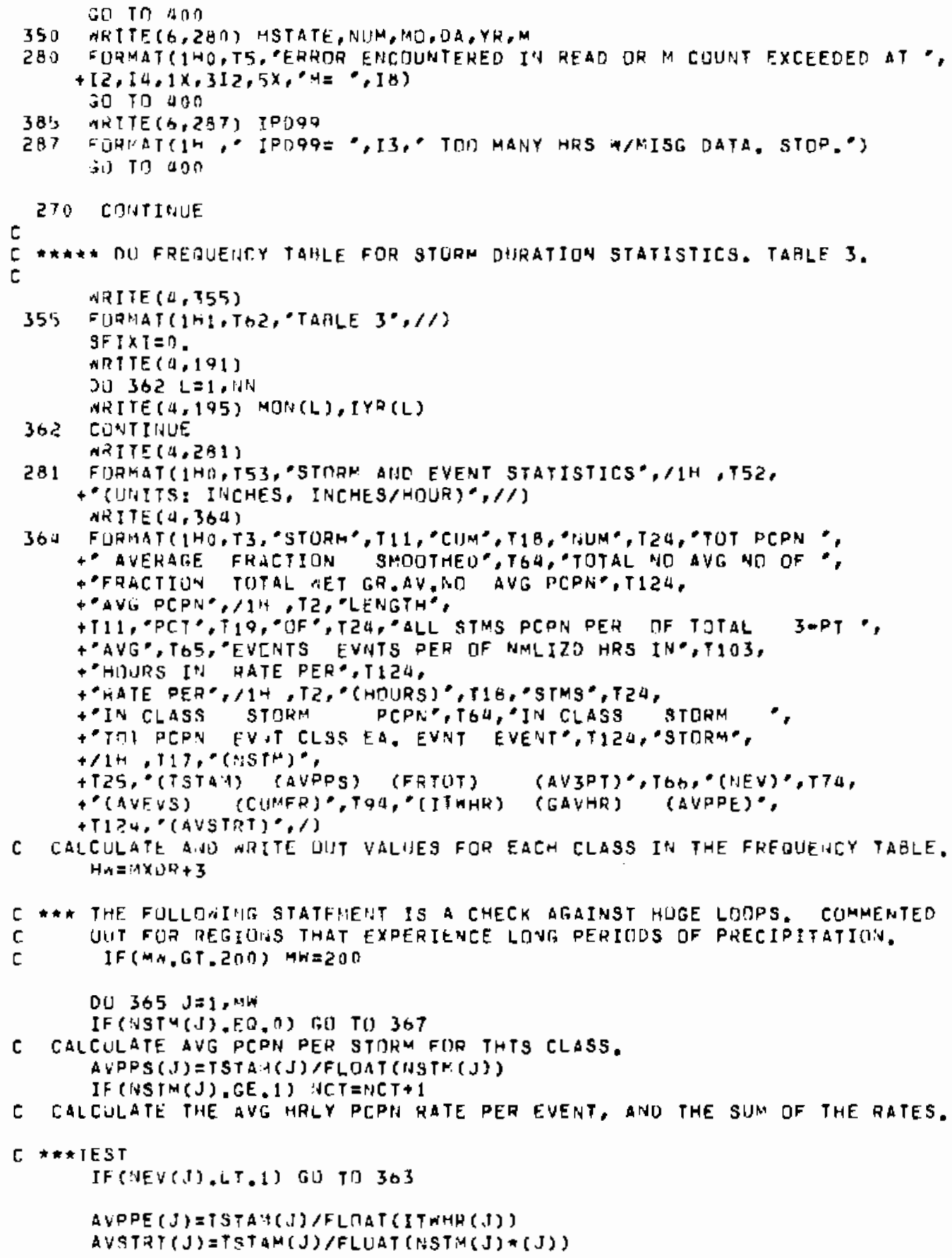

16 


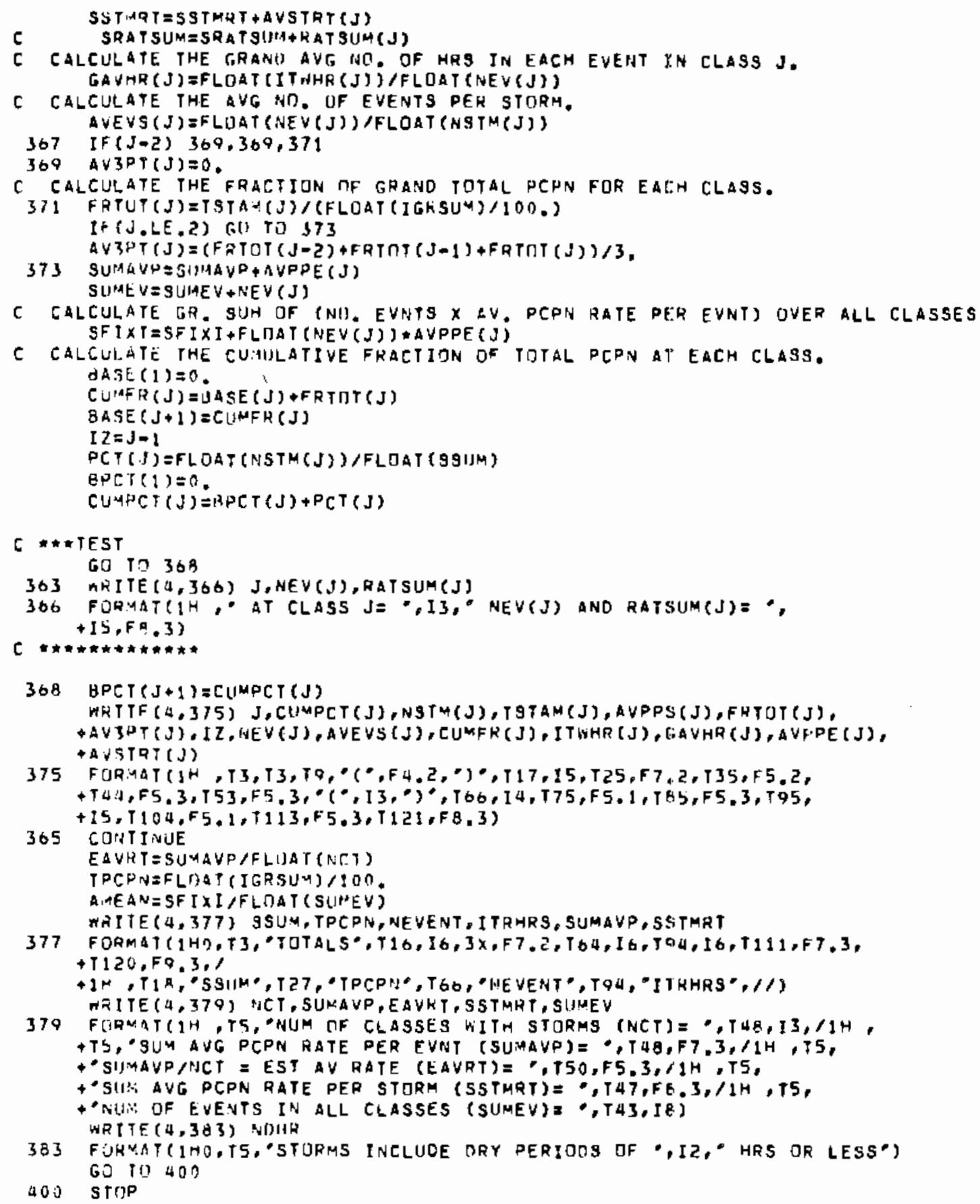


SUBROUTINE MXIHA (MX, MVAR,LOCI,LOCR, NISTATE, NUH, HO,DA, YR)

INTEGER DA, YR

$M X=M V A R$

LOC $1=M S T A T E * 10000+N U M$

LOC $C=40 * 10000+D A * 100+Y R$

RETURN

END 
SUEROUTINE DRYPRO (IDUHD, J, ISUMD, NUMOP, IDHR, ITDHRS)

C S SUBRUUTINE TO PRUCESS THE ORY PEHIOD JUST ENOEO.

INTEGER IDURD, KK, NUMISP, ITDHRS

INTEGER IDPX(4Z), ISUMU (42), IOHR (42)

DATA (IOPX(KK),KK=1,42) $10,20,00,60,00,100,120,140,160,180,200$, $+220, ? 40,260,290,300,320,300,360,380,400,420,440,460,480,500,520$,

$+540,560,580,600,620,640,660,680,700,720,740,760,780,600,25001$

$00100 \mathrm{~J}=1,42$

IF(IDURO-IDPX(J)) $80,80,100$

80 ISUMD $(J) \times I S U M C(\mathrm{~J})+1$

IUHK $(J)=I U H H(J)+I D U N D$

NUIADP $=$ NUMOP +1

IIDHRS =I TUHRS + IOURD

C WRITE QO FOR A LISTING OF EACH DRY PERIDO AS IT DECIJR.

C NRITE $(4,90)$ IDURD

C 90 FORMAT(IH,T3:"IDURD=, 14$)$

C INITIALIZE DRY PEHIOD COUNTFR FOR NEXT DKY PERIDD. IUURD $=0$

GO TO 110

100 CONTINUE

110 RETURN

END 


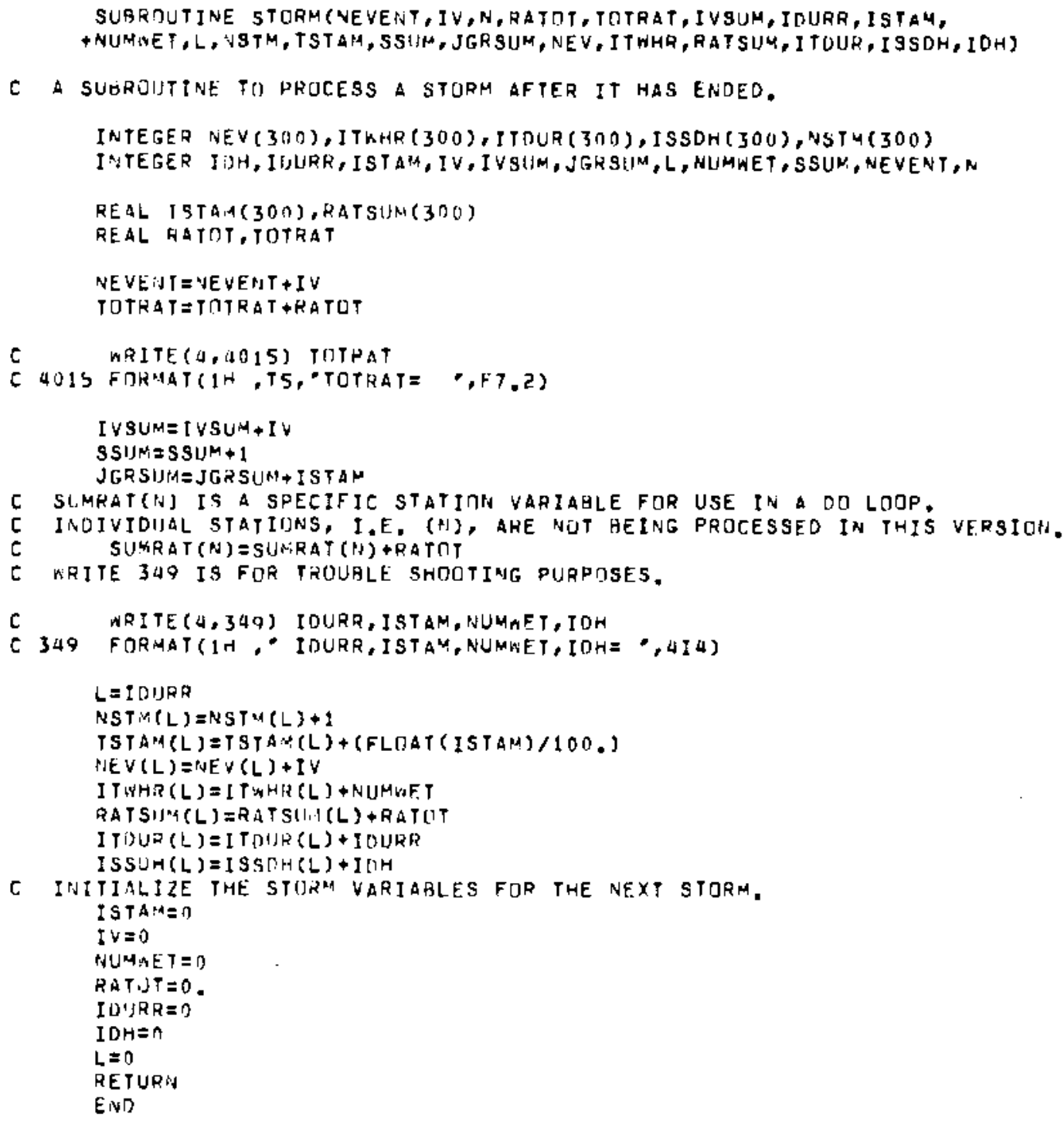




\section{APPENDIX B}

EXAMPLES OF OUTPUT 
TAPLE 1

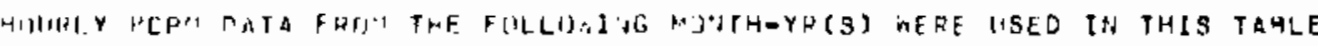

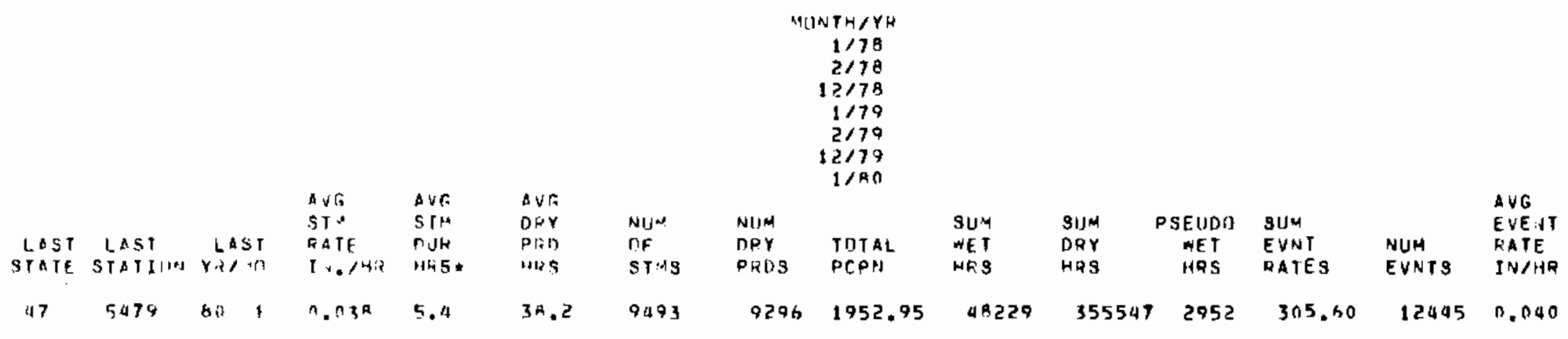

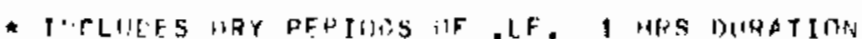

MAX HWLY ANTE 1.00 TYCHES AT $11116612037 \mathrm{~A}$

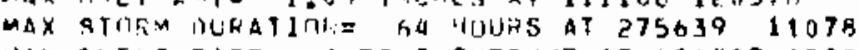

MAX EVERT RATE $=0.30$ I ICHES/AR AT 40640 ? 120878

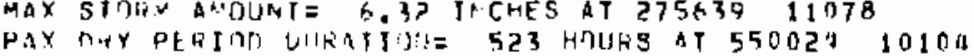

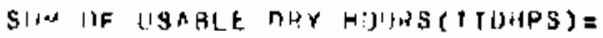

S.1\% OF USAHLE NET HIIIRS (ITRHRS) =

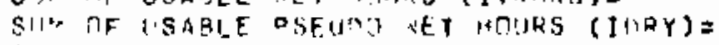

TITAL F $S$ L GLY PRT HIUUHS ANT RECIVEPED (NDH)

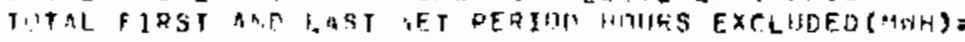

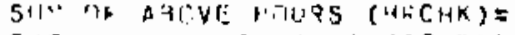

1.TAL H(IUFS I'. IJATA (ITHBS)=

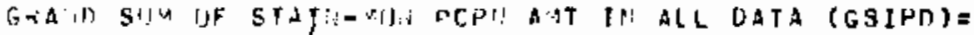

TIITAL PCPI: A"I EXCL:) IY FIR5T APE LAST PWNS (MP) =

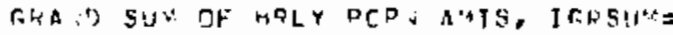

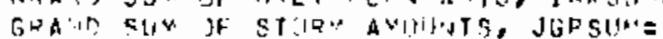

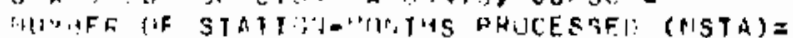

355547

48220

2952

33606

440640

440640

196037

7 प2

195245

195295

ton

WTAL FIRST AID LAST DRY PEAION MIIUAS EXCLIDED (MDH) $=33606$

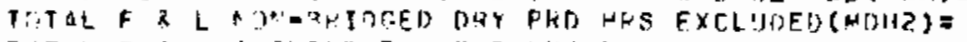

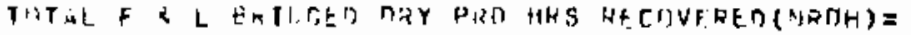

TITAL. CASE 1 STIR N SECTUERET=

TOTAI. CASE 2 STIP Q RECIVEQR! I

TITOR CASE 3 STURAS RECINEREL

TITAL CASE " JTUA : G FECIMEMEP=

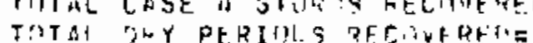

13
476
6
27
15
29
314


TAFLE 2

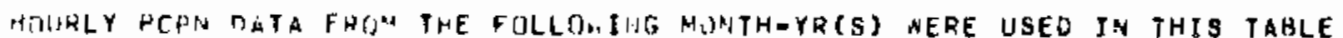

HUSTH $T / Y A$
$1 / 78$
$2 / 78$
$12 / 78$
$1 / 79$
2179
12179
$1 / 80$

FREQIIEHCY DISTRIBUTINI, OF DFY PERIOOS

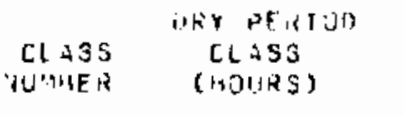

\begin{tabular}{|c|c|c|}
\hline $\begin{array}{c}.1 .4 k t+i d \\
D F\end{array}$ & PEHCE:T & SHUDTHED \\
\hline PEATOTS & Ftitol Fider & PEQCENT \\
\hline
\end{tabular}

\begin{tabular}{|c|c|c|}
\hline 1 & 1. & ?. \\
\hline 2 & $21-$ & 40 \\
\hline 5 & $41=$ & bo \\
\hline 4 & 01- & 90 \\
\hline 3 & $B_{1}=$ & 100 \\
\hline 0 & $101-$ & $i \geq 0$ \\
\hline 7 & $121=$ & 100 \\
\hline$\pi$ & 141. & (A) \\
\hline 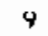 & $101=$ & $1 R_{0}$ \\
\hline 10 & $1+1-$ & 2013 \\
\hline 11 & $201-$ & (2? \\
\hline 13 & 2210 & 240 \\
\hline 13 & 2all & $2+0$ \\
\hline 14 & $201-$ & (1) \\
\hline 15 & रह1- & 320 \\
\hline in & 3 (1) - & $3 ? 0$ \\
\hline 17 & $321=$ & 340 \\
\hline $1 \mathrm{in}$ & $341=$ & $3+0$ \\
\hline 19 & 3かけー & 580 \\
\hline 20 & $341=$ & $4 \cap 0$ \\
\hline 21 & $401-$ & $\therefore \geqslant 0$ \\
\hline 22 & $421=$ & 2000 \\
\hline 23 & $441=$ & $\ln 0$ \\
\hline 24 & $401-$ & $4, R v$ \\
\hline 25 & 4की & 5 nil \\
\hline 20 & $5131=$ & 5 \\
\hline 27 & $521-$ & $5 \mathrm{HI}$ \\
\hline $2^{4}$ & $541-$ & ypit \\
\hline
\end{tabular}

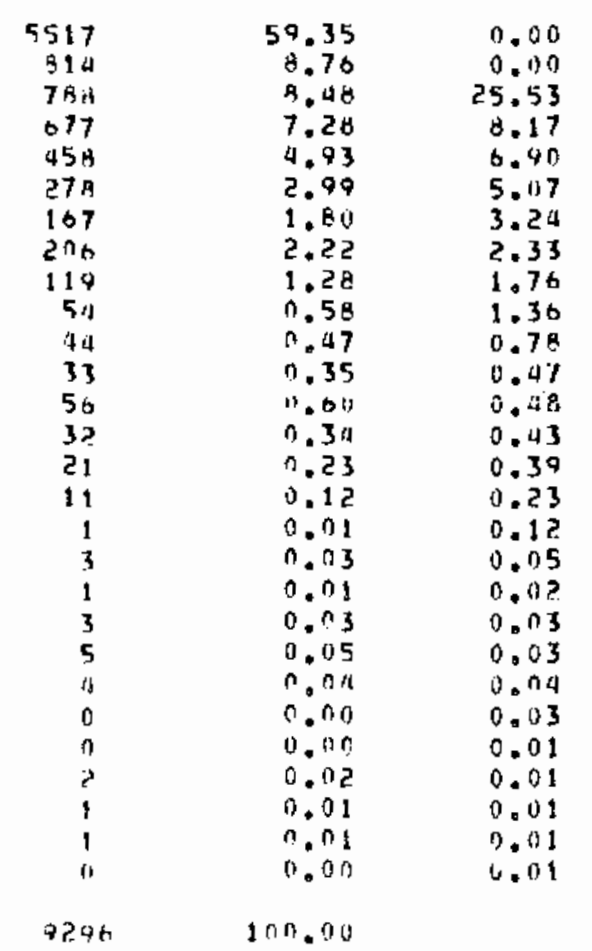


GTORM ANA EVENT STATISTICS

(UIITS; INCHES, INCHFS/HOUL)

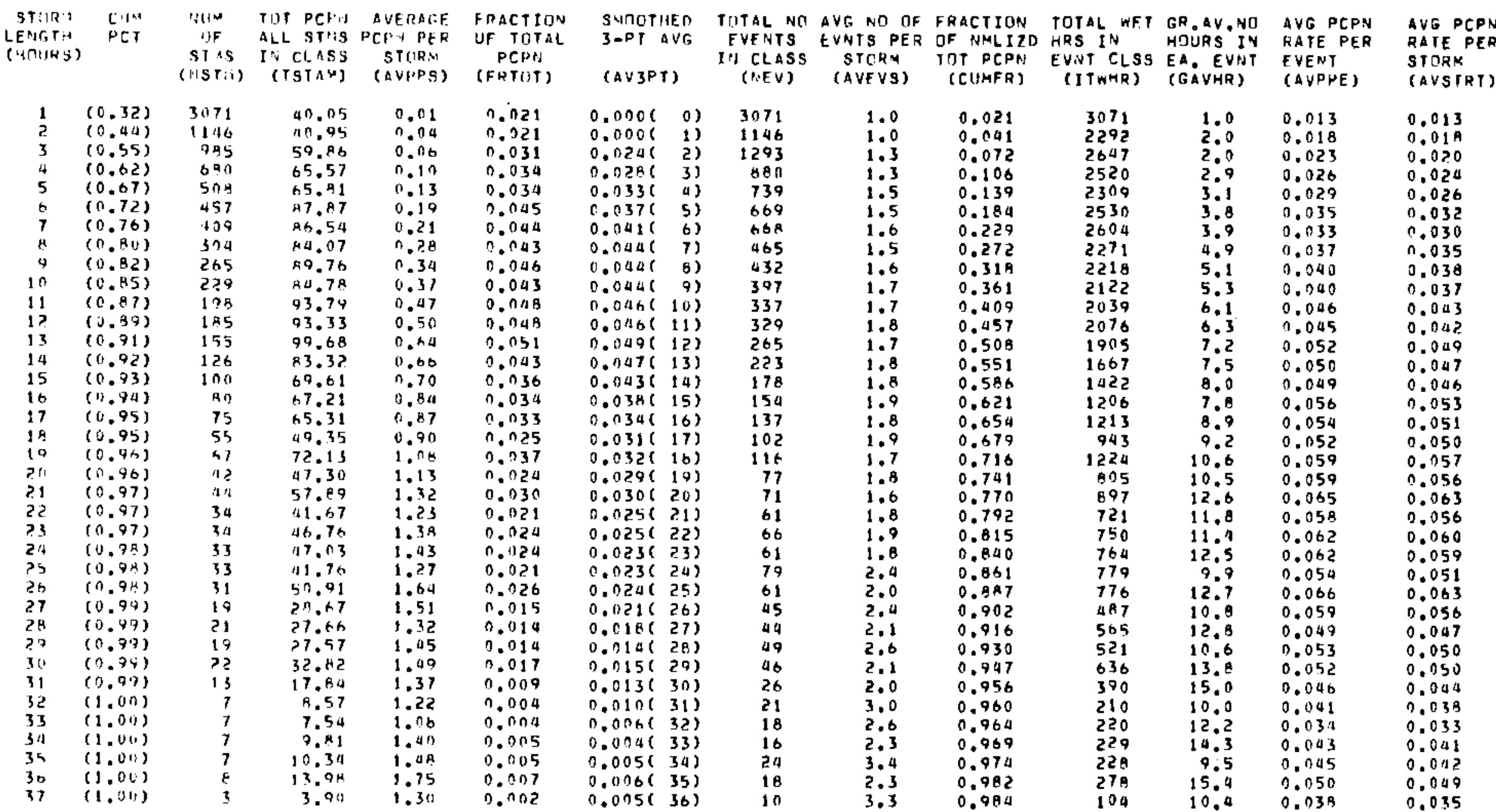




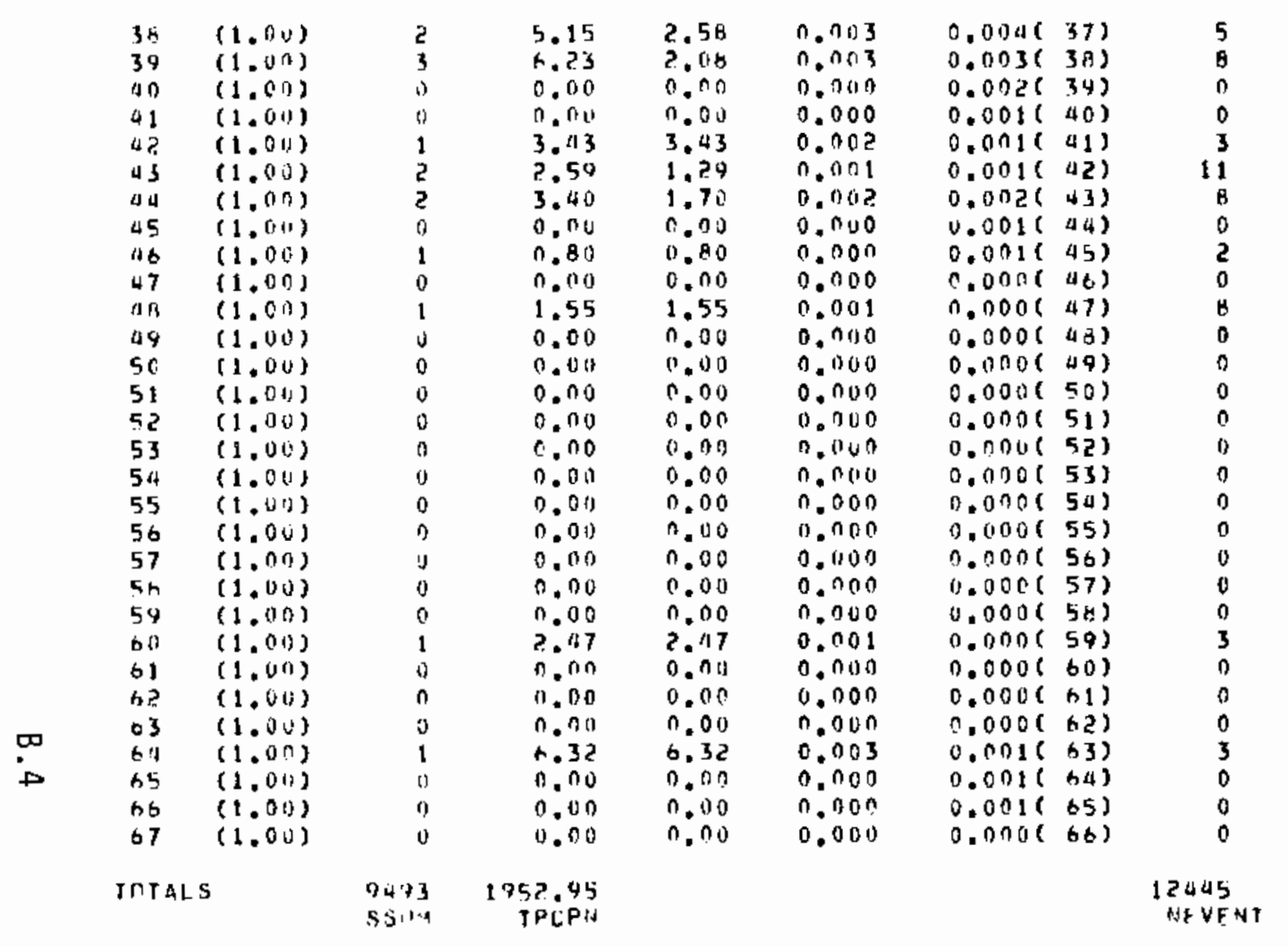

\begin{tabular}{|c|c|c|c|c|c|}
\hline \multirow[t]{2}{*}{$\begin{array}{l}2.5 \\
2.7 \\
0.0 \\
0.0 \\
3.0 \\
5.5 \\
4.0 \\
0.0 \\
2.0 \\
0.0 \\
8.0 \\
0.0 \\
0.0 \\
0.0 \\
0.0 \\
0.0 \\
0.0 \\
0.0 \\
0.0 \\
0.0 \\
0.0 \\
0.0 \\
3.0 \\
0.0 \\
0.0 \\
0.0 \\
3.0 \\
0.0 \\
0.0 \\
0.0\end{array}$} & $\begin{array}{l}0.986 \\
0.989 \\
0.989 \\
0.989 \\
0.991 \\
0.993 \\
0.994 \\
0.994 \\
0.995 \\
0.995 \\
0.995 \\
0.995 \\
0.995 \\
0.995 \\
0.995 \\
0.995 \\
0.995 \\
0.995 \\
0.995 \\
0.995 \\
0.995 \\
0.995 \\
0.997 \\
0.997 \\
0.997 \\
0.997 \\
1.000 \\
1.000 \\
1.000 \\
1.000\end{array}$ & $\begin{array}{r}73 \\
112 \\
0 \\
0 \\
40 \\
77 \\
42 \\
0 \\
45 \\
0 \\
41 \\
0 \\
0 \\
0 \\
0 \\
0 \\
0 \\
0 \\
0 \\
0 \\
0 \\
0 \\
50 \\
0 \\
0 \\
0 \\
0 ? \\
0 \\
0 \\
0\end{array}$ & $\begin{array}{r}14.0 \\
14.0 \\
0.0 \\
0.0 \\
13.3 \\
7.0 \\
10.3 \\
0.0 \\
22.5 \\
0.0 \\
5.1 \\
0.0 \\
0.0 \\
0.0 \\
0.0 \\
0.0 \\
0.0 \\
0.0 \\
0.0 \\
0.0 \\
0.0 \\
0.0 \\
19.3 \\
0.0 \\
0.0 \\
0.0 \\
20.7 \\
0.0 \\
0.0 \\
0.0\end{array}$ & $\begin{array}{l}0.071 \\
0.056 \\
0.000 \\
0.000 \\
0.086 \\
0.034 \\
0.041 \\
0.000 \\
0.018 \\
0.000 \\
0.038 \\
0.000 \\
0.000 \\
0.000 \\
0.000 \\
0.000 \\
0.000 \\
0.000 \\
0.000 \\
0.000 \\
0.000 \\
0.000 \\
0.043 \\
0.000 \\
0.000 \\
0.000 \\
0.102 \\
0.000 \\
0.000 \\
0.000\end{array}$ & $\begin{array}{l}0.068 \\
0.053 \\
0.000 \\
0.000 \\
0.082 \\
0.030 \\
0.039 \\
0.000 \\
0.017 \\
0.000 \\
0.032 \\
0.000 \\
0.000 \\
0.000 \\
0.000 \\
0.000 \\
0.000 \\
0.000 \\
0.000 \\
0.000 \\
0.000 \\
0.000 \\
0.041 \\
0.000 \\
0.000 \\
0.000 \\
0.009 \\
0.000 \\
0.000 \\
0.000\end{array}$ \\
\hline & & $\begin{array}{r}29 \\
129\end{array}$ & & 2.177 & 2.065 \\
\hline
\end{tabular}

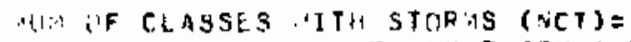
SI)" AVG PCHIA RATE FER EVIAT (SIMANP) SHI AVPAICT = EST AV RATE (EAVRT) = 4h SIJ: AVI MCP I HATE PER STLR:A (SSTMPT) A. H) UF EVEIIS IH ALL CLASSES (SUEV)

068 030 0.000 0.032 0.000

0.000

04

065

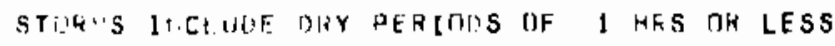




\section{DISTRIBUTION}

No. of

Copies

OFFSITE

2 J. L. Durham

ESRL/USEPA MD-57

Research Triangle Park, NC 27711

J. H. Shreffler

ESRL/USEPA MD-59

Research Triangle Park, NC 27711

F. Binkowski

ESRL/USEPA MD-80

Research Triangle Park, NC 27711

J. F. Clarke

ESRL/USEPA MD-80

Research Triangle Park, NC 27711

J. K. S. Ching

ESRL/USEPA MD-80

Research Triangle Park, NC 27711

F. A. Schiermeier

ESRL/USEPA MD-80

Research Triangle Park, NC 27711

L. K. Peters

Chemical Engineering

University of Kentucky

Lexington, KY 40506

G. R. Carmichael

Chemical \& Materials Engineering

University of Iowa

Iowa City, IA 52242

27 DOE Technical Information Center
No. of

Copies

\section{ONSITE}

DOE Richland Operations Office

H. E. Ransom

19 Pacific Northwest Laboratory

M. T. Dana

D. W. Dragnich

R. C. Easter

J. M. Hales

$P$. C. Hayes

N. S. Laulainen (5)

W. G. N. Slinn

J. M. Thorp

Publishing Coordination (2)

Technica] Information (5) 
